\title{
Weitere Experimentalbeiträge zur Kenntnis der Umlagerung von Hydrazoverbindungen;
}

\author{
von Paul Sacobson.
}

[Mitteilung aus dem Laboratorium des Hofmannhauses.]

(Eingelaufen am 26. Februar 1921.)

Im Anschluß an die Auffindung der "Semidinamlagerung" habe ich seit 1892 mit meinen Schülern and Assistenten eine beträchtliche Zahl von Hydrazoverbindungen auf ihr Verhalten bei der Umlagerung geprüft. Eine Reihe von Mitteilungen ${ }^{1}$ ), die in den Jahren 1892 bis 1909 erschienen sind, gibt von den erzielten Ergebnissen Kenntnis. Die hier folgende Abhandlung bildet den Abschluß der Untersuchungsreihe; sie gliedert sich in vier Teile:

A. Umlagerung von zweifach parasubstitaierten Hydrazoverbindungen (nach Versuchen von D. R.Boyd, M. Freund, H.L.Fulda, F. Heubach, H. Jost, G. Lockemann, A. Loeb, J. Pelzer, Wl.Sachs, H.Tigges und K.Zaar);

B. Nachträge zur Umlagerung von einfach parasubstituierten Hydrazoverbindungen (nach Versuchen von M. Jaenicke und G. Locke$\operatorname{mann})$;

C. Zur Umlagerung der nicht parasubstituierten Hydrazoverbindngen (nach Versuchen von $F$. Hönigsberger and L. Huber);

D. Versuche, die Hydrazoumlagerung zu verallgemeinern (nach Versuchen von H. Jost, St. Pinkas und P. Schmidt).

1) Ber. d. d. chem. Ges. 25, 992 (1892); 26, 681, 688, 699 (1893); 27, 2700 (1894); 28, 2541 (1895); 29, 2680 (1896); 31, 890 (1898); 36, 3841, 3857, 4069, 4086, 4112 (1903). Diese Annalen 287, 97 (1895); 303, 290 (1898); 367, 304 (1909); 369, 1 (1909). 
Die in ihr beschriebenen Versuche sind schon vor längerer Zeit angestellt worden; aber durch literarische Arbeiten danernd stark in Anspruch genommen, finde ich erst heate Zeit, sie in zusammenfassender Form mitzuteilen. Teils wurden sie im Heidelberger Chemischen Universitätslaboratorium (1894-1896), teils im I. Chemischen Institut der Universität Berlin (1897 bis 1900), teils im Laboratorium des Hofmannhauses (1903 bis 1909) ansgeführt. Allen Mitarbeitern, die mir halfen, einen Tatsachenbestand herbeizuschaffen, welcher die Vielgestaltigkeit einer der wichtigsten Umlagernngserscheinungen ins Licht stellt, sage ich für ihren Eifer wärmsten Dank. ${ }^{1}$ )

Vorauszuschicken ist, daß die Hydrazoverbindungen bei vielen Versuchen nicht in isolierter Form zur Umlagerung gelangten, sondern im "Entstehungszustand“; d. h. dab häufig die entsprechende Azoverbindung in saurem Medium gelinder Reduktion unterworfen wurde, wobei sie zunächst in die Hydrazoverbindung übergeführt, diese dann umgelagert wird. Als Agens diente, wie bei den früheren Untersuchungen, fast stets salzsaure Zinnchlorürlösung.

In dieser Abhandlung beschränke ich mich darauf, die Versuche - häufig für nähere Einzelheiten auf die Dissertationen meiner Schüler verweisend - zu beschreiben und die Erwägungen kurz mitzuteilen, die ihre Anstellung veranlaßten. Schlubfolgerungen verschiebe ich auf eine Abhandlung, die im nächsten Heft erscheinen soll. In ihr werde ich die Erfahrungen über die Hydrazoumlagerung nach ihrem heutigen Stand zusammenfassen und zeigen, welche Regeln von größerem Geltungsbereich sich für die von ihr eingeschlagene

1) Aum. der Schriftleitung: Auf Vorschlag des Verfassers ist wegen Raumersparnis ausnahmsweise von der Wiedergabe der bereits in gedruckten Dissertationen angeführten Analysen abgesehen worden. 
144 Jacobson, Weitere Experimentalbeiträge zur Kenntnis

Richtung aufstellen lassen. Daran soll sich dann eine Erörterung schließen, welche Möglichkeiten der Deutung für den "Mechanismus" dieser Umlagerung in Betracht kommen.

\section{A. Umlagerung von zweifach parasubstituierten Hydrazoverbindungen.}

1) Die Versuche, welche unter dieser Überschrift - verteilt in zehn Kapitel (Abschn. 3-38) - mitgeteilt werden sollen, schließen sich eng an die früher veröffentlichte Untersnchungsreihe ${ }^{\mathbf{1}}$ ) über die einfach parasubstituierten Hydrazokörper an.

Damals war gezeigt worden, daß einfach parasubstituierte Hydrazokörper - insoweit sie einer Umlagerung ohne Abstoßung von Substituenten unterliegen - in dreierlei Art sich isomerisieren können:

a)

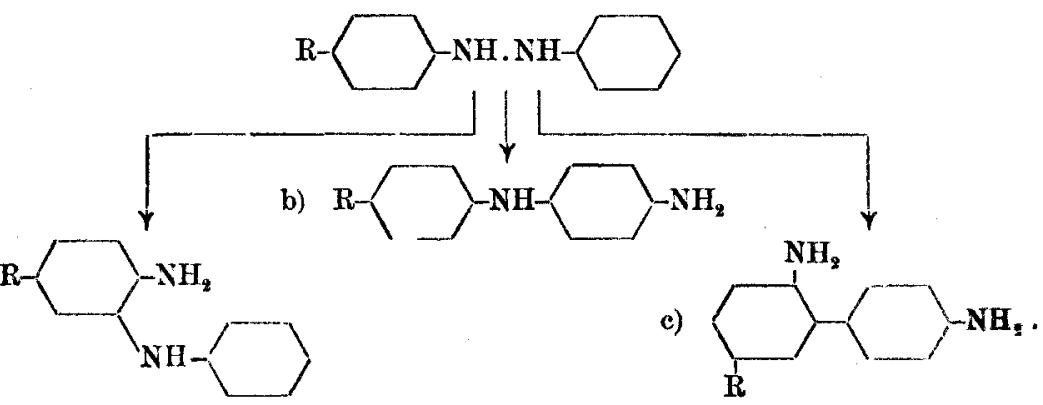

D. h. sie liefern entweder ein o-Semidin (a), das durch Platzwechsel zwischen - NH. $\mathrm{C}_{6} \mathrm{H}_{5}$ und dem zur Hydrazogruppe orthoständigen Wasserstoffatom des substituierten Kerns entstanden ist; oder ein $p$-Semidin (b), bei dessen Bildung der Rest $-\mathrm{NH} . \mathrm{C}_{6} \mathrm{H}_{4} . \mathrm{R}$ seinen Platz mit dem para-Wasserstoff des substituentenfreien Kerns getauscht hat; oder endlich ein Diamin der Diphenylreihe (c) von der Art des Diphenylins, das durch Verknüpfung der Orthostelle des substituierten mit der Parastelle des nicht-

3) Diese Annalen 303, 290 (1898). 
substituierten Kerns zustande gekommen ist. ${ }^{1}$ ) Meist spielen sich zwei dieser Vorgänge oder alle drei nebeneinander $a b$; doch wurden anch Fälle beobachtet, in denen einer von ihnen allein eintritt.

Von jenen drei Vorgängen sind bei zweifacher Parasubsitution zwei (b und c) offenbar ausgeschlossen, und es bleibt als möglich nur die Orthosemidinumlagerung (a) übrig, die aber bei Ungleichheit der beiden Parasubstituenten zu zwei isomeren $o$-Semidinen führen könnte:
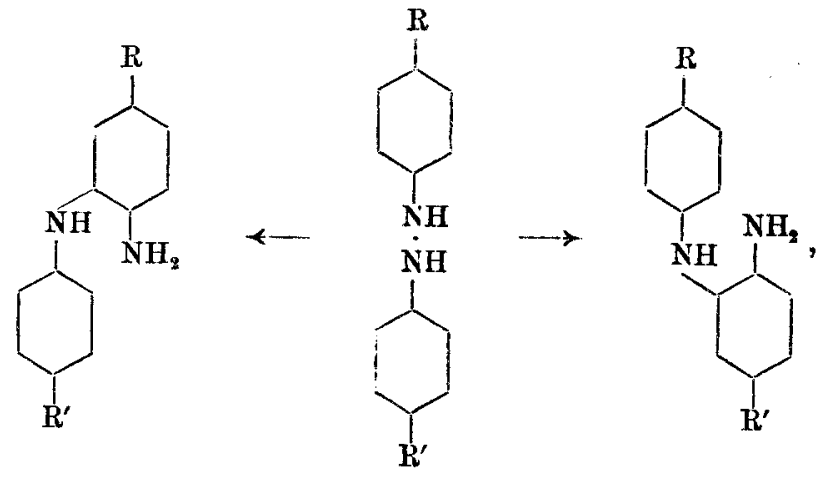

Tatsächlich wurden nun stets o-Semidine erhalten (in 7 Fällen isoliert, in einem Falle nur durch Reaktionen angedeutet). Aber immer konnte nur ein o-Semidin isoliert werden, und es wurden auch keine Anzeichen für die Bildung eines Isomeren beobachtet. Es soll nicht behauptet werden, $d a B$ die Orthosemidinbildung ausschlieblich nach einer Richtung verläuft; denn die Reinigung machte zuweilen Schwierigkeiten, und es erscheint immerhin möglich, daß in Mutterlaugen das isomere o-Semidin sich verborgen haben könnte.

Aber jedenfalls ist eine Richtung des Vorgangs diejenige, welche dem isolierten o-Semidin entspricht, -

1) $\mathrm{DaB}$ diese Diamine die 2,4'-Stellung der Aminogruppen besitzen, also Analoga des Diphenylins sind, wurde damals [diese Annalen 30:3, 294 (1898)] nur aus Analogiegründen geschlossen. Inzwischen ist von mir und A. Loeb der Nachweis dafür erbracht worden; vgl. Ber. d. d. chem. Ges. 36, 4086 ff. (1903). 
die. vorherrschende. Und man kommt daher zu der Frage, welcher von den beiden Parasubstituenten für die vorherrschende Richtung ausschlaggebend ist, d. $h$. welcher von ihnen das $z u$ ihm metaständige Wasserstoffatom seines Benzolkerns besonders geneigt macht, an ein Stickstoffatom der Hydrazogruppe zu wandern. Dieser wird im folgenden als der dirigierende Parasubstituent bezeichnet.

Die Untersuchungen über die Struktur der entstehenden o-Semidine haben in jedem einzelnen Falle zu einer sicheren Auswahl zwischen den beiden möglichen Formeln geführt. Es hat sich gezeigt, dab unter den sechs zur Prüfung gelangten Parasubstituenten:

$$
\mathrm{Br}, \quad \mathrm{J}, \quad \text { O. } \mathrm{C}_{8} \mathrm{H}_{6}, \quad \text { O.CO. } \mathrm{CH}_{8}, \quad \mathrm{~N}\left(\mathrm{CH}_{3}\right)_{2}, \quad \mathrm{CH}_{3}
$$

das Athoxyl am stärksten dirigierend wirkt, in zweiter Linie aber das Methyl (vgl. unten die Tabelle). Auch bei den Untersuchungen über einfach parasubstituierte Hydrazokörper hatte sich das Athoxyl als derjenige Parasubstitnent erwiesen, welcher die Orthosemidinumlagerung besonders begünstigt ${ }^{1}$ ).

Aber hiermit sind die Erscheinungen nicht erschöpft. Denn wie ich in den früheren Untersuchungen gezeigt habe, erfolgen Umlagerungen auch mit Abstoßung von Substituenten ${ }^{2}$. Bei einfacher Parasubstitution war das Ergebnis dann Bildung von Benzidin. Dieses könnte auch bei zweifacher Parasubstitution entstehen, wenn beide Substituenten abgestoßen werden. Doch ist ein solcher Vorgang von mir nicht beobachtet worden. Unterliegt aber nur einer von den beiden Parasubstituenten der Abstobung, so ist ein $p$-Semidin zu erwarten:

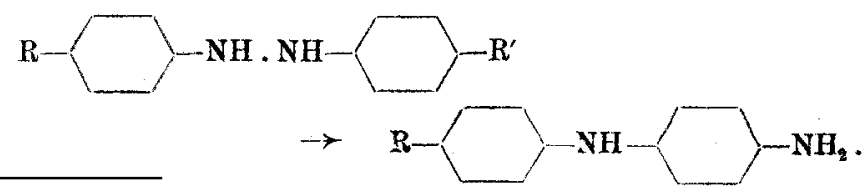

1) Vgl. dazu diese Annalen 303, 296-298 (1898); 369, 5 (1909).

2) Vgl. diese Anualen 303, 293-294, 296, 298-301 (1898); $369,5-6$ (1909). 
Die Versuche haben nun in allen Fällen, wo $\mathrm{R}^{\prime}=$ 0.C0. $\mathrm{CH}_{3}$ war, das Eintreten dieses Vorgangs erwiesen. Damit ist von neuem bestätigt, dab das Acetoxyl sich durch eine besondere Bereitschaft auszeichnet, bei der Hydrazoumlagerung seinen Platz für anderweitige Beanspruchung zu räumen.

Die folgende Tabelle, deren Einrichtung ohne weiteres verständlich sein wird, faßt die beobachteten Krgebnisse zusammen:

\begin{tabular}{|c|c|c|c|c|c|}
\hline \multicolumn{2}{|c|}{$\begin{array}{c}\text { Vorhandene } \\
\text { Parasubstitucaten }\end{array}$} & \multirow{2}{*}{ 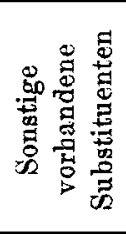 } & \multirow{2}{*}{ 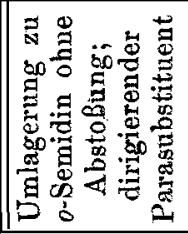 } & \multirow{2}{*}{ 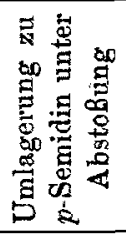 } & \multirow{2}{*}{ 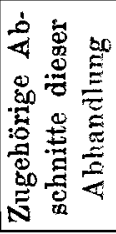 } \\
\hline in 4 & in $4^{\prime}$ & & & & \\
\hline $\mathrm{CH}_{3}$ & $J$ & 0 & $\mathrm{CH}_{8}$ & 0 & $3-7$ \\
\hline $\mathrm{CH}_{3}$ & O. $\mathrm{C}_{8} \mathrm{H}_{5}$ & 0 & $0 . \mathrm{C}_{2} \mathrm{H}_{5}$ & 0 & $8-10$ \\
\hline $\mathrm{Br}$ & O.C. $\mathrm{H}_{5}$ & 0 & O. $\mathrm{C}_{2} \mathrm{H}_{5}$ & 0 & $11-15$ \\
\hline $\mathrm{CH}_{3}$ & o. $\mathrm{CO} . \mathrm{CH}_{3}$ & 0 & $\mathrm{CH}_{\mathrm{s}}$ & $1 \stackrel{80}{g} \frac{\pi}{5}$ & $16-19$ \\
\hline $\mathrm{CH}_{3}$ & $0.00 . \mathrm{CII}_{3}$ & $\mathrm{CH}_{s}$ in $3^{\prime}$ & $\mathrm{CH}_{3}$ & 象: & $20-45$ \\
\hline $\mathrm{Br}$ & 0.CO. $\mathrm{CH}_{8}$ & 0 & $?$ & $\int_{4}^{\infty} 0$ & $26-28$ \\
\hline $\mathrm{CH}_{8}$ & $\mathrm{~N}\left(\mathrm{CH}_{3}\right)_{2}$ & 0 & $\mathrm{CH}_{3}$ & 0 & 29 \\
\hline O. $\mathrm{C}_{2} \mathrm{H}_{5}$ & $\mathrm{~N}\left(\mathrm{CH}_{9}\right)_{2}$ & 0 & o. $\mathrm{C}_{2} \mathrm{H}_{5}$ & 0 & $30-34$ \\
\hline
\end{tabular}

Außer den hier anfgeführten acht Kombinationen sind noch einige andere zar Untersuchung herangezogen worden, bei denen aber so starke Spaltung des Hydrazokörpers:

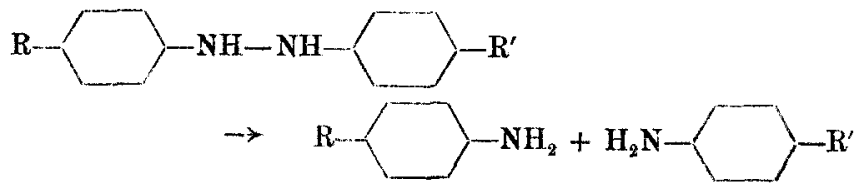

eintrat, daß über die Natar etwa nebenher entstehender Umlagerungsprodukte kein AufschluB erzielt werden konnte (vgl. in Abschn. 4 die Fußnote 3 auf S. 153 and Abschn. 35). 
2) Das im vorigen Abschnitt betreffs der „Umlagerung ohne Abstoßung" mitgeteilte Ergebnis entspricht zwar der Erwartung, zu der man gelangt, wenn man von den Frfahrungen über die einfach parasubstituierten Hydrazokörper ausgeht und diejenigen Vorgänge, welche durch die Gegenwart des zweiten Parasubstituenten unmöglich werden, ausschliebt. Wenn man aber bedenkt, $\mathrm{da} B$ in allen untersuchten Beispielen jeder der beiden Benzolkerne die Orthostellen zur Hydrazogruppe unsubstituiert enthält, so erscheint es auffallend, dab niemals eine Umlagerung beobachtet wurde, bei der zwei Orthowasserstoffatome zugleich zur Sprengung der Hydrazogruppe verwendet werden:
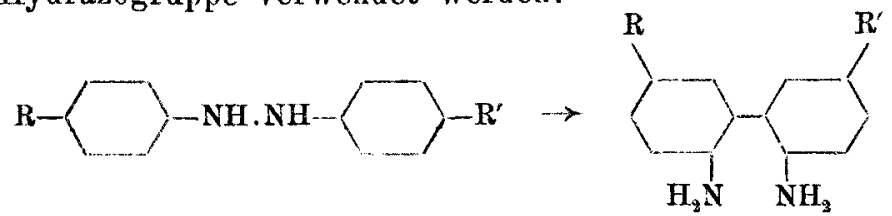

Dab diese Art der Umlagerung, die zu 2,2'-Diaminoderivaten der Diphenylreihe führen würde, bei Hydrazokörpern mit einer freien Parastelle bzw. mit zwei solchen nicht zustande kommt, ist nicht befremdlich; denn bei ihnen besteht die Möglichkeit der Diphenylverknüpfung unter Beteiligung der Parastelle (Bildung von Diaminen mit 2,4'- and 4,4'-Stellung der beiden $\mathrm{NH}_{2}$ ), und es entspricht allgemeinen Erfahrungen, wenn eine solche gegenüber der Alleinbeteiligung von Orthostellen bevorzugt wird. Bei den diparasubstituierten Hydrazokörpern aber böte die Bildung der 2,2'-Diamine - da Metastellea nicht in Betracht kommen - die einzige Möglichkeit der Diphenylverknüpfung. Warum wird sie nicht aufgesucht, obwohl doch von den zar Untersuchung herangezogenen Parasubstituenten alle mit Ausnahme von $\mathrm{O}_{2} \mathrm{C}_{2} \mathrm{H}_{5}$, wenn sie in der Einzahl vorhanden sind, den Übergang in die Diphenylreihe begünstigen ${ }^{1}$ )?

1) Vgl. die Tabelle in diesen Annalen 203 , 296 (1898); betreffs $\mathrm{CH}_{\text {s }}$ vgl. diese Annalen 369, 5 (1909). 
Man könnte dies darauf zurückführen wollen, daß in den von mir untersuchten Fällen stets zwei ungleiche Parasubstituenten zugegen waren; denn man kann sich wohl vorstellen, daB der eine Parasubstituent den Benzolkern, zu dem er gehürt, an den Orthostellen wesentlich reaktionsgeneigter macht, als der andere Parasubstituent die Orthostellen des ihm zugehörigen Kerns. Aber gerade bei einem gleichartig diparasubstituierten Hydrazokörper --. dem $p$-Hydrazotoluol - hat Täuber ${ }^{1}$ ) seinerzeit die Orthosemidinumlagerung zugleich mit mir aufgefunden; und analog dem $p$-Hydrazotoluol geben nach Untersuchungen seines Schülers $W$. Levin auch das 4, 4'-Dichlor-hydrazobenzol und 4,4'-Dibrom-hydrazobenzol nicht 2. $2^{\prime}$-Diamine der Diphenylreihe, sondern $o$-Semidine ${ }^{2}$ ).

So muß man schließen, daß in der Benzolreihe gegen die Bildung der Atomgruppierung:

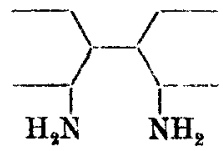

durch Hydrazo-Umlagerung ein starker Widerstand besteht ${ }^{3}$ ).

Um so überraschender waren für mich Beobachtungen in der Naphthalinreihe, die 1903 von Meisenheimer und $W^{\text {'itte }}{ }^{4}$ ) veröffentlicht wurden. Sie betreffen das

3) Ber. d. d. chem. Ges. 25, 1019 (1892).

2) Vgl.: W.Le vin, „Über Umlagerungsprodukte symmetrischer, diparahalogenierter Hydrazobenzole" (Dissertation, Berlin 1900); W'jlberg, Ber. d. d. chem. Ges. 35, 955 (1902).

3) Es muB freilich bemerkt werden, daB in einem Falle, desseu Untersuchung nicht abgeschlossen werden konnte, - nämlich beim m-Tolvolazodimethylanilin - Andeutungen gefunden wurden, daB sich neben einem 2,4'-Diamin der Diphenylreihe auch ein 2, $2^{\prime}$ Derivat bildet. Die Versuche sind in der Dissertation von D. R. Boyd - „I. Über die Reduktion einiger Dimethylaminoazoverbindungen. - II. Einige Versuche zur Bildung von Verbindungen mit asymmetrischen Kohlenstoffatomen" (IIeidelberg 1896) - anf S. 28-32 beschrieben.

4) Ber. d. d. chem, Ges. 36, 4153 (1903). 
$\beta, \beta^{\prime}$-Hydrazonaphthalin (Formel $I$, s. u.), das ja ebenso wie die Diparasubstitutionsderivate des Hydrazobenzols die Parastellen auf beiden Seiten der Hydrazogruppe derart gebunden enthält, daß sie bei der Umlagerung nicht an der Reaktion teilnehmen können. Nach den Erfahrungen aus der Benzolreihe wäre hier die Bildung

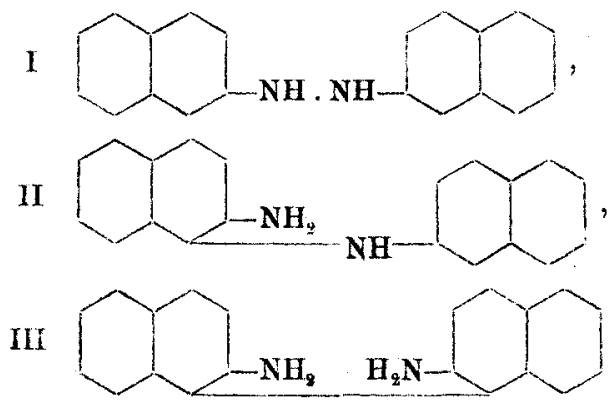

des $o$-Semidins II wahrscheinlich gewesen. Die genannten Autoren erhielten aber das 2,2'-Diaminodinaphthyl-(1,1') der Formel III. Später sind von anderen Autoren gleichfalls Beobachtungen mitgeteilt worden, welche auf die Umlagerung von Hydrazoverbindungen der Naphthalinreihe zu 2,2'-Diaminoderivaten der Dinaphthyle oder der Phenylnaphthaline hinweisen ${ }^{1}$ ).

Nun hatten Meisenheimer and Witte die Umlagerung des $\beta, \beta^{\prime}$-Hydrazonaphthalins freilich nicht unter den Bedingungen bewirkt, die bei den Arbeiten in der Benzolreihe üblich waren. Abgesehen davon, daß sie die höchst bemerkenswerte Beobachtung der Umlagerung durch Alkali machten, benutzten sie als saures Reduktionsmittel Eisessig mit Zinkstaub. Um zu ermitteln, ob die Verschiedenheit der Arbeitsweise vielleicht den unerwarteten Verlauf bedingt, habe ich $\beta, \beta^{\prime}$-Azonaphthalin der Reduktion mit salzsaurer Zinnchlorürlösung also dem von mir stets angewendeten Agens - unter-

1) Vgl.: Veselý, Ber. d. d. chem. Ges. 38, 136 (1905); Bucherer, Seyde, M. Schmidt, J. pr. [2] 77, 407 (1908); 79, 376, 377, 385, 399,411 (1909). 
worfen; aber ich konnte nur feststellen, dak auch diese Umlagerungsbedingungen kein $o$-Semidin ergeben, sondern als wesentliches Produkt jenes Diamin ron Meisenheimer und Witte. Dessen Struktur haben diese Autoren zwar schon durch Überführung in Dinaphthylenimin und besonders durch die Bildung bei der Reduktion von Dinaphthopyridazin ausreichend gestuitzt; aber mir schien für seine sichere Charakterisierung als primäres Diamin noch der Nachweis seiner Fähigkeit nicht überflüssig, sich mit 2 Aldehydmolekülen unter Abspaltung von $4 \mathrm{H}$-Atomen zu kondensieren. Diese ergänzenden Versuche sind in Abschu. 36-38 mitgeteilt.

Wir haben hier also wieder eines der nicht mehr seltenen Beispiele dafür, daB Naphthalinkörper in ihren Reaktionen wesentlich von analogen Benzolkörpern abweichen können.

\section{Umlagerung des 4-Methyl-4'-jod-hydrazobenzols. ${ }^{1}$ )}

3) Die Versuche stammen teils aus den Dissertationen der Herren G. Lockemann ${ }^{2}$ ) und F. Heubach ${ }^{3}$; zum größeren Teil aber sind sie von meinem Assistenten, Herrn Dr. A. Loeb, ausgeführt.

Sie ergaben, dab aus dem 4-Methyl-4'-jod-hydrazobenzol ein ihm isomeres o-Semidin hervorgeht. Für dieses erscheinen nach seiner Bildung die beiden Formeln:

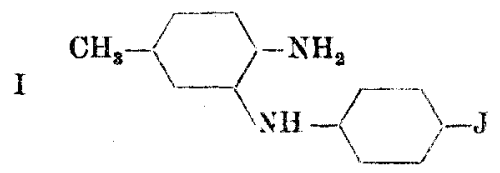

1) Anm. der Schriftleitung: Auf Vorschlig des Verfassers ist wegen der Raumersparnis ausnahmsweise von der Wiedergabe der bereits in gedruckten Dissertationen angeführten Analysen abgesehen worden.

2) "Über Amido- und Jodderivate von Homologen des Azobenzols" (Heidelberg 1896), S. 12-14, 41-48.

3) „Über Umlagerungsprodukte jodierter Hydrazoverbindungen ${ }^{6}$ (Heidelberg 1897), S. 30-34. 
und

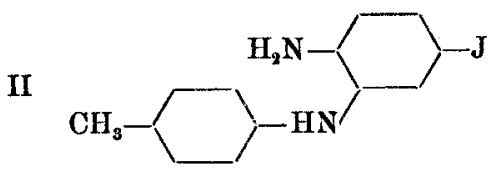

möglich. Das o-Semidin der Formel II wurde aus dem 1-Jod-3,4-dinitro-benzol auf folgendem Wege $^{1}$ ) aufgebaut:<smiles>O=[N+]([O-])C1CCC(Cl)CC1[N+](=O)[O-]</smiles>
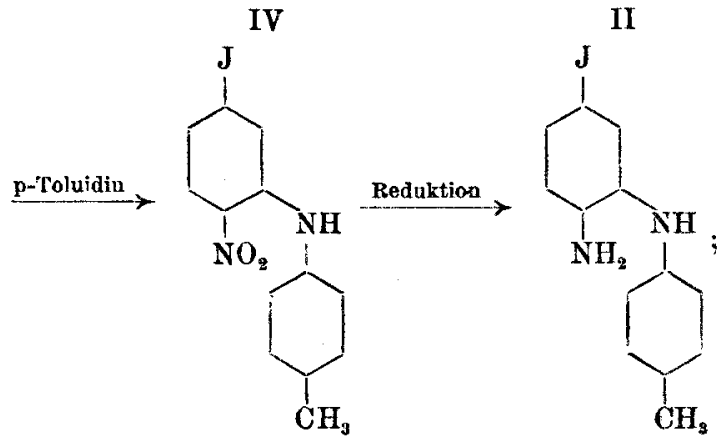

es erwies sich als verschieden von dem bei der Umlagerung des Hydrazokörpers entstehenden Amin, welchem demnach die Formel 1 des 5-Methyl-4'-jod-2-amino-diphenylamins zukommt.

Anzeichen für die gleichzeitige Bildung des Isomeren wurden nicht beobachtet (vgl. Schluß von Absatz 7).

4) Für die Darstellung des Ausgangsmaterials wandelten wir $p$-Diazoaminotoluol durch Umsetzung mit salzsaurem Anilin in 4-Methyl-4'-amino azobenzol um und ersetzten dessen Aminogruppe mit Hilfe der Diazoreaktion durch Jod.

p-Diaxoaminololuol läBt sich in vortrefflicher Ausbeute (88 Proz. der Theorie) nach der von Bamberger ${ }^{2}$ ) für Diazoaminobenzol angegebenen Vorschrift bereiten. Man gibt zu einer Lösung von $10 \mathrm{~g}$ salzsaurem $p$-Toluidin in $200 \mathrm{~g}$ Wasser, die nur durch Winstellen in kaltes Wasser gekühlt wird, unter Umrühren allmählich eine Lösung von 2,5 g Natriumnitrit und $5 \mathrm{~g}$ Natriumacetat in $70 \mathrm{~g}$ Wasser; die Mischung trübt sich allmählich und ist nach zweistündigem Stehen durch Ausscheidung des Diazoaminotoluols zu einem gelben Brei erstarrt.

1) Vgl. dazu Ber, d. d. chem. Ges. 26, 683 (1893).

3) Vgl. Me yer-Jacobson, Lehrb. d. Organ. Chemie, Bd. II, Tl. I (Leipzig 1902), S. 338. 
4-Methyl-4'-amino-azobenzol hat Nietzki') aus Diazoaminotoluol durch Umsetzung mit salzsaurem Anilin in Alkohol hergestellt Viel bessere Resultate erhält man, wenn man die Umsetzung in Anilinlösung ${ }^{2}$ ) (auf je $10 \mathrm{~g}$ Diazoaminotoluol und je $6 \mathrm{~g}$ feingepulvertes salzsaures Anilin je $25 \mathrm{~g}$ Anilin) unter häufigem Um. rühren durch einstündiges Erhitzen auf $45^{\circ}$ (Temperatur genau zu beachten!) vornimnt. Verdünnte Essigsäure fällt dann den freien Aminoazokörper aus dem Reaktionsgemisch als braunroten krystallinischen Niederschlag, der durch Überführung in das salzsaure Salz und dessen Wiederzersetzung mit Ammoniak gereinigt wird. Der Schmelzpunkt, der zunächst bei $147^{\circ}$ gefunden wird, steigt bei sehr häufigem Umkrystallisieren aus Alkohol auf 153-154.

Wenn man $10 \mathrm{~g}$ des 4-Methyl-4'-amino-azobenzols ${ }^{3}$ ) (fein zerrieben!) mit $100 \mathrm{ccm}$ Wasser anschlämmt, hierzu eine Lösung von $5 \mathrm{~g}$ Natriumnitrit in $50 \mathrm{ccm}$ Wasser gibt und nun unter Kühlung mit kaltem Wasser auf einmal eine Mischung von $15 \mathrm{ccm}$ konz. Salzsäure mit $30 \mathrm{ccm}$ Wasser hinzufügt, so erhält man eine fast klare tiefrote [Diazoniumlösung, aus der sich zuweilen beim Stehen in der Kälte rötlich schimmernde Blättchen des Diazoniumchlorids abscheiden. Diese Lösung ließen wir langsam in eine kalte wäßrige Lösung von $50 \mathrm{~g}$ Kaliumjodid einfließen, wobei Stickstoff unter starkem Aufschäumen entweicht und sich ein durch Jod schwarz gefärbter Niederschlag des 4-Methyl-4'-jod-azobenzols $\mathrm{CH}_{3} \cdot \mathrm{C}_{6} \mathrm{H}_{3} \cdot \mathrm{N}_{2} \cdot \mathrm{C}_{6} \mathrm{H}_{4} \cdot J$ abscheidet. Durch Digerieren mit

1) Ber. d. d. chem. Ges. 10, 664, 666 (1877).

2) Vgl. auch Tröger, Westerkamp, Ar. 247, 674, 682 (1909).

3) Einige Abkồmmlinge desselben, welche in der Anm. 2, S. 151 zitierten Dissertation des Herrn G. Lockemann auf S. 14 bis 20 beschrieben sind, seien hier noch kurz erwähnt:

4-Methyl-4'-acetamino-azobenzal $\mathrm{C}_{15} \mathrm{H}_{15} \mathrm{ON}_{3}=\mathrm{CH}_{3} \cdot \mathrm{C}_{6} \mathrm{H}_{4} \cdot \mathrm{N}_{2}$. $\mathrm{O}_{\mathrm{g}} \mathrm{H}_{4}$. NH.CO. $\mathrm{CH}_{3}$. Foldgelbe seidengläuzende Fasern. Schmelzp. $205^{\circ}$. Wird bei der Reduktion mit Zinnchlorür und Salzsäure nnter Eiskïhlung in so hohem Betrag gespalten, daB die Untersuchung auf Umlagerungsprodukte unterblieb.

4-Melhyl-4'-benzylidenamino-azobenzol $\mathrm{C}_{20} \mathrm{H}_{17} \mathrm{~N}_{3}=\mathrm{CH}_{3} \cdot \mathrm{C}_{6} \mathrm{H}_{4}$. $\mathrm{N}_{2} \cdot \mathrm{C}_{6} \mathrm{H}_{4} \cdot \mathrm{N}: \mathrm{CH} \cdot \mathrm{C}_{6} \mathrm{H}_{6}$. Gelbe Blättehen. Schmelzp. 125-126 .

4-Methyl-4'-[o-oxybenxylidenamino\}azobenzol $\mathrm{C}_{20} \mathrm{H}_{17} \mathrm{ON}_{3}=\mathrm{CH}_{3}$. $\mathrm{C}_{6} \mathrm{H}_{4} \cdot \mathrm{N}_{2} \cdot \mathrm{C}_{6} \mathrm{H}_{4} \cdot \mathrm{N}: \mathrm{CH} \cdot \mathrm{C}_{6} \mathrm{H}_{4} \cdot \mathrm{OH}$. Rote Nädelchen. Schmelzp. 166" bis $167^{\circ}$. 
heiber Natriumthiosulfat-Lösung wurde der abfiltrierte Niederschlag hellgelb. Die weitere Reinigung erfolgt durch Krystallisation aus Alkohol, dann aus Ligroin. Die Ausbeute betrug etwa 65 Proz. der Theorie. Aus Iigroin krystallisiert dieser Azokörper in rötlichen goldschimmernden Blättchen; er schmilzt bei $165-166^{\circ}$ und Jöst sich leicht in Äther und Benzol, ziemlich schwer in Ligroin und Alkohol.

$0,1430 \mathrm{~g}$ gaben $11,4 \mathrm{ccm}$ Stickgas bei $22^{\circ}$ und $755 \mathrm{~mm}$ Druek. $0,1169 \mathrm{~g}, \quad 0,0856 \mathrm{AgJ}$.

$\begin{array}{lcr} & \text { Ber. für } \mathrm{C}_{13} \mathrm{H}_{11} \mathbf{N}_{\mathbf{2}} \mathrm{J} & \text { Gef. } \\ \mathrm{N} & \mathbf{8 , 7 2} & \mathbf{8 , 8 8} \\ \mathrm{J} & \mathbf{3 9 , 4 2} & \mathbf{3 9 , 5 8}\end{array}$

Zur Bereitung des 4-Methyl-4'-jod-hydrazobenzols versetzten wir eine konz. heiße alkoholische Lösung des Azokörpers mit so vie] konz. wäbrigem Ammoniak, daß ein geringer bleibender Niederschlag entstand, und leiteten dann Schwefelwasserstoff ein, bis die Lösung hellfarbig. mit einem Stich ins bräunliche geworden war; nötigenfalls wurde hierbei noch ein erneuter Zusatz von Ammoniak gegeben. Nach dem Abkühlen wird der Hydrazokörper durch Wasser fast quantitativ in gelblichweißen Flocken abgeschieden. Aus siedendem Iigroin schießt er in anfangs farblosen derben Krystallen an, die sich aber schon beim Erkalten der Lösung gelbrot zu färben beginnen; aus verdünntem Alkohol krystallisiert er in weißen Nädelchen. Er schmilzt bei $134^{\circ}$ und löst sich leicht in Alkohol, Äther und Benzol.

$0,1891 \mathrm{~g}$ gaben $14,6 \mathrm{ccm}$ Stickgas bei $19^{\circ}$ und $754 \mathrm{~mm}$ Drrek. $0,1072 \mathrm{~g} " 0,1231 \mathrm{AgJ}$.

$\begin{array}{lcr} & \text { Ber. für } \mathrm{C}_{18} \mathrm{H}_{18} \mathrm{~N}_{2} \mathrm{~J} & \text { Gef. } \\ \mathrm{N} & 8,66 & 8,76 \\ \mathrm{~J} & 39,17 & 39,09\end{array}$

5) Nachdem sich herausgestellt hatte, dab bei der direkten Reduktion des 4-Methyl-4'-jod-azobenzols in Alkohol mit salzsaurer Zinnchlorturlösung, selbst wenn man unter Eiskühlung arbeitet, recht starke Spajtung (50 bis. 
60 Proz.) in Toluidin und Jodanilin eintritt, wurde bei den späteren Umlagerungsversuchen der soeben beschriebene Hydrazokörper zum Ausgangsstoff gewählt. Von den mehrfach wiederholten Versuchen beschreibe ich hier nur den letzten, bei welchem die Errahrungen der früheren Versuche za einer recht befriedigenden Aufarbeitung der Reaktionslösung führten.

$\mathrm{Zu}$ je $10 \mathrm{~g}$ 4-Methyl-4'-jod-hydrazobenzol - in $100 \mathrm{ccm}$ Alkohol suspendiert - wurde nnter Abkühlung mit Eiswasser und gutem Umrühren langsam eine Lösung von $12 \mathrm{~g}$ Zinnchlorür in $30 \mathrm{ccm} 25$ prozentiger Salzsüure zugefügt ${ }^{2}$ ). Nach kurzer Zeit ist der Hydrazokörper vollständig gelöst, und die Farbe der Lösung hellbraun geworden. Die in mehreven Operationen erhaltenen Lösungen - zusammen aus $36,6 \mathrm{~g}$ Hydrazokörper bereitet blieben 24 Stunden stehen. Dann fügte man das doppelte Volum Wasser und unter guter Abkühlung einen Überschuß von Natronlauge zu und trieb durch mehrstündige Destillation mit Wasserdampf die durch Spaltung gebildeten Amine $a b$; ihre Menge wurde durch Eindampfen des Destillats mit Salzsäure und Wägung der zurückbleibenden Hydrochloride bestimmt und entsprach einem Spaltungsbetrag von etwa 35 Proz.

In der alkalischen, von Spaltungsprodukten nunmehr befreiten Flüssigkeit findet man nach dem Abkühlen das Umlagerungsprodukt (etwa 47 Proz.) als halbfeste harzige Masse, die etwas Zinnoxyd eingeschlossen hält, abgeschieden, während sich aus der alkalischen Lösung durch Ausäthern nur ein geringer Rest (etwa 3 Proz.), der nicht weiter untersucht wurde, gewinnen läßt. Jene harzige Masse wog nach dem Trocknen 18,6 g; beim Lösen in wenig heißem Benzol blieb das in ihr enthaltene Zinnoxyd (1,6 g) zurück. Die filtrierte Benzollösung wurde mit so viel Benzol verdünnt, daß auf Ligroin-

1) Reaktionsbedingungen von Täuber; vgl. Ber. d. d. chem. Ges. 25, 1022 (1892). 
zusatz keine harzige Abscheidung erfolgt, sondern nur gelbliche Flocken einer Verunreinigung sich niederschlagen. Dampfte man nun die hiervon filtrierte BenzolLigroinlösung auf ein kleines Volum ein, setzte von neuem Ligroin hinzu, bis sich kein Harz mehr abschied, and gob von dem Harz (A) ab, so erhielt man beim Stehen der klaren Lösung allmählich 5,2 g Krystalle vom Schmelzp. $116-117^{\circ}$. Die von ihnen filtrierte Mutterlange hinterließ beim Verdunsten einen harzigen Rückstand, der mit dem Harz A zusammen wiederum in Benzol gelöst wurde. Beim Zusatz von Ligroin treten nun die gleichen Erscheinungen - zuerst Harz-, dann Krystallabscheidung - auf; und indem man diese kombinierte Benzol-Ligroin-Behandlung noch ein zweites Mal wiederholte, gelang es noch $1,8+1,3 \mathrm{~g}$ des krystallisierten Stoffs zu gewinnen. Sämtliche Krystallfraktionen zeigten den gleichen Schmelzpunkt und wurden auch bei der Überführung in das im Abschn. 6 beschriebene Salicylaldehydderivat als miteinander identisch befunden (durch Schmelzpunkte der einzelnen Präparate und ihre Mischschmelzpunkte; vgl. dazu Abschn. 7). Es waren also insgesamt $8,3 \mathrm{~g}$ eines einheitlichen Produkts gewonnen, das sich - wie im Abschn. 6 gezeigt wird als $o$-Semidin erwies.

Aber auch die harzigen Fraktionen (zusammen 8 bis $9 \mathrm{~g})$ bestehen - jedenfalls zum größten Teil - aus demselben Stofi. Denn als sie mit Schwefelkohlenstoff gekocht wurden, lieferten sie $4,7 \mathrm{~g}$ (umkrystallisiert 3,3 g) des gleichen Derivats (Schmelzp. 280-282 ${ }^{\circ}$ ), das aus dem krystallisierten o Semidin erhalten wird (vgl. $\mathbf{A b}$ schn. 6). Es wurde mit ihm auch noch durch Analyse and durch Überführung in den Nethyläther (Schmelzp. $139-140^{\circ}$ ) identifiziert; die Identität wurde in beiden Fällen noch durch Mischschmelzpunkt sichergestellt.

Man darf also sagen, daß von dem rohen Umlagerungsprodukt (etwa $17 \mathrm{~g}$, vgl. oben) mindestens drei Viertel (12-13 g) das o-Semidin darstellen, das 
nun im folgenden Abschnitt näher gekennzeichnet werden soll.

6) Das $o$-Semidin - 5-Methyl-4'-jod-2-amino-diphenylamin, Formel I (s. Abschn. 3) - bildet weiße Krystalle vom Schmel\%p. 116-117 ${ }^{\circ}$ und löst sich äußerst leicht in Methyl- und Äthylalkohol, Benzol, Äther, Chloroform, Aceton und Eisessig, schwerer in Ligroin, fast gar nicht in Wasser. Sein salzsaures Salz ist in Wasser schwer löslich. Versetzt man die verdünnte salzsaure Lösung mit Eisenchlorid, so tritt allmählich Trübung ohne charakteristische Färbung auf; langsam scheidet sich dann ein roter Niederschlag ab,

$0,1676 \mathrm{~g}$ gaben $12,4 \mathrm{~cm}$ Stickgas bei $19^{\circ}$ u. $770,5 \mathrm{~mm}$ Druek. $0,1732 \mathrm{~g} \quad 0,1252 \mathrm{AgJ}$.

$\begin{array}{ccr} & \text { Ber. für } \mathrm{C}_{13} \mathrm{H}_{13} \mathrm{~N}_{2} \mathrm{~J} . & \text { Gef. } \\ \mathrm{N} & 8,66 & 8,55 \\ \mathrm{~J} & 89,17 & 39,07\end{array}$

Als $o$-Semidin wurde dieses Amin durch sein Verhalten gegen salpetrige Säure ${ }^{1}$ ), Benzil ${ }^{2}$ ), Salicylaldehyd ${ }^{3}$ ) und Schwefelkohlenstoff ${ }^{4}$ ) gekennzeichnet.

Natrinmnitrit verursacht in der verdünnten salzsauren Lösung eine rasch vorübergehende rotviolette Färbung, darauf weiße milchige Trübung.

Bei 8 stündigem Kochen des salzsauren Salzes mit Benzil in Alkohol wurde nach der üblichen Verarbeitung eine Stilbazoniumbase erhalten, die ans Alkohol in gelbgrünen mikroskopischen Nädelchen sich abscheidet und - rasch erhitzt - bei $166-168^{\circ}$ schmilzt. Sie scheint indessen hartnäckig Wasser zurückzuhalten; denn bei der Analyse lieferte sie - selbst nach 14 tägigem Stehen über Phosphorpentoxyd - Jodwerte, die um 1-1,5 Proz. hinter dem theoretischen Wert zurückblieben. Ihre alkoholische Lösung fluoresciert nur sehr schwach. Ihr

\footnotetext{
1) Vgl. diese Annalen 287, 129 (1895).

2) Vgl. diese Annalen 287, 134 (1895).

8) Vgl. diese Annalen 303, 302 (1898).

4) Vgl. diese Annalen 287, 133 (1895).
} 
salzsaures Salz ist in Wasser schwer löslich; mit konz. Salzsäure färbt sie sich orangerot. Mit konz. Schwefelsäure gibt sie eine kirschrote Lösung, deren Farbe beim Verdïnnen mit Wasser in Gelb umschlägt.

Das Salicylaldehydderivat ${ }^{1}$ ) scheidet sich aus, wenn man $0,32 \mathrm{~g}$ des Semidins mit $0,128 \mathrm{~g}$ Salicylaldehyd in alkoholischer Lösung unter Durchleiten von Kohlendioxyd kurze Zeit kocht. Es krystallisiert in gelben Nadeln, schmilzt bei $132-134^{\circ}$ and ist in kaltem $\ddot{A}$ ther, Benzol, Aceton, Chloroform and Eisessig leicht, in heißem Methyl- and Äthylalkohol schwerer, in Ligroin schwer löslich. Beim Kochen mit frisch gefälltem Quecksilberoxyd in Alkohol wurde keine merkliche Veränderung bemerkt.

$0,1149 \mathrm{~g}$ gaben $7,1 \mathrm{ccm}$ Stickgas bei $26^{\circ}$ und $742,5 \mathrm{~mm}$ Druck. $0,0741 \mathrm{~g} \quad, \quad 0,0408 \mathrm{AgJ}$.

$0,1596 \mathrm{~g} \quad 0,0875 \mathrm{AgJ}$.

\begin{tabular}{lcrc} 
& Ber. für $\mathrm{C}_{20} \mathrm{H}_{17} \mathrm{ON}_{\mathrm{g}} \mathrm{J}$ & \multicolumn{2}{c}{ Gef. } \\
$\mathrm{N}$ & 6,56 & 6,75 & - \\
$\mathrm{J}$ & 29,66 & 29,84 & $\mathbf{2 9 , 6 4}$
\end{tabular}

Das Schwefelkohlenstoffderivat - 6-Methyl-1[p-jodphenyl-2-mercapto-benzimidazol

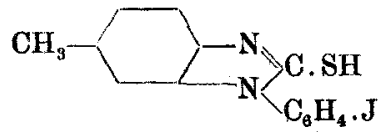

- wurde durch 10 stündiges Kochen von 1 Tl. o-Semidin mit $10 \mathrm{TIn}$. Alkohol und $5 \mathrm{TJn}$. $\mathrm{CS}_{2}$ bereitet. Es scheidet sich hierbei zum größten Teil bereits aus; der Rest wird nach dem Abdestillieren des $\mathrm{CS}_{2}$ durch Verdünnen mit angesäuertem Wasser gewonnen. Es krystallisiert aus Alkohol in feinen weißen Nadeln, schmilzt bei $284^{\circ}$ bis $285^{\circ}$ unter Zersetzung und löst sich schwer in Alkohol und in Ligroin, ziemlich schwer in Eisessig, leicht in Chloroform. Mit Alkohol verrieben, wird es von Natronlauge leicht aufgenommen; auf Zusatz von wenig Wasser fällt dann ein seidenglänzendes Natriumsalz ans, das durch

1) Vgl. zur Struktur diese Anualen 303, 302 Anm. 14 (1898). 
mebr Wasser in Lösung gebracht wird. Beim Kochen der alkoholischen Lösung des $\mathrm{CS}_{2}$-Derivats mit Quecksilberoxyd erfolgt keine Schwärzung; vielmehr scheidet sich ein weißes Quecksilbersalz in sternförmig angeordneten Nädelchen aus.

$0,1633 \mathrm{~g}$ gaben $10,6 \mathrm{ccm}$ Stickgas bei $17^{\circ}$ und $751 \mathrm{~mm}$ Druck. $0,1834 \mathrm{~g} \# \quad 0,1171 \mathrm{AgJ}$ und $0,1189 \mathrm{BaSO}_{4}$.

$\begin{array}{lcr} & \text { Ber. für } \mathrm{C}_{14} \mathrm{H}_{11} \mathrm{~N}_{2} \mathrm{JS} & \text { Gef. } \\ \mathrm{N} & \mathbf{7 , 6 9} & \mathbf{7 , 4 1} \\ \mathrm{J} & 34,77 & 34,51 \\ \mathrm{~S} & 8,78 & 8,90\end{array}$

Der Methyläther

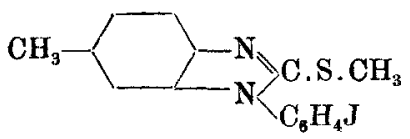

entsteht bei $4-5$ stündigem Kochen von $0,9 \mathrm{~g} \quad \mathrm{CS}_{2}$-Derivat in $20 \mathrm{ccm}$ absolutem Alkohol mit einer Lösung von $0.06 \mathrm{~g}$ Natrium in $2 \mathrm{ccm}$ abs. Alkohol und $1 \mathrm{~g}$ Methyljodid. Nach dem Einengen scheidet er sich auf Wasserzusatz zunächst klebrig aus. Aus Methylalkohol erhält man ihn in weißen Nadelbüscheln; er schmilzt bei $139^{\circ}$ bis $140^{\circ}$ und löst sich sehr leicht in Eisessig and Benzol, schwerer in Alkohol.

$$
\begin{array}{rrr}
0,1921 \mathrm{~g} \text { gaben } 0,1186 \mathrm{AgJ} \text { und } & 0,1181 \mathrm{BaSO}_{4} \text {. } \\
& \text { Ber. für } \mathrm{C}_{15} \mathrm{H}_{18} \mathrm{~N}_{2} \mathrm{JS} & \text { Gef. } \\
\mathrm{J} & 33,48 & 33,37 \\
\mathrm{~S} & 8,45 & 8,44
\end{array}
$$

7) Zum Aufbau des für den Vergleich benötigten isomeren $b$-Semidins ( $\mathrm{vgl}$. Absch. 3) stellten wir zunächst $t^{\prime}$-Methyl-5-jod-2-nitro-diphenylamin (Formel IV in Abschn. 3) her, indem wir $12,6 \mathrm{~g}$ p-Toluidin mit $12 \mathrm{~g}$ 1-Jod-3,4-dinitro-benzol vermischten, wobei unter Temperaturerniedrigung Verflüssigung eintrat. Das Gemisch blieb 8 Tage bei gewöhnlicher Temperatur stehen; da es aber immer innerhalb eines Tages festere Konsistenz annahm, so wurde es zur Begünstigung der Reaktion morgens und abends je eine Stunde auf $50^{\circ}$ erwärmt. Nach 8 Tagen 
wurde es dann mit einem Gemisch von $12 \mathrm{~g}$ kon\%. Schwefelsäure und $24 \mathrm{~g}$ Alkohol auf dem Wasserbade erwärmt, bis die Stickstoffentwicklung aufgehört hatte (Zersetzung des gebildeten Diazoaminotoluols). Als nun das ausgeschiedene Harz zwecks Beseitigung von Verunreinigungen in der Kälte mit Essigsäureanhydrid, verrieben wurde, blieb ein rotes Krystallpulver zurück, das noch zur Zersetzung etwa entstandener Acetylverbindung mit Wasser verrieben und dann aus Alkohol umkrystallisiert wurde. Aus der von dem Harz abfiltrierten alkoholischen Lösung erhält man nach dem Einengen wieder einen harzigen Rückstand, der in der gleichen Weise gereinigt werden kann. Ausbeute an krystallisierter Substanz: $6 \mathrm{~g}$. Das Methyljodnitrodiphenylamin bildet rote verfilzte Nadeln, schmilzt bei $104^{\prime \prime}$ und löst sich leicht in Alkohol, Äther, Chloroform und Benzol, schwerer in Ligroin.

$0,2425 \mathrm{~g}$ gaben $17,2 \mathrm{ccm}$ Stickgas bei $25^{\circ}$ und $756 \mathrm{~mm}$ Druck. $0,1104 \mathrm{~g} \quad, 0,0728$ AgJ.

$\begin{array}{ccr} & \text { Ber. für } \mathrm{C}_{13} \mathrm{H}_{11} \mathrm{O}_{2} \mathrm{~N}_{2} \mathrm{~J} & \text { Gef. } \\ \mathrm{N} & \mathbf{7 , 9 3} & \mathbf{7 , 9 9} \\ \mathrm{J} & 35,86 & \mathbf{3 5 , 6 5}\end{array}$

Zur Reduktion wurden $2,2 \mathrm{~g}$ des fein zerriebenen Nitrokörpers allmählich in eine auf dem Wasserbade erwärmte Lösung von $4,37 \mathrm{~g}$ Zinnchlorür in $12,4 \mathrm{ccm}$ starker Salzsäure, die mit etwa dem gleichen Volum Alkohol und einigen Stückchen granulierten Zinns versetzt war, eingetragen. Man erwärmte, unter Ersatz des verdampfenden Alkohols, bis die rote Farbe des Nitrokörpers verschwand. Das nunmehr ausgeschiedene Zinndoppelsalz wurde durch Schwefelwasserstoff entzinnt, aus der entzinnten Lösung durch überschüssiges Ammoniak das 4'-Methyl-5-jod-2-amino-diphenylamin (Formel II in Abschn. 3) gefällt. Es krystallisiert aus Ligroin in prächtigen farblosen Blättchen, und schmilzt bei $86-87^{\circ}$. Sein salzsaures Salz ist in Wasser schwer löslich. Die verdünnte salzsaure Lösung gibt mit Eisen- 
chlorid eine rotviolette 'Trübung und allmählich einen roten Niederschlag mit blanem Oberflächenschimmer ${ }^{1}$ ).

$0,1505 \mathrm{~g}$ gaben $12,0 \mathrm{cem}$ Stickgas bei $27^{\circ} \mathrm{u} .765,5 \mathrm{~mm}$ Druck. $0,1618 \mathrm{~g} \quad, \quad 0,1164$ AgJ.

$\begin{array}{ccc} & \text { Ber. für } \mathrm{C}_{13} \mathrm{H}_{13} \mathrm{~N}_{2} J & \text { Gef. } \\ \mathrm{N} & 8,66 & 8,84 \\ \mathrm{~J} & 39,17 & 38,89\end{array}$

Die Verschiedenheit von dem in Abschn. 6 beschriebenen, durch Umlagerung des Methyljodhydrazobenzols erhaltenen Amin erhellt schon aus dem Schmelzpunkt und dem Verhalten gegen Eisenchlorid. Sie wurde ferner durch Darstellung des Salicylaldehydderivats erhärtet. Dieses krystallisiert aus Ligroin in gelben Nadeln und schmilzt bei $148^{\circ}$.

$0,1000 \mathrm{~g}$ gaben $5,9 \mathrm{cem}$ Stickgas bei $20^{\circ}$ und $750 \mathrm{~mm}$ Druck. $0,1558 \mathrm{~g}, 0,0854$ AgJ.

$\begin{array}{ccr} & \text { Ber. für } \mathrm{C}_{20} \mathrm{H}_{17} \mathrm{ON}_{2} J & \text { Gef. } \\ \mathrm{N} & 6,56 & 6,7 \mathbf{1} \\ \mathrm{J} & 29,66 & 29,63\end{array}$

Am Gemisch mit dem in Abschn. 6 beschriebenen isomeren Salicylaldehydderivate beobachtet man beginnendes Sintern bei $116^{\circ}$ and unscharfes Schmelzen bei $119-123^{\circ}$. Da nun die sämtlichen, bei der Aufarbeitung des Produkts aus Methyljodhydrazobenzol erhaltenen Krystallfraktionen bei der Kondensation mit Salicylaldehyd Präparate vom Schmelzp. 132-134. ${ }^{\circ}$ lieferten, ist keine Beobachtung gemacht worden, die darauf hindeutet, daß neben dem o-Semidin der Formel I' (vgl. Abschn. 3) auch dasjenige der Formel II bei der Umlagerung des Methyljodhydrazobenzols entsteht.

\section{Umlagerung des 4-Methyl-4'-äthoxy-hydrazobenzols.}

8) Durch Umlagerung war schon in einem früheren Teil meiner Untersuchungen aus dem 4-Methyl-4'-äthoxyhydrazobenzol ( $p$-Toluolhydrazophenetol) ein $o$-Semidin

1) Vgl. diese Annalen 303, 310 (1898) das ähnliche Verhalten des 5-Chlor-2-aminodiphenylamins. 
erhalten worden, das zwar nicht selbst in reiner Form dargestellt, aber durch sein Azimid und seine Stilbazoniumbase gekennzeichnet worden war $^{1}$ ). Es konnte eine der beiden folgenden Formeln besitzen:

und

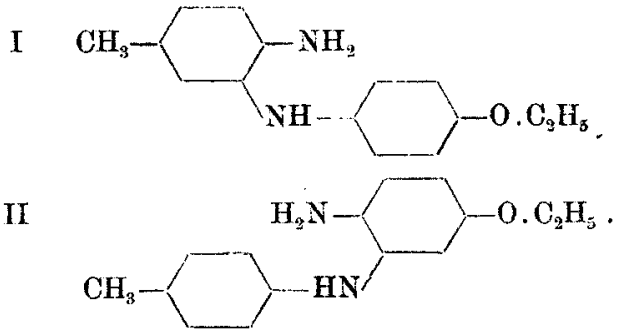

Herr Moriz Freund hat dieses o-Semidin noch durch ein Salicylaldehydderivat (s. u. Abschn. 9) charakterisiert. Fr hat ferner durch Aufbau (s. u. Abschn. 10) das o-Semidin der Formel II - 4'-Methyl-ä-äthoxy-2amino-diphenylamin - hergestellt und es identisch mit dem Amin befunden, das aus der Umlagerung des 4-Methyl-4'-äthoxy-hydrazobenzols hervorgeht. Bezüglich der präparativen Finzelheiten und analytischen Belege verweise ich auf die Dissertation des Herrn Freund ${ }^{2}$ ); in den beiden folgenden Abschnitten bringe ich nur die Frgebnisse.

9) Das Salicylaldyhydderivat $\mathrm{C}_{22} \mathrm{H}_{22} \mathrm{O}_{2} \mathrm{~N}_{2}$ wurde aus einer unter $15 \mathrm{~mm}$ Druck destillierten Probe des o-Semidins bereitet. Es krystallisiert aus Ligroin in gelben Nädelchen, schmilzt bei $121-124^{\circ}$ und ist in Methyland Äthylalkohol, Ligroin und Äther leicht löslich.

10) Der Aufbau wurde aus 1-Chlor-3,4-dinitro-benzol (Formel III, s. u.) über die Zwischenprodukte IV nnd $V$ vollzogen $\left.{ }^{3}\right)$ :

1) Diese Annalen 287, 177-179 (1895).

") "Über die Reduktion des p-Toluolazophenetols und des p-Brombenzolazophenetols" (Heidelberg 1896), S. 8-14.

3) Vgl. den analogen Aufbau des niedrigeren Homologen Ber. d. d. chem. Ges. 26, 683-686 (1893). 
III<smiles>O=[N+]([O-])C1CCC(Cl)CC1[N+](=O)[O-]</smiles>

IV<smiles>CCON(CCCC(Cl)CC)OCC</smiles>

V

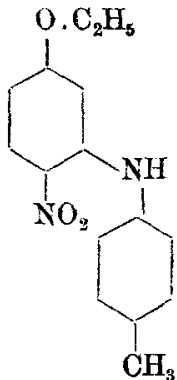

\section{Reduktion}<smiles>CCCCCCOC1CCC(N)C(NC2CCC(C)CC2)C1</smiles>

Das aus Chlordinitrobenzol und p-Toluidin entstehende 4'-Methyl5-chlor-2-nitro-diphenylamin (Formel IV, s. o.) ist schon beschrieben '). In Übereinstimmung mit Kehrmann und Krazler fanden wir seinen Schmelzpunkt bei $126-127^{\circ}$.

Das daraus durch Natriumäthylat hervorgebende $4^{\prime}$-Methyl5-äthoxy-2-nitro-diphenylamin $\mathrm{C}_{15} \mathrm{H}_{16} \mathrm{O}_{3} \mathrm{~N}_{2}$ (Formel V) krystalliaiert aus Alkohol in langen bellbraunen Nadeln, schmilzt bei $104^{\circ}$ und ist in Alkohol, Äther und Ligroin leicht löslich.

Es wird von salzsaurer Zinnchlorürlösung fast gar nicht verändert ${ }^{2}$ ) und wurde daher mit alkoholischem Schwefelammonium irn Einschlubrohr bei $130^{\circ}$ reduziert. Das Hydrochlorid des dadurch gebildeten o-Semidins wurde aus seiner wäBrigen Lösung durch Zusatz einiger Tropfen konz. Salzsäure als schwach violett gefärbter Krystallbrei abgeschieden. Das freie o-Semidin in krystallisierter Form zu erhalten, gelang hier ebensowenig, wie bei dem durch Umlagerung aus 4-Methyl-4'-äthoxy-hydrazobenzol gewonmenen Semidin. Die Identifizieruug wurde durch die Schmelzpunkte des Salicylaldehydderivats (121-124\% , s. Absehnitt 9) und der mit Benzil entstehenden Stilbazoniumbase $\left(146^{\circ}\right.$ nach bei $141^{\circ}$ beginnendem Sintern) vollzogen.

1) Laubenheimer, Ber. d. d. chem. Ges. 11, 1157 (1878); Kehrmann, Krazler, Ber. d. d. chem. Ges. 34, 1102 (1901).

2) Vgl. Ber. d. d. chem. Ges. 26, 685-686 (1893) die analoge Beobachtung bei dem niedrigeren Homologen. 
164 Jacobson, Weitere Experimentalbeiträge zur Kenntnis

\section{Umlagerung des 4-Brom-4'athoxy-hydrazobenzols.}

11) Die in der Dissertation des Herrn M. Freund ${ }^{3}$ ) ausführlicher beschriebenen Versuche zeigen, dab der in der Überschrift genannte Hydrazokörper sich recht glatt zu einem o-Semidin isomerisiert. Von den beiden, nach dieser Bildung möglichen 0 -Semidinen:

I

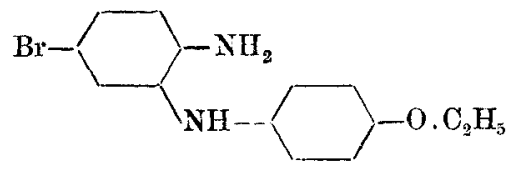

und

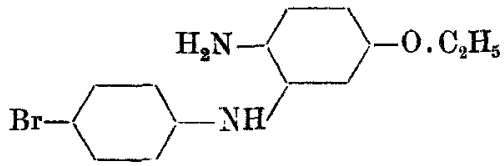

stellte Herr K. Zaar ${ }^{2}$ ) das erste durch Aufbau aus 1-Brom-3,4-dinitrobenzol auf einem ähnlichen Wege dar, wie er in Abschn. 3 in der Formelreihe III $\rightarrow$ IV $\rightarrow$ II erläutert ist (Austausch einer Nitrogruppe durch die Phenetidinogruppe, darauf Reduktion der zurückgebliebenen Nitrogruppe). Es erwies sich als verschieden von dem durch Umlagerung gebildeten Amin, das demnach die Formel II des $4^{\prime}$-Brom-5-äthoxy-2-aminodiphenylamins besitzt.

12) Darstellung des Ausgangsmaterials. p-Brombenzolazophenol ${ }^{3}$ ) wurde mit alkoholischer Natriumäthylatlösung und Äthyljodid in seinen Äthyläther - 4-Brom$4^{\prime}$-äthoxy-azobenzol - übergeführt. Dieser krystallisiert aus Alkohol in gelben glänzenden Blättern, schmilzt bei $135-136^{\circ}$ and ist in Alkohol, Äther und Eisessig löslich, während er von Ligroin kaum anfgenommen wird.

1) Vgl. die in FuBnote 2, S. 162 zitierte Dissertation, S. 15-32.

2) Dissertation „Über die drei isomeren Brombenzolazophenole und ihre Abkömmlinge" (Heidelberg 1897), S. 27-32.

3) Hewitt, Moore, Pitt, Ber. d. d. chem. Ges. 31, 2116 (1898) Fox, Hewitt, Journ. chem. Soc. 93, 340 (1908). 
$0,1473 \mathrm{~g}$ gaben $12,15 \mathrm{ccm}$ Stickgas bei $22^{\circ}$ und $753 \mathrm{~mm}$ Druck. $0,1270 \mathrm{~g} \quad, \quad 0,078 \mathrm{~g} \mathrm{AgBr}$.

$\begin{array}{lcr} & \text { Ber. für } \mathrm{C}_{14} \mathrm{H}_{13} \mathrm{ON}_{2} \mathrm{Br} & \text { Gef. } \\ \mathrm{N} & 9,20 & 9,31 \\ \mathrm{Br} & 26,20 & 26,14\end{array}$

$\mathrm{Zu}$ einer auf dem Wasserbade erwärmten Lösung von $1 \mathrm{Tl}$. dieses Azophenoläthers in $10 \mathrm{Tln}$. Alkohol gab man 2 Tle. Natronlauge von 28 Proz. $(\mathrm{D}=1,32)$ und unter Umschütteln so lange Zinkstaub, bis vollständige Entfärbung (erkenubar am Auftreten eines farblosen Schaums) eingetreten war. Versetzt man nun die heiB filtrierte Lösung mit heißem Wasser, bis eine bleibende 'l'rübung entsteht, so scheidet sich beim Erkalten das 4-Brom-4'äthoxy-hydrazobenzol in schönen weißen Krystallen aus, die aber beim Aufbewahren - selbst in verschlossenen Gefäßen und im Dunkeln - sich gelb färben. Es krystallisiert aus Ligroin in weißen Nädelchen, schmilzt bei $81-83^{\circ}$ und ist in kaltem Alkohol schwer, in heißem leicht löslich.

$0,1713 \mathrm{~g}$ gaben 14,0 eem Stickgas bei $20^{\circ}$ und $730 \mathrm{~mm}$ Druck. $0,0670 \mathrm{~g} \quad, \quad 0,0411 \mathrm{~g} \mathrm{AgBr}$.

$\begin{array}{lcr} & \text { Ber. für } \mathrm{C}_{14} \mathrm{H}_{15} \mathrm{ON}_{2} \mathrm{Br} & \text { Gef. } \\ \mathrm{N} & 9,12 & 8,93 \\ \mathrm{Br} & 25,97 & 26,10\end{array}$

13) Unter den "normalen Reduktionsbedingungen"1) erleidet das 4-Brom-4'-äthoxy-azobenzol eine Spaltung von $7 \check{5}$ Proz, in $p$-Bromanilin und $p$-Phenetidin. Daher wurden die Umlagerungsversuche unter den Täuberschen Bedingungen ${ }^{2}$ ) am 4-Brom-4'-äthoxy-hydrazobenzol angestellt. $\mathrm{Zu}$ einer Suspension von $4 \mathrm{~g}$ dieses Hydrazokörpers in $40 \mathrm{~cm}$ Alkohol gab man $12 \mathrm{~g}$ einer Lösung, welche aus $60 \mathrm{~g}$ krystallisiertem Zinnchlorür und $150 \mathrm{ccm}$ 28 prozentiger Salzsäure bereitet war, tropfenweise unter guter Kühlung und stetem Umrühren. Das Reaktionsgemisch stellt dann einen dicken, violett gefärbten Brei

i) Diese Annalen 287, 105, 110 (1895).

3) Vgl. FuBnote 1, S. 155 . 
dar. Nach 24 stündigem Stehen saugt man das ansgeschiedene Zinndoppelsalz $a b$; in seiner Mutterlauge befinden sich die durch Spaltung gebildeten Amine, deren Menge unter diesen Bedingungen einem Spaltungsbetrage von nur etwa 25 Proz. entspricht.

Wenn man das Zinndoppelsalz in heißer wäßriger lösung durch Schwefelwasserstoff entzinnt und heib vom Schwefelzinn filtriert, scheidet sich beim Abkühlen ein dicker weißer Krystallbrei des salzsauren o-Semidins ab. Dieses wurde abgesaugt, wieder in heißem Wasse. gelöst und nach dem Abkühlen der lösung auf etwa $40^{\circ}$ durch Sodalösung zersetzt; das freie o-Semidin (etwa 48 Proz. des angewendeten Hydrazokörpers) setzt sich dann als harte Masse ab und kann durch Krystallisation aus Ligroin leicht gereinigt werden. Aus der Mutterlauge des salzsauren Salzes gewinnt man durch Zersetzen mit Sodalösung eine weitere Menge (etwa 18 Proz. des angewendeten Hydrazokörpers) freien Amins, das sich durch seinen Schmelzpunkt (nach der Krystallisation aus Ligroin) sowie durch den Schmelzpunkt seines Azimids (vgl. den nächsten Abschnitt) als das gleiche o-Semidin erwies. Uieses ist also das wesentliche lirzeugnis der Reaktion; da es leicht oxydierbar ist, muB man bei seiner Abscheidung und Krystallisation Luftzutritt möglichst beschränken und rasch arbeiten.

14) Das 4'-Brom-5-äthoxy-2-amino-diphenylamin (Formel II in Abschn. 11), dessen Gewinnung eben beschrieben wurde, stellt in reinem Zustand weibe Näde\}chen dar, schmilzt bei $67-68^{6}$, ist in Alkohol und Äther leicht löslich und färbt sich an der Luft rasch violett bis dunkelblau. Es erweist sich als "-Semidin dadurch, dab Natriumnitrit in seiner salzsauren Lösung reichliche Trübung bewirkt, und daß mit Benzil Kondensation zu einem Produkt von den allgemeinen Eigenschaften der Stilbazoniumbasen ${ }^{1}$ ) erfolgt.

1) Vgl. diese Annalen 287, 134 (1895). 
$0,1296 \mathrm{~g}$ gaben $10,2 \mathrm{ccm}$ Stickgas bei $14^{0}$ and $750 \mathrm{~mm}$ Druck. $0,0790 \mathrm{~g}, 0,0485 \mathrm{AgBr}$.

$\begin{array}{lcr} & \text { Ber. für } \mathrm{C}_{\mathbf{1 4}} \mathrm{H}_{15} \mathrm{ON}_{\mathbf{2}} \mathrm{Br} & \text { Gef. } \\ \mathrm{N} & 9,12 & 9,09 \\ \mathrm{Br} & 25,97 & \mathbf{2 6 , 1 3}\end{array}$

Die im folgenden beschriebenen Abkömmlinge bestätigen sämtlich die Zugehörigkeit zur Gruppe der $o$-Semidine.

Das Azimid - 1-[p-Bromphenyl $]-6$-äthoxy-benztriazol

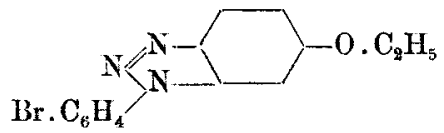

- erhält man, wenn man $1 \mathrm{~g}$ salzsaures Salz in Alkohol suspendiert, eine Lösung von $1,8 \mathrm{~g}$ Amylnitrit in $14 \mathrm{ccm}$ Alkohol hinzufügt, die jetzt dunkelviolette Lösung im Wasserbade aufkocht, dann mit Eisessig ansäuert, 1 Stunde unter Rückfluß kocht und nun nach dem Abkühlen in viel kaltes Wasser gießt. Es krystallisiert aus Ligroin in weißen langgestreckten Blättchen, schmilzt bei $145-146^{\circ}$ (bei viermaliger Umkrystallisation konstant gefunden, vgl. das isomere Azimid im Abschn. 15) und ist in kaltem Alkohol, in Ligroin und Äther sehr leicht löslich.

$0,1808 \mathrm{~g}$ gaben $21,0 \mathrm{~cm}$ Stickgas bei $18^{\circ}$ und $751 \mathrm{~mm}$ Druek. $0,1440 \mathrm{~g} \quad, \quad 0,0842 \mathrm{AgBr}$.

$\begin{array}{lcr} & \text { Ber. für } \mathrm{C}_{14} \mathrm{H}_{12} \mathrm{ON}_{3} \mathrm{Br} & \text { Gef. } \\ \mathrm{N} & 13,23 & 13,19 \\ \mathrm{Br} & 25,13 & 24,88\end{array}$

Durch Kochen von $2 \mathrm{~g}$ salzsaurem o-Semidin mit $20 \mathrm{~g}$ wasserfreier Ameisensäure und Eingießen der Lösung in kaltes Wasser gewinnt man das Methenglderivat - 1-[p-Bromphenyl]-6-äthoxy-benzimidazol

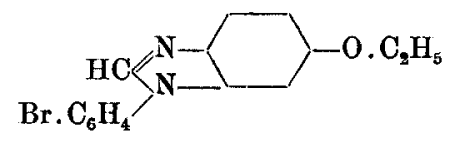

- zunächst als ameisensaures $\mathrm{Salz}$ in farblosen $\mathrm{Kry}$ stallen. Löst man $2 \mathrm{~g}$ dieses $\mathrm{Salz}$ in $1 \frac{1}{2}$ Liter heiben 
Wassers und fügt bei etwa $40^{\circ}$ konz. Sodalösung hinzu, so scheidet sich das freie Methenylderivat zuerst in Form einer milchigen Trübung, dann in weißen Flocken ab. Es krystallisiert aus verdünntem Alkohol in weißen Nadeln, die sich an der Luft violett färben, schmilzt bei $120^{\circ}$ und löst sich leicht in Alkohol, Äther und Ligroin. Sein Nitrat ist sehr schwer löslich. In warmer verdünnter Salzsäure gelöst, gibt das Methenylderivat mit Quecksilberchlorid einen weißen gallertartigen Niederschlag.

$0,1402 \mathrm{~g}$ gaben $11,0 \mathrm{~cm}$ Stickgas bei $21^{\circ}$ und $751 \mathrm{~mm}$ Druck. $0,0920 \mathrm{~g}, \quad 0,0548 \mathrm{AgBr}$.

$\begin{array}{lcr} & \text { Ber. für } \mathrm{C}_{15} \mathrm{H}_{13} \mathrm{ON}_{\mathbf{2}} \mathrm{Br} & \text { Gef. } \\ \mathrm{N} & 8,85 & 8,78 \\ \mathrm{Br} & 2 \overline{\mathbf{5}}, 22 & \mathbf{2 5 , 3 4}\end{array}$

Dieses Methenylderivat ist gegen 25 prozentige Schwefelsäure bei sechsstündigem Erhitzen auf $160^{\circ} \mathrm{im}$ Kinschlußrohr noch beständig. Bei $180^{\circ}$ aber wird es verändert, indem das Äthoxyl zu Hydroxyl verseift wird, ohne daß der Imidazolring sich aufspaltet. Verdünnt man die schwefelsaure Lösung, die sich nach sechsstündigem Erhitzen mit 10 TIn. 25 prozentiger Schwefelsäure auf $180^{\circ} \mathrm{im}$ Rohr findet, mit Wasser und versetzt dann mit Natron, so trübt sie sich nur vorübergehend, wird aber auf Zusatz von mehr Natronlauge wieder klar. Leitet man nun Kohlendioxyd ein, so fällt reichlich ein weißer flockiger Niederschlag aus; beim Aus-

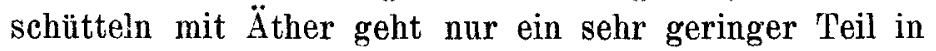
ätherische Lösung. Die Hauptmenge jenes Niederschlags bleibt ungelöst. Durch Krystallisation aus Alkohol erhält man daraus das 1-[p-Bromphenyl]-5-oxy-benzimidazol.<smiles>OC1CCC2C(C1)N1CCN2C1[13CH2]Br</smiles>

in schwach violett gefärbten Nädelchen vom Schmelzpunkt $295^{\circ}$; es löst sich leicht in verdünnten Alkalien wie auch in verdünnten Säuren, sogar in verdünnter Essigsäure. 
$0,0885 \mathrm{~g}$ gaben $7,6 \mathrm{ccm}$ Stickgas bei $28^{\circ}$ und $758 \mathrm{~mm}$ Druck. $0,1570 \mathrm{~g} \quad, \quad 0,1030 \mathrm{AgBr}$.

$\begin{array}{lcr} & \text { Ber. für } \mathrm{C}_{13} \mathrm{H}_{9} \mathrm{ON}_{2} \mathrm{Br} & \text { Gef. } \\ \mathrm{N} & 9,71 & 9,49 \\ \mathrm{Br} & 27,66 & 27,91\end{array}$

Jurch sechsstündiges Kochen von 1 Tl. o-Semidin mit 5 Tln. $\mathrm{CS}_{3}$ in $5 \mathrm{Tln}$. Alkohol wurde das Schwefelkohlenstoffderivat - 1-[p-Bromphenyl]-6-äthoxy-2mercapto-benzimidazol

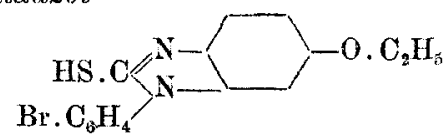

- bereitet. Hs krystallisiert aus Benzol in weißen spitzen Nadeln, schmilzt bei $255^{\circ}$ und löst sich schwer in kaltem, leicht in heibem Alkohol, nicht in Äther. Von verdïnntem Alkali wird es aufgenommen, durch Säuren wieder daraus gefällt.

$0,1630 \mathrm{~g}$ gaben $11,0 \mathrm{ccm}$ Stickgas bei $19^{\circ}$ und $753 \mathrm{~mm}$ Druck. $0,1055 \mathrm{~g} \# \quad 0,0566 \mathrm{AgBr}$ und $0,0698 \mathrm{BaSO}_{4}$.

$\begin{array}{lcr} & \text { Ber. für } \mathrm{C}_{15} \mathrm{H}_{13} \mathrm{ON}_{2} \mathrm{BrS} & \mathrm{Gef} \\ \mathbf{N} & 8,04 & 7,65 \\ \mathrm{Br} & 22,90 & 22,82 \\ \mathrm{~S} & 9,18 & 9,08\end{array}$

Das Salicylaldehydderivat des o-Semidins krystallisiert aus Ligroin in kleinen, zu Büscheln vereinigten, gelben Nadeln, schmilzt bei $151^{\circ}$, löst sich in Alkohol mit gelber Farbe und reduziert in alkoholischer Lösung frisch gefälltes Quecksilberoxyd langsam zu metallischem Quecksilber.

$0,1126 \mathrm{~g}$ gaben $7,2 \mathrm{ecm}$ Stickgas bei $17^{\circ}$ und $753 \mathrm{~mm}$ Druck. $0,1226 \mathrm{~g} " 0,0550 \mathrm{AgBr}$.

$$
\begin{array}{lcr} 
& \text { Ber, für } \mathrm{C}_{21} \mathrm{H}_{19} \mathrm{O}_{2} \mathrm{~N}_{2} \mathrm{Br} & \text { Gef. } \\
\mathrm{N} & 6,83 & 7,32 \\
\mathrm{Br} & 19,45 & 19,09
\end{array}
$$

15) Für den Aufbau des isomeren o-Semidins (Formel $I$ in $11 \mathrm{Abschn.)} \mathrm{wurde} \mathrm{zunächst} \mathrm{5-Brom-4'-äthoxy-}$ 2-nitro-diphenylamin durch dreitägiges Stehenlassen einer Mischung aus 1 Molgew. 1-Brom-3,4-dinitro-benzol und 
3 Molgew. p-Phenetidin hergestellt. Das vollkommen hart gewordene Reaktionsgemisch wurde durch Ausziehen mit verdünnter Essigsäure von unverändertem Phenetidin befreit, dann zur Zersetzung der darin enthaltenen Diazoaminoverbindung mit 5 prozentiger Schwefelsäure gekocht, worauf man einen Wasserdampfstrom zur Entfernung des zugehörigen Phenols durchleitete. Aus dem festen Rückstand erhielt man nun das gewünschte Nitroamin durch Krystallisation aus Alkohol in dunkelroten Nadeln vom Schmelzp. $115^{\circ}$.

$0,0932 \mathrm{~g}$ gaben $6,8 \mathrm{~cm}$ Stickgas bei $20^{\circ}$ und $758 \mathrm{~mm}$ Druck. $0,1320 \mathrm{~g}, 0,0745 \mathrm{AgBr}$.

$\begin{array}{lcr} & \text { Ber. für } \mathrm{C}_{14} \mathrm{H}_{19} \mathrm{O}_{3} \mathrm{~N}_{2} \mathrm{Br} & \text { Gef. } \\ \mathrm{N} & 8,33 & 8,32 \\ \mathrm{Br} & 23,72 & 24,02\end{array}$

Das hieraus durch Reduktion mit salzsaurem Zinnchlorür entstehende 5-Brom-4-äthoxy-2-amino-diphenylamin (Formel I in Abschn. 11) konnte im Gegensatz zu. dem so leicht krystallisierenden o-Semidin, das durch Umlagerung des 4-Brom-4'äthoxy-hydrazobenzols gewonnen war (vgl. Abschn. 13 u. 14), nicht in krystallisierter Form erhalten werden.

Es wurde durch ein Azimid-- 1-[p-Äthoxyphenyl $]-$ (j-brom-benztriazol

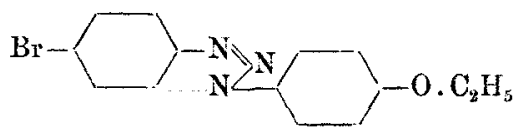

- charakterisiert. Dieses krystallisiert aus Ligroin in weiBen Nadeln und schmilzt bei $129^{\circ}$; durch viermaliges Umkrystallisieren stieg der Schmelzpunkt nicht über diese Zahl. Fs ist also verschieden von dem in Abschn. 14 beschriebenen Arimid.

$0,1314 \mathrm{~g}$ gaben $15,9 \mathrm{ccm}$ Stickgas bei $28^{\circ}$ und $758 \mathrm{~mm}$ Druck。 $0,1352 \mathrm{~g} \quad, \quad 0,0806 \mathrm{AgBr}$.

$\begin{array}{lcr} & \text { Ber. für } \mathrm{C}_{14} \mathrm{H}_{12} \mathrm{ON}_{3} \mathrm{Br} & \text { Gef. } \\ \mathrm{N} & 13,23 & 13,38 \\ \mathrm{Br} & 25,13 & 25,37\end{array}$


Desgleichen zeigte sich die Verschiedenheit an dem Salicylaldehydderivat, das in langen rotgelben Nadeln krystallisiert und bei $146-147^{\circ}$ schmilzt.

\section{Umlagerung des 4-Methyl-4'-acetoxyhydrazobenzols.}

16) Die Versuche wurden in diesem Fall nicht an der Hydrazoverbindung, sondern an der entsprechenden Azoverbindung - dem Acetyl-p-toluolazophenol $\mathrm{CH}_{3}$. $\mathrm{C}_{6} \mathrm{H}_{4} \cdot \mathrm{N}: \mathrm{N} . \mathrm{C}_{6} \mathrm{H}_{4} \cdot 0 . \mathrm{CO}_{2} \mathrm{CH}_{3}$, das schon von H. Goldschmidt und Brubacher') beschrieben worden ist, angestellt. Sie sind von Herrn H. Tigges ausgeführt und in seiner Dissertation ausführlich mitgeteilt; auf diese Dissertation ${ }^{2}$ ) sei bezüglich präparativer Einzelheiten und analytischer Belege verwiesen.

Ihr Ergebnis besteht darin, dab ein o-Semidin gebildet wird, welches dem $p$-Toluolhydrazophenol isomer ist, also unter Umlagerung und unter gleichzeitiger Verseifung der Acetoxyl- zur Hydroxylgruppe entstanden ist. Nach seiner Entstehung kommen für dieses o-Semidin zwei Strukturmöglichkeiten in Betracht:

I

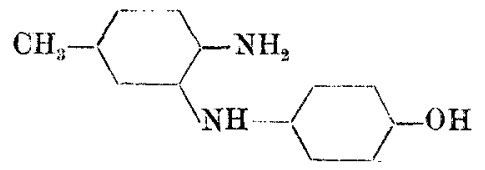

1) Ber. d. d. chem. Ges. 24, 2310 (1891). - Zur Konstitution vgl.: Jacobson und Tigges, diese Annalen 303, 341 (1898). H. Goldschmidt, I,öw-Beer, Ber. d. d. ehem. Ges. 35, 110 (1905). - Auwers, Ber. d. d. chem. Ges. 40, 2159 (1907). Diese Annalen 360, 17 (1908). - Dem von Goldsehmidt u. Brubacher [Ber. d. d. chem. Ges. 24, 2311 (1891)] beschriebenen Isomeren des Acetyl-p-toluolhydrazophenols $\mathrm{C}_{15} \mathrm{H}_{16} \mathrm{O}_{2} \mathrm{~N}_{2}$ (erhalten durch Reduktion des Acetyl-p-toluolazophenols mit Zinkstaub und Schwefelsäure) sind wir bei unseren Versuchen nicht begegnet; die dafür von den genannten Autoren aufgestellte Formel eines 5'-Methyl-5-oxy-2amino-2'-acetamino-diphenyls kann jedenfalls nach den heute rorliegenden Erfabrungen nicht mehr aufrecht erhalten werden.

2) „Über Reduktion von acetylierten $p$-Oxyazokörpern" (Heidelberg 1896), S. 7-9, 20-32. 
und

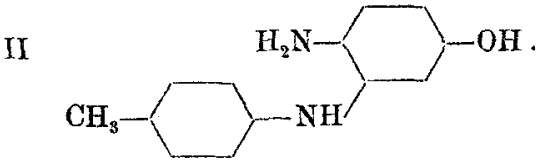

Auf zwei Wegen konnte die Richtigkeit der Formel I bewiesen werden. Träfe nämlich die Formel II zu, so mübte das Azimid der Verbindung bei der Äthylierung das gleiche äthoxylhaltige Azimid IIT geben, das aus

III

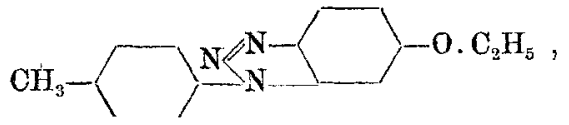

dem Umlagerungsprodukt des p-Toluolhydrazophenetols entsteht, für welches in Abschn. 8-10 dieser Abhandlung die Struktur des 4'-Methyl-5-äthoxy-2-amino-diphenylamins nachgewiesen ist; das äthylierte Azimid erwies sich aber als durchans verschieden von dieser schon in einem früheren Teil meiner Untersuchungen beschriebenen Verbindung ${ }^{2}$ ). Sodann konnte das $o$-Semidin durch Spaltung mit Salzsäure in Hydrochinon und 3,4-Diaminotoluol zerlegt werden - ein Verlauf, der bei Annahme der Formel I ohne weiteres verständlich, bei Formel II aber unmöglich erscheint. Das o-Semidin ist daher gemäß Formel I als 5-Methyl-4'-oxy-2-amino-diphenylamin aufzufassen.

Aber daneben entsteht in reichlichem Betrage ein $p$-Semidin. Da wir von einem zweifach $p$-substituierten Hydrazokörper (Substituenten: $\mathrm{CH}_{3}$ und $0 . \mathrm{CO} . \mathrm{CH}_{3}$ ) ausgegangen waren, konnte ein solches nur durch völlige AbstoBung eines Parasubstituenten gebildet sein. Die Abstobung von Methyl konnte kaum in Betracht kommen. Bei der Untersuchung des $p$-Acetoxyazobenzols aber war schon die merkwürdige Feststellung gemacht worden, dab die Acetoxylgruppe im Gegensatz zur Äthoxyl- und Hydroxylgruppe leicht abgestoßen wird ${ }^{2}$ ); dies gab sich

1) Diese Annalen 287, 178 (1895).

2) Diese Annalen 303, 300, 343 (1898). 
dort durch Bildung von Benzidin kund. Hier konnte ein analoger Vorgang zum $p$-Semidin der Formel IV (s. u.) führen; und in der Tat erwies sich das entstandene

IV

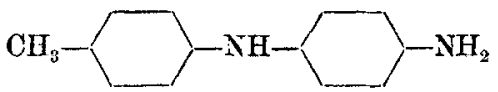

$p$-Semidin durch seine empirische Zusammensetzung and durch seine Eigenschaften als 4'-Methyl-4-amino-diphenylamin, das schon früher von Reichold ${ }^{3}$ ) aus Phenyl-ptolylamin durch einander folgende $N$-Nitrosierung, Umlagerang (nach 0 . Fischer und Hepp) and Reduktion erhalten worden war.

17) Die Umlagerung wurde unter den Bedingungen vollzogen, die früher für Acetyl-p-oxyazobenzol angegeben sind ${ }^{2}$ ). Nach eintägigem Stehen der aus $10 \mathrm{~g}$ Acetylp-toluolazophenol und $60 \mathrm{~g}$ Zinnchlorürlösung erhaltenen Reaktionslösung findet man eine kleine Menge eines Zinndoppelsalzes abgeschieden, aus dessen wäBriger Lösung man durch Entzinnen mit Schwefelwasserstoff, Finengen im Kohlendioxydstrom und Versetzen mit gesättigter Natriumsulfitlösung das o-Semidin in krystallisierter Form erhält.

Die von diesem Zinndoppelsalz abfiltrierte saure zinnhaltige Lösung wurde mit Natronlauge partiell neutralisiert, wodurch ein brauner harziger Niederschlag entsteht. Er wurde nach eintägigem Stehen von der Mutterlange getrennt, die nur Spaltungsprodukte (Toluidin und Aminophenol) enthält, und dann in möglichst wenig kochendem Wasser gelöst. Beim Erkalten dieser Lösung scheidet sich nun das salzsaure $p$-Semidin zinnfrei in Krystallform ab; in der zinnhaltigen Lösung steckt noch eine erhebliche Menge o-Semidin, die sich aus ihr durch die oben angegebenen Operationen (Entzinnen usw.) gewinnen läßt.

1) Diese Annalen 255, 166 (1889).

^) Diese Annalen 303, 341 (1898). 
174 Jacobson, Weitere Experimentalbeiträge zur Kenntnis

In dieser Weise gelang eine so gut wie vollständige Aufarbeitung; denn es ergab sich, dab

31,2 Proz. des Azokörpers zu o-Semidin umgelagert,

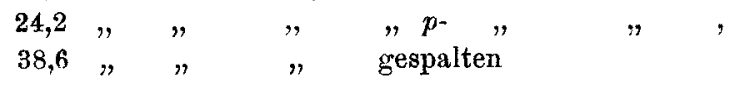

werden, wodurch für 94 Proz. der Nachweis ihres Schicksals erbracht ist. Das o-Semidin war in freiem Zustand vor dem Umkrystallisieren, das $p$-Semidin als salzsaures Salz (vgl. oben) gewonnen; der Spaltungsbetrag wurde durch Wägung des salzsauren Toluidins ermittelt ${ }^{1}$ ).

18) Das o-Semidin - 5-Methyl-4'-oxy-2-aminodiphenylamin $\mathrm{C}_{13} \mathrm{H}_{14} \mathrm{ON}_{2}$ (Formel $\mathrm{I}$ in Abschn. 16) krystallisiert aus Benzol in weißen glänzenden Nadeln, schmilzt bei $137^{\circ}$ und färbt sich an der Luft bald rötlich. Es löst sich leicht in Alkohol und Äther, schwer in Benzol und heißem Wasser, sehr wenig in Ligroin. Von stark verdünnter Natronlauge wird es leicht aufgenommen; die alkoholische Lösung ist anfangs farblos, färbt sich jedoch sehr rasch violettblau und darauf braun unter Abscheidung eines schmutzigen Niederschlags. In Wasser unter Zusatz von wenig Salzsänre gelöst, gibt das o-Semidin mit einem Tropfen verdünnter Eisenchloridlösung eine hellgelbbraune, nach einiger Zeit dunkelrot werdende Färbung und nach längerem Stehen dunkle Flocken; oxydiert man etwas gröBere Mengen mit Fisenchlorid ${ }^{2}$ ) und äthert dann die wäBrige Flüssigkeit aus, so hinterläßt der Äther beim Verdunsten eine braune Masse von starkem Chinongeruch.

Die o-Semidinnatur wurde - abgesehen von dem unten beschriebenen Azimid - noch durch Kondensation mit Benzil zu einer Stilbazoniumbase bestätigt, welche zwar nicht in reinem Zustand gewonnen wurde, aber als solche durch die charakteristischen Reaktionen ${ }^{3}$ ) sich zu erkennen gab.

1) Vgl. diese Annalen 303, 343 (1898)。

2) Unter den diese Annalen 287, 136 (1895) angegebenen Belingungen.

3) Vgl. diese Annalen 287, 134 (1895). 
Die in Abschn. 16 erwähnte Spaltung wurde durch sechsstündiges Erhitzen von $5 \mathrm{~g}$ o-Semidin mit $12,5 \mathrm{ccm}$ konz. Salzsäure und $12,5 \mathrm{ccm}$ Wasser in einer mit Kohlendioxyd gefiillten Bombe auf $150-160^{\circ}$ bewirkt.

Die biernach erhaltene saure Iösung schüttelte man mehrmals rait kleinen Mengen Äther (A) aus; dann machte man sie stark alkalisch und schüttelte wieder mit Äther (B) aus. Die ätherische Lösung A binterlieB Hydrochinon, identifiziert durch den Schmelzpankt $169^{\circ}$ (nach dem Umkrystallisieren aus Benzol), die Reduktion von ammoniakalischer Silberlösung und die Entwickelung starken. Chinongeruchs bei Behandlung mit Chromsäuregemisch. Der Rückstand der ätherischen Lösung B wurde durch Destillation unter $25 \mathrm{~mm}$ Druck gereinigt und erwies sich als 3,4-Diamino-toluol (Schmelzp. 88,5\%); dieses wurde noch durch Kondensation mit Phenanthrenchinon in Toluphenanthrazin ${ }^{1}$ ) übergeführt, dessen Vorliegen durch den Schmelzp. 215,5-216,5 ${ }^{\circ}$, die Rotfärbung mit Salzsänre und durch Stickstoff bestimmung bestätigt wurde.

Wenn man eine $1 / 10$ prozentige Lösung des o-Semidins (1 Molgew.) in sehr verdünntèr Salzsäure (3 Molgew. HCl) nnter Kühlung allmählich mit 1 prozentiger wäßriger Nitritlösung (1 Molgew. $\mathrm{NaNO}_{2}$ ) versetzt, entsteht infolge der Bildung des Azimids - 6-Methyl-1-[p-oxyphenyl]-benztriazol

$$
\mathrm{C}_{19} \mathrm{H}_{11} \mathrm{ON}_{3}=\mathrm{CH}_{3}-\longrightarrow-\mathrm{N}_{\mathrm{N}} \mathrm{N}_{\mathrm{C}_{6} \mathrm{H}_{4} . \mathrm{OH}}
$$

- eine braune Trübung. Man äthert aus, schüttelt die 花herische Lösung mit Wasser und einigen Tropfen Natronlauge, worin sich das Aximid in seiner Eigenschaft als Phenol löst, und fällt es durch Kohlendioxyd aus. Zur Reinigung wurde es mehrmals in verdünnter Natronlauge gelöst, durch $\mathrm{CO}_{2}$ wieder gefällt und wiederholt aus verdünntem Alkohol krystallisiert. Fs bildet gelblichweiße Blättchen, schmilzt bei $187,5-189,5^{\circ}$ unter geringer Zersetzung und löst sich leicht in Alkohol und Äther, schwerer in Benzol, nur wenig in Ligroin; anch löst es sich in konz. Salzsäure und wird durch Wasser wieder daraus abgeschieden.

1) Vgl. Hinsberg, diese Annalen 237, 341 (1887). - Boyd, Journ. chern. Soc. 65, 838 (1894). 
Zur Äthylierung (vgl. Abschn. 16) warde dieses Azimid (1 Molgew.) mit einer alkoholischen Lösung von Natrium (1 $1 / 2$ Atomgew.) und Äthyljodid (1 $1 / 8$ Molgew.) mehrere Stunden gekocht. Man goB dann in Wasser, dem etwas Natronlauge (zur Lösung von unäthyliert gebliebenen Azimid) zugefügt war, und reinigte den ausfallenden Azimidäthyläther durch Krystallisation aus verdünntem Alkohol, dann aus Petroläther. Das 6-Methyl1-[p-äthoxyphenyl]-benztriazol

$$
\mathrm{C}_{15} \mathrm{H}_{15} \mathrm{ON}_{8}=\mathrm{CH}_{3}-\sum_{\mathrm{N}}^{\mathrm{N}_{\mathrm{C}_{6} \mathrm{H}_{4}} .0 . \mathrm{C}_{9} \mathrm{H}_{6}}
$$

scheidet sich aus Alkohol in langgestreckten schiefwinkligen Tafeln mit abgestumpften Ecken (unter dem Mikroskop betrachtet) ab, schmilat bei $91^{\circ}$ und löst sich sehr leicht in Alkohol und Eisessig, etwas schwerer in Iigroin.

Durchaus verschieden davon ist das $1-[p-T o l y l]-6-$ äthoxy-benztriazol ${ }^{1}$ ) der Formel III (Abschn. 16), das zum Vergleich nochmals aus $p$-Toluolhydrazophenetol hergestellt wurde. Es krystallisiert aus Alkohol in gleichseitigen rechtwinkligen Tafeln und schmilzt bei $115^{\circ}$ (früher gefunden: $117^{\circ}$ ).

19) Das $p$-Semidin $\mathrm{C}_{13} \mathrm{H}_{14} \mathrm{~N}_{2}$ wurde mit dem von Reichold ${ }^{2}$ ) beschriebenen 4'-Methyl-4-amino-diphenylamin (Formel IV in Abschn. 16) durch vollständige Analyse, seinen Schmelzpunkt $\left(118-119^{\circ}\right)$ and die Schmelzpunkte seines Benzaldehyd- und seines Salicylaldehydderivats (139 bzw. 142\%) identifiziert. Seine verdünnte salzsaure Lösung wird durch einen Tropfen Natriumnitritlösung ${ }^{9}$ ) anfangs intensiv kirschrot, dann orangerot, schließlich goldgelb und bleibt hierbei völlig klar. Verdünnte Eisenchloridlösang erregt in der salz-

1) Diese Annalen 287, 178 (1895). - Zur Straktur $\nabla g 1$. Abschnitt 8.der vorliegendeu Abhandlung.

) Diese Annalen 25j, 166 (1889).

s) Vgl. dazu diese Annalen 287, 180 (1895). 
sauren Lösung eine blanviolette, allmählich in Fuchsinrot übergehende Färbung, die durch Zusatz von konz. Salzsäure in Gelb umschlägt. Fine ätherische Lösung - mit Bleisuperoxyd geschüttelt, dann filtriert - hinterläßt beim Verdunsten einen schmutzigroten Rückstand, der sich in Eisessig grünstichig-blauviolett löst. Kocht man das Amin mit Kaliumdichromat nnd Schwefelsänre, so entwickelt sich starker Chinongeruch.

\section{Umlagerung des $3^{\prime}, 4$-Dimethyl-4'-acetoxy- hydrazobenzols.}

20) Von dem im vorhergehenden Kapitel behandelten Falle unterscheidet sich das jetzt zur Besprechung gelangende Beispiel nur dadurch, daß der umzulagernde Hydrazokörper in dem Benzolkern, welcher die Acetoxylgruppe trägt, orthoständig zu dieser noch ein Methyl enthält. Die Untersuchung, welche in der Dissertation des Herrn J. Pelzer ${ }^{1}$ ) ausführlicher mitgeteilt ist auf diese sei zur Ergänzung der Einzelheiten, auch bezüglich der analytischen Belege verwiesen - zeigte, daß durch diesen Unterschied der Verlauf der Reaktion qualitativ nicht verändert wird. Quantitativ erschien die o-Semidinbildung ein wenig begünstigt.

Es entstand also unter Verseifung der Acetoxylgruppe ein 0 -Semidin, für welches nach seiner Bildung aus dem Hydrazokörper der Formel I (s. u.) die drei Formeln II, III und IV in Betracht gezogen werden

I

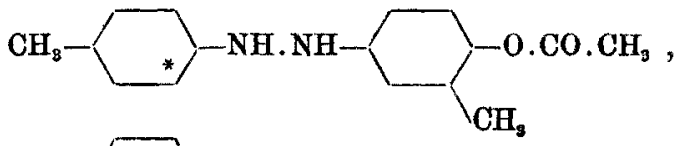

II

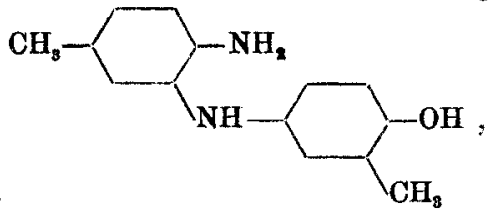

1) „I. Über Semidinumlagerung von acetylierten Paraoxyazoverbindungen. - II. Kryoskopische Untersuchungen über substituierte Sänreanilide" (Heidelberg 1897), S. 8-22. 
III

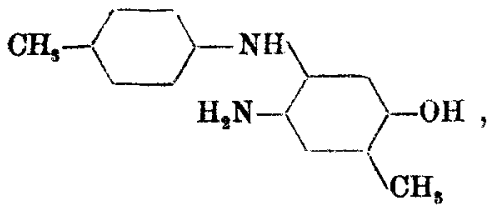

IV

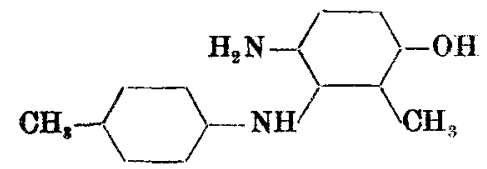

könnten. Von ihnen ist IV wegen der Nachbarstellung von 4 Substituenten in einem Benzolkern sehr unwahrscheinlich. Aus demselben Grunde wurde für das aus p-Toluolhydrazo-o-kresetol - dem der Formel I analogen Äthyläther $V$ - hervorgehende $o$-Semidin die Formel V] geschlossen ${ }^{1}$ ), welche den Äthyläther ron III darstellt.
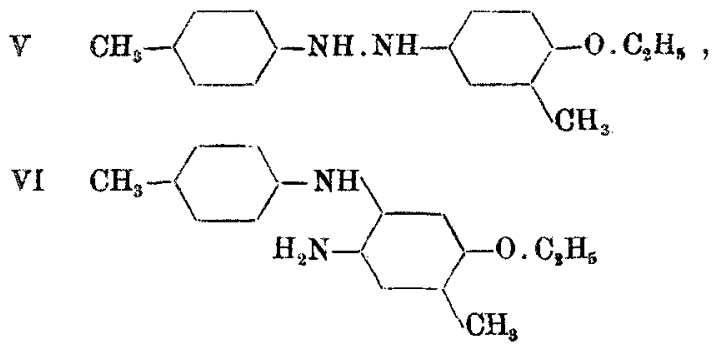

Wenn man diese Art der Schlußfolgerung zuläßt, mäßte man erwarten, daß - sofern bei der o-Semidinbildung der Hydrazokörper I ein Wasserstoffatom aus dem mit Acetoxyl und Methyl zugleich beladenen Benzolkern austreten läbt - das entstehende o-Semidin die Struktur III besitzt und durch Äthylieren in das aus $\mathrm{V}$ sich bildende $o$-Semidin VI überführbar ist. Der Versuch, der aus praktischen Gründen nicht am Semidin selbst, sondern an seinem Methenylderivat ausgeführt wurde (vgl. Abschn. 23 und 24), zeigte aber, daB die Äthylierung zu einem anderen $\ddot{A}$ thyläther führt. Hierdurch wird bestätigt, daß - wie nach der Untersuchung des niedrigeren Homologen (Abschn. 16) zu erwarten war - auch hier der Hydrazokörper

) Diese Anualen 887, 203 (1895). 
(I, s. o.) dasjenige Wasserstoffatom, das für die o-Semidinbildung aus einem Benzolkern zum Stickstoff der Hydrazogruppe wandern maB, aus dem acetoxylfreien Kern hergibt (also aus der in Formel I mit * bezeichneten Stelle), und daB dem o-Semidin die Formel II des $3^{\prime}, 5$ Dimethyl-4'-oxy-2-amino-diphenylamins zukommt.

Das durch vollständige Abstoßung des Acetoxyls zustande kommende $p$-Semidin kann seiner Bildung znfolge nur die Formel VII:

VII.

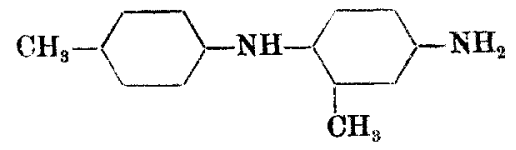

des 2,4'-Dimethyl-4-amino-diphenylamins besitzen.

21) Als Ausgangsmaterial für die Versuche diente auch hier nicht der Hydrazokörper (s. Formel $I$ in Abschn. 20), sondern der entsprechende Azokörper, das 3', 4-Dimethyl-4'-acetoxy-azobenzol $\mathrm{C}_{16} \mathrm{H}_{16} \mathrm{O}_{2} \mathrm{~N}_{2}=\mathrm{CH}_{8}$. $\mathrm{C}_{6} \mathrm{H}_{4} \cdot \mathrm{N}_{2} \cdot \mathrm{C}_{6} \mathrm{H}_{3}\left(\mathrm{CH}_{3}\right) \cdot 0 \cdot \mathrm{CO} \cdot \mathrm{CH}_{3}$. Es warde aus $20 \mathrm{~g}$ $p$-Toluolazo-o-kresol ${ }^{\mathrm{l}}$ ) durch 2-3 stündiges Kochen mit $10 \mathrm{~g}$ entwässertem Natriumacetat und $35 \mathrm{~g}$ Essigsäureanhydrid gewonnen, krystallisiert aus Alkohol in dicken Blättchen, ans Ligroin in warzenförmigen Aggregaten von feinen Nädelchen, schmilzt bei $65-66^{\circ}$ and löst sich leicht in absolutem Alkohol and $\ddot{A}$ ther, schwerer in Ligroin und Benzol.

22) Zur Vmlagerung wurden je $10 \mathrm{~g}$ dieses fein gepulverten und sorgfältig getrockneten Stoffs in je $60 \mathrm{ccm}$ Zinnchlorürlösung (aus $100 \mathrm{ccm} 38$ prozentiger Salzsäure und $40 \mathrm{~g}$ Zinnchlorïr) nach und nach im Verlaufe einer Stunde unter fortwährendem energischen Schütteln eingetragen, wobei man Sorge trug, dab die Temperatur nicht über $35^{0}$ stieg. Nach etwa 20 stündigem Stehen ließ man - unbekümmert um etwaige Ausscheidung von Zinndoppelsalzen - unter fortwährendem Um-

1) Nölting u. Werner, Ber. d. d. chem. Ges. 29, 3261 (1890). 
rühren and sorgfältiger Eiskühlung allmählich $23,1 \mathrm{ccm}$ Natronlauge vom spez. Gew. 1,36 hinzufließen. Man lieb nun die noch saure Lösung einige Zeit stehen und dekantierte schließlich die klar gewordene Flüssigkeit, welche die Spaltungsprodukte und wenig $p$-Semidin enthält, von einem harzigen Zinndoppelsalz.

Das ausgeschiedene Zinndoppelsalz wurde in etwa $35 \mathrm{ccm}$ heißen Wassers gelöst. Beim Frkalten krystallisiert das salzsaure Salz des $p$-Semidins zinnfrei in glänzenden Blättchen aus; durch vorsichtigen Zusat\% yon Wasser kann man noch einen weiteren (geringeren) Anschuß dieser Krystalle gewinnen. Die von dem salzsauren $p$-Semidin filtrierte Lösung lieferte, nachdem sie in üblicher Weise durch Schwefelwasserstoff entzinnt war, durch Zusatz eines geringen Überschusses von möglichst konzentrierter Natriumsulfitlösung das freie o-Semidin. Ks scheidet sich zunächst milchig ab, wird aber nach längerem Stehen oder sofort bei kräftigem Umschütteln in Form einer harzigen Masse erhalten, die als zähe klebrige Paste ans der gekühlten Flüssigkeit mit einem Spatel entfernt werden kann.

Der Spaltungsbetrag wurde durch Wägung des mit Wasserdampf übergetriebenen $p$-Tolnidins (als Hydrochlorid) ermittelt, das $p$-Semidin als Hydrochlorid, das o-Semidin im Zustand jener Paste gewogen. Es ergab sich, dab

waren.

etwa 40 Proz. des Azokörpers zu o-Semidin umgelagert,

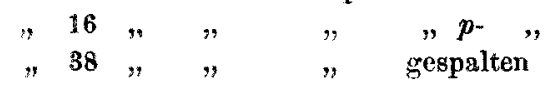

23) Das o-Semidin selbst - 3',5-Dimethyl-4'-oxy2-amino-diphenylamin ( $\mathrm{g} g \mathrm{l}$. Abschn. 20) - in analysenfähiger Form zu erhalten, gelang nicht; auch bei den sehr leicht Jöslichen Salzen mit Salzsäure und Schwefelsäure wurde kein besserers Resultat erzielt. Seine Natur als hydroxylhaltiges o-Semidin gab sich aber darin zu erkennen, dab es leicht löslich in verdünnten 
Alkalien ist nnd daraus durch Kohlendioxyd wieder ausgefällt wird, und daß seine angesäuerte Lösung mit Natriumnitrit sich zuerst dunkelviolett färbt und dann sofort sich trübt.

Analysiert (in bezug anf $\mathrm{C}, \mathrm{H}$ and $\mathrm{N}$ ) wurde es in Form seines Methenylderivats - 1 -[m-Methyl-p-oxyphenyl]-6-methyl-benzimidazol

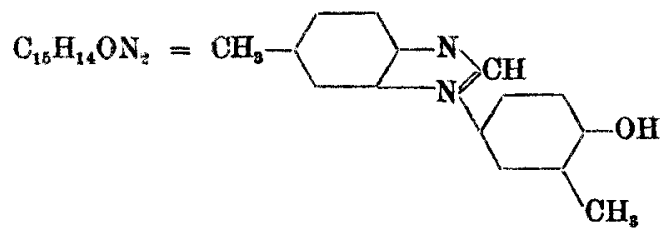

-, das aus der rohen Paste (s. Abschn. 22) durch sechsstündiges Kochen mit wasserfreier Ameisensüure hergestellt wurde. Man setzte zu der rotbrann gefärbten Lösung viel Wasser and etwas Salzsäure hinzu, wobei eine Trübung entstand und nach kräftigem Schütteln Abscheidung von Verunreinigungen in harziger Form erzielt wurde. Die hiervon filtrierte klare Lösung wurde fraktioniert mit Sodalösung gefällt; die erste Fällang ist noch unrein, während nachher eine leicht krystallinisch werdende Fraktion gewonnen wird. Das Methenylderivat krystallisiert ans heißem Alkohol bei vorsichtigem Znsatz von Wasser in glänzenden Blättchen, schmilyt bei $196-197^{\circ}$ und löst sich leicht in Äther. In verdünnten Alkalien erweicht es zuerst and geht dann farblos in Lösung; durch Kohlendioxyd wird es daraus wieder gefüllt. Aus seiner Lösung in verdünnter Salzsäure wird durch weiteren Zusatz von Salzsänre das Hydrochlorid in weißen Blättchen ausgeschieden. Das Nitrat ist in Wasser sehr schwer joslich.

Die Äthylierung dieses Methenylderivats geht beim Kochen in alkoholischer Lõsung mit Natriumäthylat und Äthyljodid leicht von statten. Das freie 1-[m-Methylp-äthoxyphenyl-6-methyl-benzimidazol 


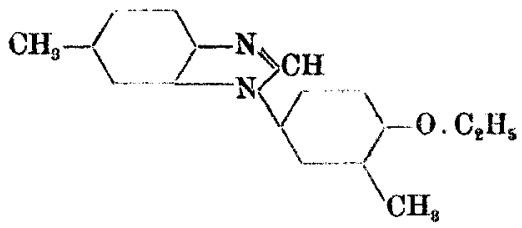

konnte trotz vieler Versuche nicht zum Krystallisieren gebracht werden. Sehr schön krystallisierte aber ans heiBem Wasser in feinen, wohlausgebildeten, rhombisch zugeschärften, langen Nadeln das Hydrochlorid, für welches die Analysen ( $\mathrm{N}$ und $\mathrm{Cl}$ ) die Formel $\mathrm{C}_{17} \mathrm{H}_{18} \mathrm{ON}_{\mathrm{g}}$ $+\mathrm{HCl}$ bestätigten. Auch das in heibem Alkohol schwer lösliche Pikrat wurde krystallisiert - in flachen Prismen vom Schmelzp. 186-187 - erhalten, seine Zusammersetzung $\mathrm{C}_{17} \mathrm{H}_{48} \mathrm{ON}_{2}+\mathrm{C}_{6} \mathrm{H}_{3} \mathrm{O}_{7} \mathrm{~N}_{3}$ durch Stickstoffbestimmung kontrolliert.

24) Aus den im Abschn. 20 dargelegten Gründen wurde zum Vergleich das aus $p$-Tolnolhydrazo-o-kresetol hervorgehende o-Semidin - 4,4'-Dimethyl-5-äthoxy-?amino-diphenylamin, Formel VI (Abschn. 20) --, das schon früher beschrieben worden ist ${ }^{1}$ ), von nenem hergestellt.

Hierbei wurde für das an der Luft leicht veründerliche Arnias ein höherer Schmelzpunkt $-89-90^{\circ}$ - beobachtet als früher $\left(76^{\circ}{ }^{\circ}\right.$ Daher wurde die Zusammensetzung $\mathrm{C}_{10} \mathrm{H}_{20} \mathrm{ON}_{2}$ nochmals durch Stickstoff bestimmung kontrolliert. Zudem wurden für sein Schwefelkohlenstoffderivat und die ihm zugehörige Stilbazoniumbase die früheren Angaben genau bestätigt gefunden.

Aus diesem Semidin warde nun durch Kochen mit Ameisensäure sein Methenylderivat - 5-Methyl-1[p-tolyl]-6-äthoxy-benzimidazol

$$
\mathrm{C}_{17} \mathrm{H}_{18} \mathrm{ON}_{2}=\stackrel{\mathrm{CH}_{8} \cdot \mathrm{C}_{6} \mathrm{H}_{4}-\mathrm{HC}}{-0 . \mathrm{C}_{8} \mathrm{H}_{5}}
$$

- bereitet. Im Gegensatz zu dem krystallisationsträgen Isomeren, das am SchlnB des Abschn. 23 beschriebea ist, krystallisierte es außerordentlich leicht aus ver-

7) Diese Annalen 287, 201-203 (1895). 
dünntem Alkohol in feinen Nadeln, die sich zu strahligen Aggregaten anordnen; es schmilzt bei $102,5^{\circ}$. Sein Hydrochlorid ist in Salzsäure schwer löslich, sein Nitrat schon in Wasser schwer löslich. Sein Pikrat krystallisiert in Nadeln und schmilzt bei $228^{\circ}$, also etwa $40^{\circ}$ höher als das Pikrat jener äthylierten Methenylverbindung, zu deren Vergleich die Versuche unternommen wurden.

Die Verschiedenheit der beiden äthoxylhaltigen Methenylverbindungen erhellt daraus deutlich. Zudem sei noch hervorgehoben, dab jene krystallisationsträge harzige Methenylverbindung, welche das Pikrat vom Schmelzp. 186-187 ${ }^{\circ}$ liefert, tagelang mit Kryställchen der bei $102,5^{\circ}$ schmelzenden, eben beschriebenen Methenylverbindung in Berührung gelassen wurde und auch hierbei keine Neigang zur Krystallisation zeigte.

25) Das $p$-Semidin, das bei der in Abschn. 22 geschilderten Aufarbeitung als wohl krystallisiertes, in Wasser schwer lösliches Hydrochlorid erhalten wurde, krystallisiert auch in freiem Zustand - durch Natriumsulfit aus der Lösung des Hydrochlorids in viel Wasser abgeschieden - leicht. Die vollständige Analyse $(\mathrm{C}, \mathrm{H}, \mathrm{N})$ fïhrte zur sauerstofffreien Formel $\mathrm{C}_{14} \mathrm{H}_{16} \mathrm{~N}_{2}$ des 2,4'-Dimethyl-4-amino-diphenylamins ( $\mathrm{s}$. Formel VII in $\mathrm{Ab}$ schnitt 20). Aus Ligroin wird es in feinen glänzenden Nadeln rom Schmelzp. $78,5^{\circ}$ erhalten; es ist - außer in den üblichen organischen Lösungsmitteln - auch in heißem Wasser löslich und mit Wasserdämpfen etwas flüchtig. Seine verdünnte salzsaure Lösung gibt mit einem Tropfen Eisenchlorid eine violettrote Färbung, die auf Zusatz von konz. Salzsäure erst nach längérem Stehen verschwindet. Natriumnitrit läbt in der verdünnten salzsauren Lösung eine tief karminrote Färbung entstehen, die langsam verblaßt und schließlich durch grünliches Orange in lichtes Hellgelb übergeht. Wie hierdurch die $p$-Semidin-Natur angezeigt wird, so auch durch das Verhalten des freien Amins beim Schütteln mit 
Bleisuperoxyd in ätherischer Lösung; die Lösung färbt sich tief gelb und hinterläbt beim Verdunsten einen roten Rückstand, dessen tief blauviolette Fisessiglösung durch Zinkstaub entfärbt wird. Die schwefelsanre Lösung des Amins; mit Kaliumdichromat gekocht, zeigt dentlich den stechenden Chinongerach.

Endlich wurde noch das Salicylaldehydderivat $\mathrm{C}_{21} \mathrm{H}_{20} \mathrm{ON}_{2}$ $=\mathrm{CH}_{3} \cdot \mathrm{C}_{6} \mathrm{H}_{4} \cdot \mathrm{NH} \cdot \mathrm{C}_{6} \mathrm{H}_{3}\left(\mathrm{CH}_{3}\right) \cdot \mathrm{N}: \mathrm{CH}_{2} \mathrm{C}_{6} \mathrm{H}_{4} \cdot \mathrm{OH}$ dargestellt und in seiner Zusammensetzung durch Stickstoffbestimmung bestätigt. Es krystallisiert aus Alkohol in Nadeln, schmilzt bei $116,5^{\circ}$ und wird durch Kochen mit verdünnter Schwefelsänre wieder gespalten.

\section{Umlagerung des 4-Brom-4'-acetoxy-hydrazobenzols.}

26) Auch dieses Beispiel läßt die Leichtigkeit hervortreten, mit der bei der Hydrazonmlagerung die paraständige Acetoxylgruppe vollständig abgestoben wird. Denn als Umlagerungsprodukt wurdè ein $p$-Semidin erhalten, für das nach seiner Zusammensetzung and Entstehung nar die Formel:

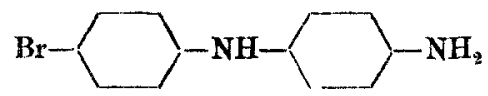

des 4'-Brom-4-amino-diphenylamins in Betracht gezogen werden kann. Freilich bildet es sich nur in geringer Menge (isoliert wurden etwa 5 Proz.); denn trotz vorsichtiger Reduktion wurden mindestens etwa 70 Proz. des 4-Brom-4'-acetoxy-azobenzols, das als Ausgangsmaterial diente, gespalten.

Daneben warden Anzeichen für die Bildung eines o-Semidins beobachtet.

Die Versuche sind ebenso, wie diejenigen des vorigen Kapitels, von Herrn J. Pelzer ausgeführt und in seiner Dissertation ${ }^{1}$ ) eingehender beschrieben.

1) Vgl. die in FuBnote 1, S. 177 zitierte Dissertation, S. 3-8. 
27) Die Umlagerung wurde - unter Anwendung von 4.Brom-4'-acetoxy-azobenzol ${ }^{1}$ ) - in derselben Weise vorgenommen, wie dies in Abschn. 22 für $3^{\prime}, 4$-Dimethyl4'-acetoxy-azobenzol angegeben ist. Der Azokörper löst sich dabei nicht völlig auf, sondern es schied sich beim kintragen jeder Portion sofort ein grauer krystallinischer Niederschlag ab, der sich beim Stehen über Nacht noch vermehrte. Er besteht zum größten T'eil aus dem Zinndoppelsalz des durch Spaltung gebildeten $p$-Bromanilins, enthält aber als Beimengung geringe Mengen eines o-Semidins; denn aus der nach dem Entzinnen daraus mit Natriumsulfit ausgefällten Aminfraktion konnte durch Kochen mit Benzil and einigen Tropfen Salzsäure in alkoholischer Lösung nnd übliche Aufarbeitung ${ }^{2}$ ) ein Präparat rom allgemeinen Verhalten der Stilbazoniumbasen erhalten werden.

Die von diesem ersten Zinndoppelsalz-Anschub befreite Mutterlauge warde mit zwei Drittel ihres Volums Wasser versetzt, wodurch Abscheidung eines zweiten Zinndoppelsalz-Anschusses in bedeutender Menge erzielt wnrde. Man löste es in wenig heißem Wasser, versetzte die Lösung mit Natronlauge bis zur Auflösung der Zinnhydroxyde und schüttelte dann mehrfach mit Äther aus. Der Äther hinterläßt nach dem Abdestillieren das $p$-Semidin, das durch Krystallisation aus Ligroin gereinigt wird. Die Ausbente an $p$-Semidin betrug indessen kanm 5 Proz. des angewendeten Azokörpers.

28) Das $p$-Semidin-4'-Brom-4-amino-diphenylamin - krystallisiert ans Ligroin in farblosen derben Nadeln, schmilzt bei $93,5^{\circ}$ and färbt sich bei längerem Liegen an der Luft bräunlich. Sein Hydrochlorid ist sehr. schwer löslich in Wasser, ebenfalls sein Sulfat.

1) Vgl. Hewitt, Moore, Pitt, Ber. d. d. chem. Ges. 31, 2116 (1898).

2) Vgl. diege Annalen 287, 134-135 (1895). 
$0,1714 \mathrm{~g}$ gaben 17,15 eem Stickgas bei 26 u. $750 \mathrm{~mm}$ Druck. $0,0859 \mathrm{~g} \quad$ " $0,0610 \mathrm{AgBr}$.

$\begin{array}{lcc} & \text { Ber. für } \mathrm{C}_{12} \mathrm{H}_{11} \mathrm{~N}_{2} \mathrm{Br} & \text { Gef. } \\ \mathrm{N} & 10,67 & 10,96 \\ \mathrm{Br} & 30,38 & 30,21\end{array}$

Als $p$-Semidin erwies es sich durch die folgenden Reaktionen:

Die verdünnte salzsaure Lösung gibt mit eincta 'Tropfen Nitritlösung eine dunkelrote Färbung, die durch Orange in Hellgelb übergeht, während die Flüssigkeit klar bleibt. Mit Eisenchloria gibt sie zuerst eine blanviolette Färbung, die in Kirschrot umschlägt; durch Zusatz von konz. Salzsäure tritt dann Entfärbung ein. Die schwefelsaure Lösung entwickelt beim Kochen mit Kaliumdichromat starken Chinongeruch. Die ätherische Lösung färbt sich auf Zusatz von Bleisuperoxyd hellgelb and hinterläßt dann einen Rückstand, dessen Fisessiglösung rotviolett ist und durch Zinkstaub entfärbt wird.

Sodann warde noch das Salicylaldehydderivat $\mathrm{Br}, \mathrm{C}_{6} \mathrm{H}_{4}$. NH. $\mathrm{C}_{6} \mathrm{H}_{4} \cdot \mathrm{N}: \mathrm{CH} \cdot \mathrm{C}_{6} \mathrm{H}_{4} \cdot \mathrm{OH}$ hergestellt, das aus Alkohol in gelben Blättern anschiebt und bei $172^{\circ}$ schmilzt.

$0,1758 \mathrm{~g}$ gaben $11,9 \mathrm{ccm}$ Stickgas bei $19^{\circ}$ und $760 \mathrm{~mm}$ Drusk.

$$
\begin{aligned}
& \text { Ber. für } \mathrm{C}_{89} \mathrm{H}_{18} \mathrm{ON}_{2} \mathrm{Br} \quad \text { Gef. } \\
& \mathrm{N} \quad \mathbf{7 , 6 5} \quad \mathbf{7 , 7 5}
\end{aligned}
$$

Über 4'-Brom-4-amino-diphenylamin liegen schon Angaben ${ }^{1}$ ) vor, nach denen es bei $79^{\circ}$ bzw. $75,5-76^{\circ}$ schmelzen soll; es war aber nur als Nebenprodukt in änBerst geringen Mengen erhalten worden, die genügende Reinigung wohl nicht zuließen. Abgesehen ron dem höheren Schmelzpunkt $\left(93^{\circ}\right)$, der sich daraus erklärt, dab das an der Luft veränderliche Amin, da es uns in etwas gröberer Menge zur Verfügung stand, besser gereinigt werden konnte, stimmen die obigen Beobachtungen mit den früheren Befunden überein.

1) Jacobson u. Grosse, diese Annalen 303, 329-330 (1898).

Bamberger, Ham, diese Annalen 389, 112 (1911). 


\section{Umlagerung des 4-Methyl-4'-dimethylamino- hydrazobenzols.}

29) Die Umlagerung des in der Überschrift genannten Hydrazokörpers wurde durch direkte Reduktion des entsprechenden Azokörpers ( $p$-Toluolazodimethylanilin) mit Zinnchlorür und Salzsäure ausgeführt and ergab in reichlicher Menge (neben Spaltungsprodukten) ein isomeres Amin, das sich darch seine Reaktionen als o-Semidin erwies. Unter den beiden hiernach möglichen Formeln:

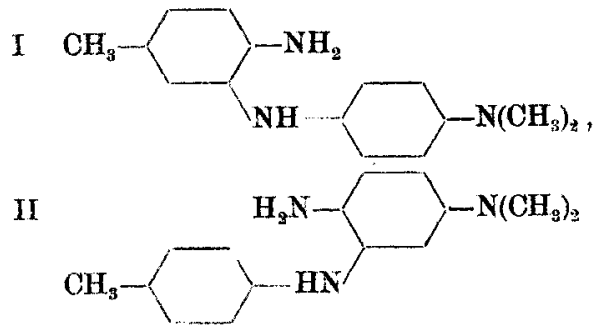

wurde die erste als zutreffend erkannt; denn das erhaltene o-Semidin konnte durch Erhitzen mit Salzsäure im Einschlubrohr (unter Abspaltung des Dimethylaminrestes) in 3,4-Diamino-toluol und Hydrochinon zerlegt werden. Es wurden keine Anzeichen beobachtet, dab sich daneben das o-Semidin der Formel II bildet.

Die Versuche sind von meinem Schüler Herrn D. R. Boyd ausgeführt and von ihm bereits mit meinem Finverständnis ausführlich in der Zeitschriftenliteratur beschrieben. Auf diese Veröffentlichung ${ }^{1}$ ) sei daher bezüglich des Ganges der Untersuchung und der Figenschaften des Semidins und seiner Derivate verwiesen.

\section{Umlagerung des 4-Äthoxy-4'-dimethylamino- hydrazobenzols.}

30) Die Untersuchung führte in diesem Fall zu eunem völlig analogen Frgebnis, wie in dem Beispiel des vorangehenden Kapitels. Fs entstand neben Spaltungs-

1) Journ, chem. Soc. 65, 879 (1894). 
188 Jacobson, Weitere Experimentalbeiträge zur Kenntnis produkten reichlich ein o-Semidin, für das sich die Formel I (s. u.) als zutreffend erwies. Auch hier batte

I

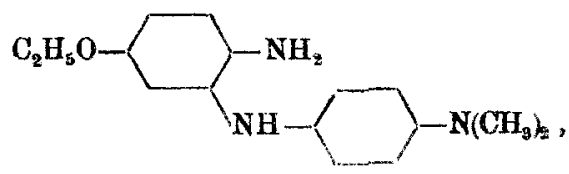

II

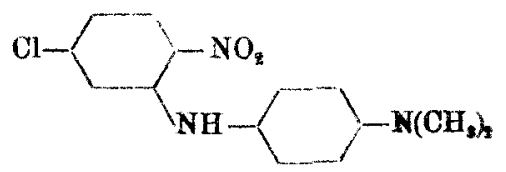

also nicht derjenige Benzolkern, welcher die basische Dimethylaminogruppe als Parasubstituenten enthält, das für die Sprengung der Hydrazograppe nötige Wasserstoffatom hergegeben, sondern der andere Benzolkeru, dessen Parasubstituent indifferenten Charakter ${\left(\mathrm{CH}_{3}\right.}$ in Kap. 7, $\mathrm{C}_{2} \mathrm{H}_{5} \mathrm{O}$ hier) besitzt.

Diese Struktur des o-Semidins warde anf synthetischem Wege bewiesen. Dnrch Einwirkung von $p-A$ minodimethylanilin auf 1-Chlor-3,4-dinitro-benzol stellte man den Nitrokörper der Formel II (s. o.) dar; als man dann in II das Chlor durch Äthoxyl ersetzte und darauf die Nitrograppe reduzierte, gelangte man zu einem Amin, das sich identisch erwies mit dem durch die Hydrazo-Umlagerung gebildeten o-Semidin.

Herr W1. Sachs hat die Versuche ausgeführt. nnd in seiner Dissertation ${ }^{1}$, , welche die ausführliche $\mathrm{Be}$ schreibung und die analytischen Belege enthält, mitgeteilt.

31) Das als Ausgangsmaterial dienende 4 - Athoxy- 4 dimethylamino-azobenzol $\mathrm{C}_{16} \mathrm{H}_{19} \mathrm{ON}_{3}=\mathrm{C}_{2} \mathrm{H}_{5} \cdot 0 \cdot \mathrm{C}_{6} \mathrm{H}_{4} \cdot \mathrm{N}_{2} \cdot \mathrm{C}_{6} \mathrm{H}_{4}$. $\mathrm{N}\left(\mathrm{CH}_{3}\right)_{2}$ wurde in guter Ausbeute ans diazotiertem salzsauren $p$-Phenetidin und salzsaurem Dimethylanilin gewonnen, indem man die miteinander vereinigten Lösungen mit Natriumacetat versetzte. Es krystallisiert aus Benzol

1) „Über die Reduktion des Phenetolazodimethylaniling und des $m$-Xylolazodimethylaniling" (Bern 1895), S. 13-34. 
in vierseitigen schiefwinkligen Täfelchen von glänzend brauner Farbe, schmilzt bei $149-150^{\circ}$ and löst sich leicht in heißem Alkohol; von Eisessig wird es mit rotvioletter, ron Salzsäure mit tiefvioletter Farbe aufgenommen. Das salzsaure Salz bildet nach dem Trocknen eine filzartige, aus mikroskopischen Härchen bestehende, intensiv metallglänzende, blaue Masse.

32) Zur Umlagerung wurden $5 \mathrm{~g}$ dieses Azokörpers (fein zerrieben) in $35 \mathrm{~g}$ schwach erwärmte salzsaure Zinnchlorürlösung (aus $40 \mathrm{~g}$ Zinnchlorür und $100 \mathrm{ccm}$ Salzsäure von 38 Proz.), allmählich eingetragen. Die durch ausgeschiedenes Zinndoppelsalz getrübte Reaktionsmischung wurde dann in Wasser gelöst und mit einem Überschuß von Natronlange versetzt. Hierauf schüttelte man mit $\ddot{A}$ ther aus und destillierte den Rückstand der ätherischen Lösung, der in seinem Gewicht dem angewendeten Azokörper gleichkam, unter $32 \mathrm{~mm}$ Druck; zwischen $190^{\circ}$ und $210^{\circ}$ (Badetemperatur) destillierten die Spaltungsprodukte $a b$, während nun das Umlagerungsprodukt in öliger Form zurückblieb.

Unter diesen Bedingungen wurden annähernd 50 Proz. rohes Umlagerungsprodukt neben 50 Proz. Spaltungsprodukten erhalten. Führte man aber die Reduktion des Azokörpers in Gegenwart von Alkohol ans, so war die Spaltung viel bedeutender (gegen 70 Proz.).

33) Jenes ölige Umlagerungsprodukt enthält ein Amin - nach Formel I (Abschn. 30) als 5-Äthoxy - 4'dimethylamino-2-amino-diphenylamin anfzufassen --, dessen Natur als o-Semidin durch die unten aufgeführten, aus dem Rohprodukt direkt gewonnenen, gut krystallisierbaren Derivate außer Zweifel gestellt wird. Aber es war selbst nicht zum Krystallisieren za bringen. Diese Abneigung gegen die Krystallisation ist nicht allein auf Beimengungen zurückzuführen, die etwa anßer ihm bei der Umlagerung entstehen (vgl. den letzten Absatz von Abschn. 34). Denn auch als es aus dem prächtig krystallisierten Salicylaldehydderivat (s. a.) durch Säure- 
spaltung regeneriert wurde, kam es aus Ligroin der Hauptmenge nach harzig heraus; nur wenige Kryställchen schieden sich daneben ab, die zur Feststellung der Figenschaften nicht genūgten.

Das Methenylderivat - 1-[p-Dimethylaminophenyl] 6. äthoxy-benzimidazol

$$
\mathrm{C}_{17} \mathrm{H}_{19} \mathrm{ON}_{3}=\mathrm{C}_{2} \mathrm{H}_{5} . \mathrm{O} \longrightarrow \mathrm{N}_{\mathrm{C}_{6} \mathrm{H}_{4} \cdot \mathrm{N}_{\left(\mathrm{CH}_{3}\right)_{2}}}^{\mathrm{N}}
$$

- wurde durch 4 stündiges Kochen jenes Rohproduktes mit 10 TIn. Ameisensänre bereitet. Nach dem Verdünnen mit Wasser, Alkalisieren mit Soda und Ausäthern kam es ölig aus seiner ätherischen Lösung heraus. Durch fraktionierte Fällung der alkoholischen Lösung mit Pikrinsäure schaffte man zunächst Verunreinigungen fort und erhielt dann das Pikrat in schönen grüngelben Nadeln. Als dieses Pikrat nun mit Ammoniak zersetzt wurde, krystallisierte die Methenylverbindung sofort aus Ligroin in Nädelchen. Sie schmilzt bei $141-143^{\circ}$ und löst sich sehr leicht in verdünnter Salzsäure. In der salzsauren Lösung erzeugt Quecksilberchlorid zunächst eine Trübung dann scheiden sich farblose Stäbchen eines Doppelsalzes $\mathrm{ab}$, die sich zu baumartigen Gebilden vereinigen.

Die Stilbazoniumbase - 2,3-Diphenyl-1-[p-dimethylaminophenyl]-2-oxy-7-äthoxychinoxalindihydrid- $(1,2)$

$$
\mathrm{C}_{30} \mathrm{H}_{29} \mathrm{O}_{2} \mathrm{~N}_{3}=\mathrm{C}_{2} \mathrm{H}_{5} . \mathrm{O}-\underbrace{\mathrm{N}-\mathrm{C}(\mathrm{OH}) \cdot \mathrm{C}_{6} \mathrm{H}_{5}}_{\mathrm{C}_{6} \mathrm{H}_{4} \cdot \mathrm{N}\left(\mathrm{CH}_{3}\right)_{2}}
$$

- wurde in üblicher Weise ${ }^{1}$ ) durch Kondensation mit Benzil bereitet. Die aus der salzsauren Lösung durch Ammoniak ausgefällte Base wurde beim Auskochen mit Alkohol allmählich schwerer löslich. Sie krystallisiert aus Alkohol in feinen kanariengelben Nadeln, schmilat bei $187-190^{\circ}$ und löst sich schwer in Alkohol, Äther

1) Vgl, diese Annalen 287,134 (1895). 
and Ligroin, leicht dagegen in Chloroform. In konz. Schwefelsäure löst sie sich mit prächtig karminroter Farbe, die auf Wasserzusatz plötzlich in Gelb umschlägt.

Als man das rohe Umlagerungsprodukt (1 Tl.) mit 10 Tln. Alkohol und 0,5 Tln. Salicylaldehyd 4 Stunden unter Durchleiten von Kohlendioxyd auf dem Wasserbade erhitzt hatte, schied sich beim Abkühlen eine krystallinische Kruste ab, die teils aus goldgelben Blättchen, teils aus schmutzigweißen Krystallwarzen bestand. Der gelbe Stoff ließ sich vermöge seiner erheblich größeren Löslichkeit in warmem Alkohol leicht von dem weißen trennen. Lr erwies sich als ein Salicyl aldehydderivat, während der weiße Stoff das daza gehörige Salicylsäurederivat ist. Dieses gegenseitige Verhältnis wird dadurch bewiesen, daß der gelbe Stoff beim Kochen in Alkohol mit frisch gefälltem Quecksilberoxyd unter Schwärzung des Quecksilberoxyds und Entfärbung seiner gelben Lösung in den weißen Stoff übergeführt wird ${ }^{1}$ ).

Das Salicylaldehydderivat $\mathrm{C}_{23} \mathrm{H}_{25} \mathrm{O}_{2} \mathrm{~N}_{8}$ krystallisiert aus Alkohol in prachtvollen goldgelben Blättchen mit grünem metallischem Reflex, schmilzt bei $141,5-142,5^{\circ}$ und löst sich leicht in warmem Alkohol mit goldgelber Farbe, auch in Äther sehr leicht, schwerer in Ligroin. Erwärmt man seine gelbe Lösung in verdünnter Schwefelsäure, so wird sie farblos, indem der Geruch des Salicylaldehyds auftritt. Das nach dem Abtreiben des Aldehyds mit Wasserdampf durch Soda abgeschiedene o-Semidin war - wie sebon oben erwähnt ist - nicht zum Krystallisieren zu bringen; an der so erhaltenen Probe wurde indes noch das charakteristische Verhalten der salzsauren Lösung gegen Eisenchlorid beobachtet, das auch das eivfachste äthoxylhaltige $o$-Semidin auszeichnet ${ }^{2}$ ): zunächst intensive Rotfärbung, die nach Zusatz von konz. Salzsäure in Violett umschlägt.

Das Salieylsäurederivat - $1-[p$-Dimethylaminophenyl $]$ 2-[0-0xyphenyl $]$-6-äthoxy-benzimidazol

1) Vgl. dazu diese Annalen 303, 303-304 (1898).

2) Vgl. Ber. d. d. chem. Ges. 25, 996 (1892).

Annalen der Chemie 427. Band. 
Jacobson, Weitere Experimentalbeiträge zur Kenntnis

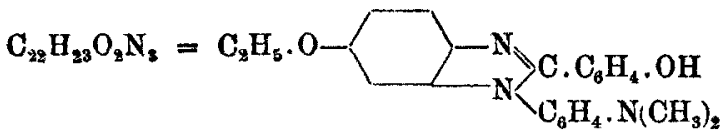

- krystallisiert aus Benzol in weiBen glänzenden Nadeln, schmilzt bei $182-183^{\circ}$ und ist in Alkohol und Äther schwer, in Benzol leicht löslich. Es löst sich in Mineralsäuren ohne Färbung; kocht man diese Lösung, so wird ein Geruch nicht wahrgenommen, und man erhält bei nachherigem Neutralisieren mit Soda dic Verbindung unverändert zurück. Sie ist also im Gegensatz zum Aldehydderivat durch Säuren nicht spaltbar.

34) Für den Strukturnachwers wurde, wie in Abschn. 30 angekündigt ist, zunächst das 5-Chlor-4'-dimethylamino-2nitro-dipherylamin $\mathrm{C}_{14} \mathrm{H}_{14} \mathrm{O}_{2} \mathrm{~N}_{3} \mathrm{Cl}$ (Formel II in Abschn. 30) dargestellt. Die Reaktion des 1-Chlor-3,4-dinitro-benzols (1 Molgew.) mit $p$-Aminodimethylanilin (3 Molgew.) verläuft viel heftiger, als die entsprechende Reaktion mit Monaminen ${ }^{1}$ ); sie muß sehr vorsichtig gehandhabt werden, wenn sie nicht gar zu stürmisch werden soll. Man erwärmte das Gemisch im lanwarmen Wasserbade, bis ein in das Gemisch eingesetztes Thermometer durch rasches Steigen den Beginn der Reaktion anzeigte; dann mäßigte man sie durch sofortiges Einstellen des Kolbens in Eiswasser. Nach kurzer Zeit war das Gemisch nun erstarrt. Durch verdünnte Essigsäure löste man darauf das unveränderte Aminodimethylanilin und dessen Diazoaminoderivat. Der in verdünnter Essigsäure nicht lösliche Rückstand ist das Chlornitroamin der Formel II; er wurde mit Alkohol ausgekocht und aus Benzol umkrystallisiert. Die Verbindung bildet prächtige rotbraune Nädelchen, schmilzt bei $181^{\circ}$ und löst sich leicht in Benzol; viel schwerer in Alkohol. Sie löst sich leicht in verdünnten Mineralsäuren, in verdünnter Essigsäure dagegen auch beim Erwärmen kaum.

Der Austausch des Chlors geht leicht and vollständig beim Kochen $\left(1 \frac{1}{2}-2\right.$ Stunden) mit Natriumäthylat in

1) Vgl. Laubenheimer, Ber. d. d. chem. Ges. 9, 771 (1876). 
absolutem Alkohol vor sich. Schon während des Siedens scheidet sich das 5-Äthoxy-4'-dimethylamino-2-nitro-dipherylamin

$$
\mathrm{C}_{10} \mathrm{H}_{19} \mathrm{O}_{8} \mathrm{~N}_{8}=\mathrm{C}_{2} \mathrm{H}_{8} \cdot 0-\mathrm{NO}_{\mathrm{NH} . \mathrm{C}_{6} \mathrm{H}_{4} \cdot \mathrm{N}_{\left(\mathrm{CH}_{3}\right)_{2}}}
$$

aus. Es krystallisiert aus Ligroin in dunkelbraunen scharfbegrenzten Kryställchen, schmilzt bei $122-123^{\circ}$ und löst sich in Benzol und Alkohol sehr leicht, in Ligroin schwer. Verdünnte Salzsäure löst mit goldgelber Farbe. In Natronlauge ist es unlöslich.

Dieser Nitrokörper wurde nun durch andauerndes Erhitzen mit salzsaurer Zinnchlorürlösung unter Zusatz von etwas Alkohol am Rückflußkühler zum 5-Äthoxy-4'-dimethylamino-2-amino-diphenylamin reduziert. Auch hier blieb dieses o-Semidin beim Abdestillieren seiner ätherischen Lösung in öliger Form zurück und konnte nicht in krystallinischer Form erhalten werden (vgl. den Anfang von Abschn. 33). Aber es konnte mit dem durch Umlagerung gebildeten o-Semidin durch Darstellung der Derivate einwandfrei identifiziert werden. Die Stilbazoniumbase wurde mit dem Schmelzp. 187-190 ${ }^{\circ}$, das Salicylaldehydderivat (auch durch Stickstoff bestimmung kontrolliert) mit dem Schmelzp. 141,5-142,5 ${ }^{\circ}$, das daraus durch Oxydation mittels Quecksilberoxyds bereitete Salicylsäurederivat mit dem Schmelzp. $182-183^{\circ}$ erhalten. Bemerkt za werden verdient, da $\beta$ bei der Kondensation mit Salicylaldehyd zunächst nur das Aldehydderivat, nicht daneben das Säurederivat beobachtet wurde (vgl. dagegen den drittletzten Absatz von Abschn. 33); man kann also daraus schließen, daß in dem rohen Umlagerungsprodukt (vgl. Abschn. 32) sich noch ein Stoff befindet, welcher die partielle Oxydation des Aldehydderivats zum Säurederivat bewirkt. 
194 Jacobson, Weitere Experimentalbeiträge zur Kenntnis

\section{Versuche zur Umlagerung von $\boldsymbol{N}$-Derivaten des 4,4'-Diamino-hydrazobenzols.}

35) In der Dissertation des Herrn H. L. Fulda ${ }^{1}$ ) sind Versuche beschrieben, bei denen die folgenden $\mathrm{Ab}-$ kömmlinge des zweifach parasubstituierten Azobenzols:

a) 4-Amino-4'-dimethylamino-azobenzol $\left.{ }^{2}\right) \mathrm{H}_{2} \mathrm{~N} \cdot \mathrm{C}_{6} \mathrm{H}_{4} \cdot \mathrm{N}_{2}$. $\mathrm{C}_{6} \mathrm{H}_{4} \cdot \mathrm{N}\left(\mathrm{CH}_{3}\right)_{2}$,

b) 4-Acetamino-4'-dimethylamino-azobenzol $\left.{ }^{3}\right) \mathrm{CH}_{3} . \mathrm{CO}$. NH. $\mathrm{C}_{6} \mathrm{H}_{4} \cdot \mathrm{N}_{2} \cdot \mathrm{C}_{6} \mathrm{H}_{4} \cdot \mathrm{N}\left(\mathrm{CH}_{3}\right)_{2}$,

c) $4,4^{\prime}-$ Bis-dimethylamino-azobenzol $\left.{ }^{4}\right)\left(\mathrm{CH}_{3}\right)_{2} \mathrm{~N} \cdot \mathrm{C}_{6} \mathrm{H}_{4} \cdot \mathrm{N}_{3}$. $\mathrm{C}_{6} \mathrm{H}_{4} \cdot \mathrm{N}\left(\mathrm{CH}_{3}\right)$

der vorsichtigen Reduktion mit salzsanrer Zinnchlorürlösung unter verschiedenen Bedingungen unterworfen worden sind. Es wurden aber stets nur Spaltungsprodukte ( $\mathrm{p}$-Phenylendiamin bzw. $p$-Aminoacetanilid und p-Aminodimethylanilin) isoliert, ohne da $B$ Anzeichen für die gleichzeitige Bildung von Umlagerungsprodakten beobachtet wurden.

Besonders stark ist die Spaltbarkeit bei der Verbindung c). Sie erleidet quantitative Spaltung bei der Reduktion mit Zinnchlorür und Salzsäure unter Bedingungen (allmähliches Eintragen bei etwa $60^{\circ}$ ), unter denen die weniger symmetrisch gebauten, gleichfalls den Dimethylaminrest tragenden Azokörper:

$\mathrm{C}_{6} \mathrm{H}_{5} \cdot \mathrm{N}_{2} \cdot \mathrm{C}_{6} \mathrm{H}_{4} \cdot \mathrm{N}\left(\mathrm{CH}_{3}\right)_{2}, \mathrm{CH}_{3} \cdot \mathrm{C}_{6} \mathrm{H}_{4} \cdot \mathrm{N}_{2} \cdot \mathrm{C}_{6} \mathrm{H}_{4} \cdot \mathrm{N}\left(\mathrm{CH}_{3}\right)_{2}$ (vgl. Abschn. 29), $\mathrm{C}_{2} \mathrm{H}_{5} \cdot \mathrm{O} \cdot \mathrm{C}_{6} \mathrm{H}_{4} \cdot \mathrm{N}_{2} \cdot \mathrm{C}_{6} \mathrm{H}_{4} \cdot \mathrm{N}\left(\mathrm{CH}_{3}\right)_{2}$ (vgl. Abschn. 30 ff.)

”) „1. Über einige zweifach parasubstituierte Derivate des Azobenzols. II. Über para-Toluolazometaxylenol" (Heidelberg 1896), S. $13-22$.

9) Wir stellten diese Verbindung dureh Verseifen ihres Acetylderivates $b$ mit alkoholischer Kalilauge dar und fanden den Schmelzpunkt $186-187^{\circ}$ in Übereinstimmung mit Nölting, Ber. d. d. chem. Ges. 20, 2994 (1887).

7) Gewonnen aus diazotiertem p-Aminoacetanilid und Dimethylanilin. Schmelzp. 223-224 ${ }^{\circ}$. Meldola, der es auf anderem Wege erhielt (Journ. chem. soc. 45, 108 [1884]) gibt $217^{\circ}$ an.

4) Dargestellt nach Lippmann u. Lange, Ber. d. d. chem. Ges. 13, 2136 (1880). 
nur etwa zur Hälfte gespaiten werden. Auch bei dem Versuch, sie mit alkoholischem Schwefelammonium im Rohr zur entsprechenden Hydrazoverbindung za reduzieren, trat quantitative Spaltung ein. Es zeigt sich hierin wieder, wie sehr symmetrischer Bau die Spaltbarkeit der parasubstituierten Azokörper erhöht' ${ }^{1}$ ).

\section{Umlagerung von $\beta, \beta^{\prime}$-Hydrazonaphthalin.}

36) In der Einleitung (Abschn. 2) ist auseinandergesetzt worden, warum dieser Fall zur Ergänzung der von Meisenheimer and Witte $^{3}$ ) veröffentlichten Beobachtnngen nochmals bearbeitet wurde.

Die Versuche, welche mein Assistent, Herr Dr.H.Jost, anstellte, zeigen, daß auch unter den Bedingungen, die bei meinen Untersuchungen für zweifach parasubstituierte Azo- bzw. Hydrazokörper der Benzolreihe stets eingehalten wurden, - Behandlung mit salzsaurer Zinnchlorïrlösung - aus $\operatorname{dem} \beta, \beta^{\prime}$-Azonaphthalin nicht ein o-Semidin entsteht, sondern dasselbe Amin, das Meisenheimer und Witte durch Umlagerung in essigsaurer and in alkalischer Lösung erhielten. DaB dieses Amin entsprechend der Ansicht der genannten Autoren als diprimäres Diamin - also als 2,2'-Diamino-dinaphthyl- $\left(1,1^{\prime}\right)$ - aufzufassen ist, wurde noch durch sein Verhalten gegen Anisaldehyd bestätigt; denn es lieferte ein Kondensationsprodukt, das $z$ wei Aldehydreste enthält und beim Kochen mit Säure diese beiden Aldehydreste wieder unter Rückbildung des ursprünglichen Diamins abspaltet (Abschnitt 38).

37) Das für die Versuche benötigte $\beta, \beta^{\prime}$-Azonaphthalin (Schmelzp. $208^{\circ}$ ) wurde bequem nach dem Verfahren von M. Lang ${ }^{3}$ ) erhalten. Zur Umlagerung suspendierten

1) Tgl. diese Annalen 287, 115-117 (1895).

2) Ber. d. d. chem. Ges. 36, 4154-4156, 4159, 4161 (1803); vgl. auch Bucherer, M. Schmidt, J. pr. [2] 79, 400 (1909).

э) D.R.P. 78225 (Frdl. 4, 1017). 
wir $5 \mathrm{~g}$ dieses feingepulverten Azokörpers in $50 \mathrm{ccm}$ heißem Alkohol, gaben allmählich $80 \mathrm{~g}$ salzsaure Zinnchlorürlösung (aus 40 g krystallisiertem Zinnchlorür and $100 \mathrm{ccm}$ Salzsänre von 38 Proz.) und erhielten etwa eine Viertelstunde in schwachem Sieden. Dann gossen wir von dem geringen Bodensatz ab, dampften anf etwa die Hälfte ein und stellten in Eis. Das reichlich abgeschiedene Zinndoppelsalz wurde in $100 \mathrm{ccm}$ heißen Wassers nnter Zusatz von wenig Salzsäure gelöst und in der warmen Lösung durch Schwefelwasserstoff entzinnt. Aus der rom Schwefelzinn filtrierten Lösung erhielten wir durch Fällang mit Soda $3 \mathrm{~g}$ eines weißen Niederschlags, der durch Umkrystallisieren aus Alkohol $2 \mathrm{~g}$ reines $2,2^{\prime}-D i$ amino-dinaphthyl- $\left(1,1^{\prime}\right)$ - durch Mischschmelzpunkt $\left(190^{\circ}\right)$ mit einem nach Meisenheimer und Witte aus $\beta, \beta^{\prime}$ Azonaphthalin in Eisessig durch Zinkstaub bereiteten Präparat identifiziert - lieferte. Es gibt in salzsaurer Lösung mit Natriumnitrit eine goldgelbe kJare Jobsung, die mit alkalischer $\alpha$-Naphthol-Lösung einen schmutzigroten Niederschlag erzengt.

Dieses Diamin ist also das wesentliche Produkt der Reaktion. Wenn wir nur 40 Proz. in reiner Form isolierten, so liegt dies daran, daß sich ihm bei der Reaktion bzw. während der Aufarbeitung durch sekundäre Veranderung (Abspaltung von $\mathrm{NH}_{3}$ ) das Dinaphthylenimin beimengt, dessen Gegenwart in manchen Fraktionen durch die Rotfärbung mit konz. Schwefelsäure deutlich angezeigt wurde. Meisenheimer and Witte haben diese Umwandlung quantitativ durch Erhitzen des trockenen Hydrochlorids bewirkt; sie geht partiell wohl auch in der warmen salzsauren Lösung vor sich. Wir haben beobachtet, daß auch bei der Reduktion des $\beta, \beta^{\prime}$-Azonaphthalins mit Eisessig und Zinkstaub (nach Meisenheimer und Witte) neben dem Diaminodinaphthyl eine beträchtliche Menge (etwa 20 Proz.) des Dinaphthylenimins (durch Schmelzpunkt and Stickstoffbestimmung identifiziert) entsteht. 
38) Zur Darstellung des 2,2'-Bis-[p-methoxybenxylidenamino]dinaphthyls-(1,1) $\left[\mathrm{CH}_{3} \cdot 0 . \mathrm{C}_{6} \mathrm{H}_{4} \cdot \mathrm{CH}: \mathrm{N} . \mathrm{C}_{10} \mathrm{H}_{6}-\right]_{3}$ losten wir $1 \mathrm{~g} \mathrm{Di-}$ aminodinaphthyl durch längeres Kochen in $.50 \mathrm{~g}$ Alkohol, gaben $5 \mathrm{~g}$ Anisaldehyd hinzu, kochten 3 Stunden und engten dann auf etwa ein Drittel ein. Die nach einiger Zeit ausgefallenen hellgrauen Krystalle wurden zerrieben und mit $100 \mathrm{ccm}$ Alkohol eine hatbe Stunde gekocht, wobei nur ein geringer Teil in Lösung ging; den Rückstand lösten wir in etwa $15 \mathrm{cem}$ heiBem Chloroform. Als aun zur filtrierten Chloı oformlösung etwa $35 \mathrm{ccm}$ Methylalkohol gesetzt wurden, schied sich $1 \mathrm{~g}$ der reinen Verbindung als gelbes krystallinis'hes Pulver (unter dem Mikroskop durchsichtige, scharf begrenzte, dicktaflige Krystalle) aus. Schmelzp. 194-195 ${ }^{\circ}$. Leicht 16slich in heiBem Chloroform, Benzol und Aceton; fast unlöslich in Petroläther, Methyl- und Äthylalkohol.

$0,2717 \mathrm{~g}$ gaben $0,8240 \mathrm{CO}_{2}$ und $0,1361 \mathrm{H}_{2} \mathrm{O}$.

$0,2471 \mathrm{~g} " 12,45 \mathrm{ccm}$ Stickgas bei $19^{\circ}$ u. $751 \mathrm{~mm}$ Druck.

$\begin{array}{ccc} & \text { Ber. für } \mathrm{C}_{98} \mathrm{H}_{28} \mathrm{O}_{\mathbf{9}} \mathrm{N}_{2} & \text { Gef. } \\ \mathrm{C} & \mathbf{8 2 , 6 0} & 82,70 \\ \mathrm{H} & 5,39 & 5,60 \\ \mathrm{~N} & 5,37 & 5,70\end{array}$

LäBt man verdünnte Mineralsăure anf die Verbindung in warmer alkoholischer Lösung wirken, so wird das Diaminodinophthyl (durch Mischschmelzpunkt identifiziert) zurückgewonnen.

\section{B. Nachträge zur Umlagerung von einfach} parasubstituierten Hydrazoverbindungen.

39) Die Nachträge za früheren Untersuchungsreihen, die ich im folgenden mitteile, betreffen zwei Fälle, in denen außer einem Parasubstituenten andere Substituenten in Meta- bzw. Orthostellung zur Hydrazogruppe zagegen sind. Solche Fälle waren schon früher von mir häufig geprüft ${ }^{1}$ ), und es hatte sich dabei gezeigt, daB der Parasubstituent seinen Einflub anf die Richtungen, welche der Umlagerungsvorgang einschlägt, in qualitativer Hinsicht stets beibehielt, dab aber die in anderen Stellungen vorhandenen Substituenten das quantitative Verhältnis der verschiedenen, nebeneinander verlaufenden Vorgänge

1) Vgl.: diese Annalen 287, 97 (1895); 369, 1 (1909); Ber. d. d. chem. Ges. 27. 2703 (1894); 29, 2685 (1896); 36, 3857 (1903) 
wesentlich verăndern können. Abstoßungen von Nichtparasubstituenten waren bisher nicht beobachtet worden.

Das erste Beispiel, über das ich unten berichte, verdient nun deshalb einige Beachtung, weil bei ihm Abstoßung eines in Metastellung befindlichen Carboxyls ${ }^{2}$ ) eintritt, ohne daß dessen Platz in anderer Weise beansprucht wird. Das zweite Beispiel bringt eine Kombination von paraständiger Acetaminogruppe mit nichtparaständigen Methyl-Gruppen; bei ihm treiben die Methyle die Umlagerung in eine Richtung, die bei alleiniger Gegenwart jenes Parasubstituenten nicht anfgesucht wird.

\section{Umlagerung von 4-Methoxy-hydrazobenzol- 3-carbonsäure.}

40) Die Reduktion von 4-Methoxy-azobenzol-3-carbonsäure (Formel I, s. unten) mit Zinn und Salzsäure ergab als einzig faBbares Umlagerungsprodukt das o-Semidin II
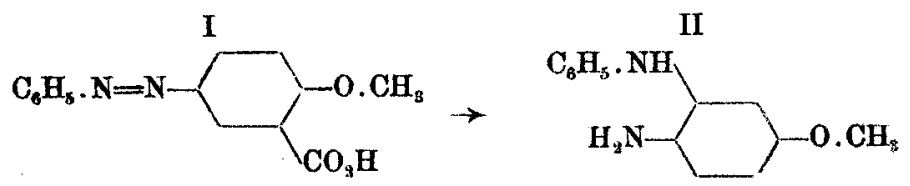

(5-Methoxy-2-amino-diphenylamin). Das Carboxyl war also abgestoßen. Es erscheint dies anffällig, da bei der Re-

1) C̈ber Abspaltung von paraständigem Carboxyl vgl. diese Annalen 303, 389 (1898).

Ich benutze diese Gelegenheit, um ein von mir, diese Annalen 367, 329 (1909), betreffs der Azobenzolcarbonsäuren begangenes Versäumnis nachzuholen. Ich habe daselbst die meta-Säure als neu beschrieben; sie war aber zu jener Zeit schon von Freundler [Compt. rend. 143, 910; Bull. soc. chim. [4] 1, 220 (1907)] auf einem anderen, als dem von mir eingeschlagenen Wege erhalten worden, und ich hätte daher die Veröffentlichung von Freundler gitieren sollen. Die Versuche freilich, auf die ich mich an jener Stelle stütze, waren schon viel früher auBerhalb der Zeitschriftenliteratur in der Dissertation von A. Steinbrenk [, Über die Monocarbonsäuren des Azobenzols usw." (Heidelberg 1896)], S. 24-29 mitgeteilt worden. 
duktion von 5-Nitro-salicylsäure $\mathrm{O}_{2} \mathrm{~N}^{5} \cdot \mathrm{C}_{6} \mathrm{H}_{3}(\mathrm{OH})^{2}\left(\mathrm{CO}_{2} \mathrm{H}\right)^{\mathrm{x}}$ mit dem gleichen Agens Aminosalicylsäure erbalten wird ${ }^{1}$ ), ohne dab daneben Bildung von Aminophenol bemerkt worden ist; auch ergibt die Reduktion der Benzolazosalicylsänre selbst, von der sich I als Methyläther ableitet, Aminosalicylsäure in guter Aasbeute ${ }^{2}$ ).

Die Versuche sind ausführlicher in der Dissertation des Herrn M. Jaenicke ${ }^{3}$ ) beschrieben.

41) Zur Darstellung des Ausgangsmaterials wurde 4-Oxy-azobenzol-3-carbonsäuremethylester ${ }^{4}$ ) (Benzolazosalicylsäuremethylester) zunächst durch Methylierung (Einwirkung von Methyljodid auf das Silbersalz oder Natriumsalz; in beiden Fällen nur mäbige Ausbeute) in 4-Methoxy-azobenxol-3-carbonsäuremethylester $\mathrm{C}_{6} \mathrm{H}_{5} \cdot \mathrm{N}_{2}$. $\mathrm{C}_{6} \mathrm{H}_{8}\left(0 . \mathrm{CH}_{3}\right) \cdot \mathrm{CO}_{2} \mathrm{CH}_{3}$ übergeführt. Colombano $\left.0^{5}\right)$ hat inzwischen dieses Dimethylderivat direkt aus der Benzolazosalicylsäure durch Methylierung in alkalischer Lösung mit Dimethylsulfat gewonnen und beobachtete dafür den Schmelzp. 63-64 $4^{\circ}$, während wir ihn etwas höher $\left(65-67^{\circ}\right)$ fanden. Als Nebenprodukt erhielt Colombano das Monomethylderivat - die 4-Methoxy-axobenzol-3-carhonsäure (Formel I, s. oben), die wir aus dem Dimethylderivat in guter Ausbeute durch Verseifen mit kochender wäbrig-alkoholischer Kalilauge bereiteten. Diese Säure krystallisiert aus Alkohol in kleinen hochroten Nadeln, schmilzt bei $167^{\circ}$ (Colom bano: 162-165') und löst sich leicht in heiBem Alkobol, Benzol und Eisessig, schwer in kaltem Alkohol, Äther und Ligroin; aus ihrer Lösung in verdünnter Natronlange wird dureh überschüssiges Natron ibr Natriumsalz gefällt.

42) Zur Umlagerung versetzten wir eine heiße Lösung von $10 \mathrm{~g}$ Methoxyazobenzolcarbonsäure in $70 \mathrm{ccm}$ heiBem Methylalkohol, in welche $4 \mathrm{~g}$ metallisches Zinn gebracht waren, allmählich mit Salzsäure, bis Entfärbung eingetreten war. Die vom unverbrauchten Zinn abgegossene Lösung warde dann mit der vierfachen Menge Wasser verdünnt und in der Wärme durch Sehwefelwasserstoft entzinnt.

1) R. Sehmitt, Zeitschr. f. Chemie 1864, 324; Beilstein, diese Annalen 130, 243 (1864); Hübner, diese Annalen 195̃, 18 (1879).

2) A. Fischer, Schar-Rosenberg, Ber. d. d. chem. Ges. 32,81 (1899).

3) „Über Reduktion des Benzolazoanisols und der Benzolazoanisolcarbonsäure" (Heidelberg 1896), S. 19-29.

4) Limpricht, diese Annalen 263, 228 (1891).

s) R. A. L. [5] 16, II, 549 (1916). 
Die entzinnte Lösung setzte, nachdem sie im KohlendioxydStrom auf etwa ein Fünftel eingeengt war, bei längerem Stehen nötigenfalls nach Zusatz von etwas konz. Salzsäure - einen SalzanschuB in silbergrauen Nadeln ab. Die aus diesem AnsehuB durch neutrales Natriumsulfit in Freiheit gesetzte Base erwies sich als nicht emheitlich. Beim Auskochen mit Ligroin hinterblieb in sehr geringer, die nähere Untersuchung nicht zulassender Menge ein auch in Wasser, Alkohol, Äther und Benzol unlöslicher Rückstand, der sich aber sowohl in verdünnter Essigsäure wie in Ammoniak löste, vermutlich also eine Aminosäure darstellte. Aus der Ligroinlösung aber krystallisierte das 5-Methoxy-2-aminomiphenjlamin (Formel II in Abschn. 40), das früher aus dem Benzolazoanisol durch saure Reduktion erhalten worden war ${ }^{1}$ ); es wurde durch seinen Schmelzpunkt $\left(73^{\circ}\right), N$-Bestimmung, die Eisenchloridreaktion und die Schmelzpunkte des Schwefelkonlenstoff- und des Salicylaldehydderivats $\left(208^{\circ}\right.$ bzw. $\left.132^{\circ}\right)$ identifiziert. Auch von diesem Produkt wurden indessen nicht erhebliche Mengen erhalten (in reiner Form etwa 10 Proz.). Der gröBte Teil der angewandten Azocarbonsäure hatte Spaltung erlitten; die Wägung des hierdurch gebildeten Anilins lieb auf einen Spaltungsbetrag von 70-75 Proz. schlieBen.

\section{Umlagerung von 2',3-Dimethyl-4-acetamino- hydrazobenzol.}

43) Bei der Umlagerung des p-Acetamino-hydrazobenzols ${ }^{2}$ ) war früher das entsprechende $p$-Semidin (4-Amino-4'-acetamino-diphenylamin) als einziges Umlagerungsprodukt in einer Ausbeute von etwa $25 \mathrm{Proz}$. erhalten worden; da daneben Spaltungsprodukte im Betrage von $6 z-63$ Proz. nachgewiesen wurden, war fast vollständige Aufarbeitung erzielt. Es bot sich kein Anzeichen dafür, daß Umlagerung noch in anderer Richtung. sich abspielt.

Bei dem in der Überschrift bezeichneten Homologen aber, das wir im Zustand des Entstehens aus dem zagehörigen Azokörper (Formel I, s. unten) untersuchten, beobachteten wir nun weit geringere Spaltungsneigung

1) Ber. d. d. ehem. Ges. 29, 2681 (1896).

) Diese Annalen 303, 363 (1898). 


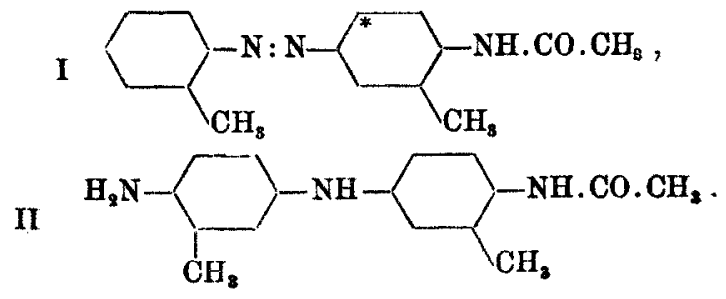

(etwa 18 Proz.). Wir konnten die Bildung des $p$-Semidins II zwar feststellen, aber nur in geringem Betrage (wenige Prozente). Dagegen bildete überraschenderweise ein Amin der Diphenylreihe das Hauptprodukt (etwa 65-70 Proz.). Wir haben über die Stellung seiner einzelnen Grappen zur Verknüpfungsstelle der Benzolkerne $z$ war keine besondere Ermittlung eingeleitet; man darf ihm aber auch ohne eine solche wohl auf Grund sonstiger Erfahrungen die Formel III des 3',4-Dimethyl-2,4'-diamino5-acetamino-diphenyls zuerteilen.

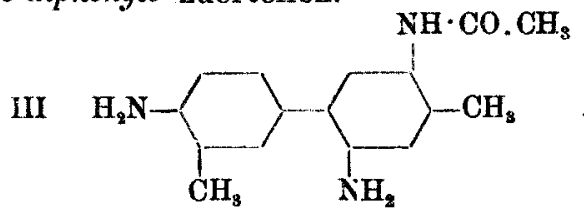

Die Methyle haben hier also bewirkt, dab die Diphenylumlagerung, die bei dem methylfreien p-Acetaminoazokörper völlig ansbleibt, in außerordentlich hohem Anteil eintritt. In erster Linie wird diese starke Wirkung wohl dem in der 3.Stelle befindlichen Methyl zuzuschreiben sein, welches das zu ihm paraständige Wasserstoffatom - in Formel I durch * bezeichnet für die Wanderung zur Hydrazogruppe bereit macht.

Ausführliche Beschreibung der Versuche mit den analytischen Belegen findet man in der Dissertation von Herrn G. Lockemann ${ }^{1}$ ).

44) Das Ausgangsprodukt - 2',3-Dimethyl-4-acetamino-azobenzol (Formel $I$ in Abschn. 42) - ist schon

1) „Über Amino. und Jodderivate von Homologen des Azobenzols" (Heidelberg 1896), S. 20-40. 
von G. Schultz' ${ }^{1}$ ) beschrieben; wir fanden den Schmelzpunkt bei $186-187^{\circ}$ (Schultz 185 ).

Zur Umlagerung wurden $3 \mathrm{~g}$ mit $6 \mathrm{ccm}$ Wasser verrieben und unter Eiskühlung allmählich mit $15 \mathrm{ccm}$ Zinnchlorürlösung (aus $40 \mathrm{~g}$ Zinnchlorür und $100 \mathrm{ccm}$ konz. Salzsäure) versetzt. Als sich das Gemenge, das von Zeit zu Zeit mit einem Pistill gründlich durchgerieben wurde, nach zweistündigem Stehen entfärbt hatte, wurde das abgeschiedene graue Zinndoppelsalz abgesaugt; es enthält das $p$-Semidin (vgl. Abschn. 45). Das Filtrat wurde allmählich unter Wasserkühlung mit starker Natronlauge versetzt; als die zuerst ausfallenden Zinnhydroxyde wieder in Lösung gingen, schied sich dann auf weiteren Zusatz von Natronlauge ein brauner schwammiger Klumpen ab. Dieser wurde durch Aaskochen mit Wasser gereinigt und stellte dann eine wachsartige Masse dar, in welcher die rohe Diphenylbase (vgl. Abschn. 46) - das Hauptprodukt (65-70 Proz.) der Reaktion - vorliegt.

45) Das freie $p$-Semidin - 3,3'-Dimethyl-4-amino4 -acetamino-diphenylamin $\mathrm{C}_{18} \mathrm{H}_{19} \mathrm{ON}_{3}$ (Formel II in Abschn. 43) - gewannen wir, indem wir jenes Zinndoppelsalz (vgl. Abschn. 44) in schwacher Salzsäure lösten und unter Kühlung Natronlange bis zur ziemlich vollständigen Wiederauflösung der anfangs niederfallenden Zinnhydroxyde zusetzten, zunächst in harzigem schwam-

1) Ber. d. d. chem. Ges. 17, 470 (1884). Zor Charakterisierung des 2',3-Dimethyl-4-amino-axobenzols (gewöhnlich „o-Aminoazotoluol" genant) hat Hr. Lockemann noch die folgenden beiden Aldehydderivate dargestellt:

Benzaldehydderivat $\mathrm{C}_{21} \mathrm{H}_{19} \mathrm{~N}_{3}=\mathrm{C}_{6} \mathrm{H}_{4}\left(\mathrm{CH}_{3}\right) \cdot \mathrm{N}_{9} \cdot \mathrm{C}_{6} \mathrm{H}_{3}\left(\mathrm{CH}_{3}\right) \cdot \mathrm{N}$ : CH. $\mathrm{C}_{6} \mathrm{H}_{5}$. Dunkelrote glänzende Säulchen. Schmelzp. 96-97". Sehr leicht löslich in Chloroform und Benzol, leicht in warmem Alkohol, ziemlich leicht in kaltem Äther und Ligroin.

Salicylaldehydderivat $\mathrm{C}_{21} \mathrm{H}_{19} \mathrm{ON}_{8}=\mathrm{C}_{6} \mathrm{H}_{4}\left(\mathrm{CH}_{3}\right) \cdot \mathrm{N}_{2} \cdot \mathrm{C}_{6} \mathrm{H}_{3}\left(\mathrm{CH}_{8}\right) \cdot \mathrm{N}$; CH. $\mathrm{C}_{6} \mathrm{H}_{4} \cdot \mathrm{OH}$. Orangegelbe Nädelchen oder Blättchen. Schmelzp. $111-112^{\circ}$. Sehr leicht löslich in Chloroform und Benzol, ziemlich leicht in warmem Alkohol und kaltem Äther. 
migen Zustand. Durch Auskochen mit Wasser and daranf folgende Krystallisation aus heißem Benzol erhielten wir es dann in weißen Kryställchen vom Schmelzpunkt $174-175^{\circ}$. Seine verdünnte salzsaure Lösung gibt mit Eisenchlorid eine rotviolette Färbung.

Als $p$-Semidin erweist es sich dadarch, dab seine verdünnte salzsaure Lösung mit Nitritlösung eine intensiץ rotviolette Färbung gibt, die nach einiger Zeit ohne Eintreten einer Trübung in Hellgelb übergeht, and dab seine schwefelsaure Lösung beim Kochen mit Kaliumdichromat Chinongeruch entwickelt, endlich durch die Zasammensetzung seines Salirylaldehydderivats $\mathrm{C}_{23} \mathrm{H}_{23} \mathrm{O}_{2} \mathrm{~N}_{2}$ $=\mathrm{OH} \cdot \mathrm{C}_{8} \mathrm{H}_{4} \cdot \mathrm{CH}: \mathrm{N} \cdot \mathrm{C}_{6} \mathrm{H}_{3}\left(\mathrm{CH}_{3}\right) \cdot \mathrm{NH} \cdot \mathrm{C}_{6} \mathrm{H}_{3}\left(\mathrm{CH}_{3}\right) \cdot \mathrm{NH} \cdot \mathrm{CO} \cdot \mathrm{CH}_{3}$, das aus Alkohol in gelben Nädelchen krystallisiert und bei $185-186^{\circ}$ schmilzt.

46) Die Diphenylbase - 3',4-Dimethyl-2,4'-diamino-5-acetamino-diphenyl (Formel III in Abschn. 43) - haben wir als solche nicht in analysenfähigem Znstand gewonnen. Wir stellten aber aus jenem rohen wachsartigen Produkt drei Derivate dar, durch deren Zusammensetzung es mit Sicherheit als primäres Diamin von der Formel $\mathrm{C}_{18} \mathrm{H}_{19} \mathrm{ON}_{3}$ gekennzeichnet wurde. Das Salicylaldehydderivat (s. unten) wurde in so großer Ausbeute erhalten, dab dieses Diamin als der wesentliche Bestandteil jenes Rohprodukts angesehen werden darf.

Das Benzaldehydderivat $\mathrm{C}_{30} \mathrm{H}_{27} \mathrm{ON}_{3}-3^{\prime}, 4-D i$ methyl-2, 4'-bis-[benzylidenamino]-5.acttamino-diphenyl $\mathrm{C}_{6} \mathrm{H}_{5}$. $\mathrm{CH}: \mathrm{N} . \mathrm{C}_{6} \mathrm{H}_{3}\left(\mathrm{CH}_{3}\right) \cdot \mathrm{C}_{6} \mathrm{H}_{2}\left(\mathrm{CH}_{3}\right)\left(\mathrm{N}: \mathrm{CH} . \mathrm{C}_{6} \mathrm{H}_{5}\right) \cdot \mathrm{NH} . \mathrm{CO}^{-\mathrm{CH}_{3}-}$ scheidet sich ans Alkohol in gelblich-weißen Kryställchen vom Schmelzp. 204-205 ab.

Das Salicylaldehydderivat $\mathrm{C}_{30} \mathrm{H}_{27} \mathrm{O}_{3} \mathrm{~N}_{3}-3^{\prime}, 4$ Dinethyl-2,4'bis-[o-oxybenzylidenamino]-5-acetamino-diphenyl $\mathrm{HO} . \mathrm{C}_{6} \mathrm{H}_{4} \cdot \mathrm{CH}: \mathrm{N} . \mathrm{C}_{6} \mathrm{H}_{3}\left(\mathrm{CH}_{3}\right) \cdot \mathrm{C}_{6} \mathrm{H}_{2}\left(\mathrm{CH}_{3}\right)\left(\mathrm{N}: \mathrm{CH} \cdot \mathrm{C}_{6} \mathrm{H}_{4} \cdot \mathrm{OH}\right)$. NH.CO. $\mathrm{CH}_{3}$ - krystallisiert aus Alkohol in hellgelben Nädelchen, schmilzt bei $239-240^{\circ}$ und ist in heißem Benzol schwer, in heißem Alkohol leicht löslich.

Durch 7 stündiges Kochen mit Eisessig wurde aus 
dem wachsigen Rohprodukt das Acetylderivat, $\mathrm{C}_{20} \mathrm{H}_{23} \mathrm{O}_{3} \mathrm{~N}_{3}-3^{\prime}, 4$-Dimethyl-2,4',5-tris-[acetylamino]-diphenyl $\mathrm{CH}_{3}$. CO.NH. $\mathrm{C}_{6} \mathrm{H}_{3}\left(\mathrm{CH}_{3}\right) \cdot \mathrm{C}_{6} \mathrm{H}_{2}\left(\mathrm{CH}_{3}\right)\left(\mathrm{NH} . \mathrm{CO} . \mathrm{CH}_{3}\right)_{2}$ - bereitet. Es scheidet sich aus Eisessig bei langsamer Krystallisation in wasserhellen rautenförmigen Täfelchen $\mathrm{ab}$, schmilzt bis $360^{\circ}$ noch nicht und ist in heiBem Alkohol leicht, in heißem Eisessig weniger leicht, in heißem Äther and Benzol nicht löslich.

\section{Zur Umlagerung der nicht parasubstituierten Hydrazoverbindungen.}

47) Sind beide Parastellen eines Hydrazokörpers unsubstituiert, so ist diejenige Art der Umlagerung, welche nach allen bisherigen Erfahrungen die bevorzugte ist, möglich: die Bildung einer "Benzidinbase", d. h. eines diprimären 4,4'-Diamins der Diphenylreihe.

Die Frage, ob sie unter allen Umständen die bevorzugte bleibt, oder ob Gegenwart von Substituenten an Nichtparastellen ( $o$ oder $m$ ) die Umlagerung ganz oder teilweise in andere Richtung lenken kann, hat mich schon mehrfach beschäftigt ${ }^{1}$ ). Bei den bisher geprüften Fällen war ein irgend wesentlicher Einfluß der Nichtparasubstituenten nicht hervorgetreten. Denn stets wurden als Hanptprodukte Diamine der Diphenylreihe erhalten, die als Homologe bzw. Substitutionsprodukte des Benzidins angesehen werden dürfen; stellten sich auch Anzeichen ein, daß daneben Semidine entstehen, so zeigte doch die Aufarbeitung der Mutterlaugen, daß es sich höchstens um sehr geringe Mengen von ihnen handeln $\operatorname{kann}^{2}$ ).

Noch nicht geprüft war der Fall des Vorhandenseins zweier Metasubstituenten in einem Kern, wie er z. B. in dem 3,5-Dimethyl-hydrazobenzol (Formel I,

1) Ber. d. d. chem. Ges. 28, 2541 (1895); 36, 4069 (1903).

) Ber. d. d. chem. Ges. 28, 2557 (1895); 36, 4075-4076, 4080 bis 4082 (1903). 
s. u.) vorliegt. Man konnte nun mit der Möglichkeit rechnen, daB gerade diese Substituentenverteilung die Benzidinumlagerung beeinträchtigen würde. Denn das Diamin, das in diesem Falle durch die sonst stets bevorzugte Art der Umlagerung entstünde, weist eine Anhäufung von Substituenten beiderseits der Kernverknüpfungsstelle auf (Formel II), und gegen das Zustandekommen

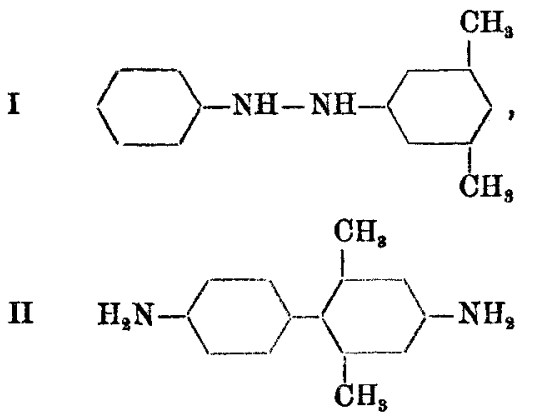

ähnlicher Atomgrappierungen hat sich in manchen Beobachtungen ein gewisser Widerstand erkennen lassen ${ }^{1}$ ). Unter den Formeln aber, welche sich bei anderen Arten der Umlagerung als möglich ergeben, besticht die Formel III

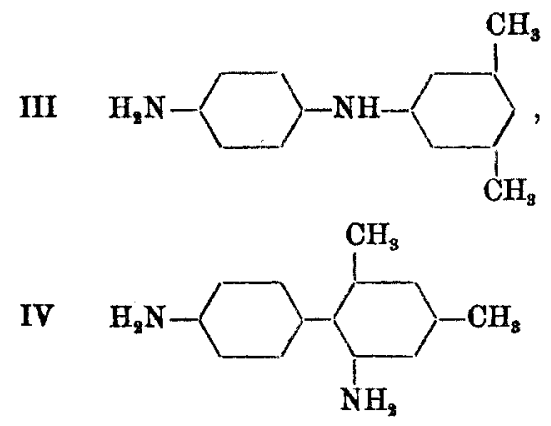

eines $p$-Semidins dadurch, dab sie jeder Nachbarstellung von A tomgruppen "answeicht".

Auf Grund dieser Erwägung habe ich mit meinen Assistenten - Herrn Dr. F. Hönigsberger und Herrn

1) Vgl. diese Annalen 287, 113-115, 118, 122. Ber. d. d. chem. Ges. 31, 893 (1898); 36, 3871-3872 (1903). 
Dr. L. Huber - diesen Fall antersucht. Wir fanden aber durchaus keine Anzeichen für die Bildung eines Semidins, erhielten vielmehr in vortrefflicher Ausbeute ein Diamin der Diphenylreihe. Für dieses könnten zwar auber der Formel II noch die Formeln IV und $V$ mit „Diphenylin".Stellung der Aminogruppen in Betracht gezogen werden. Von ihnen haben wir IV ausgeschlossen,
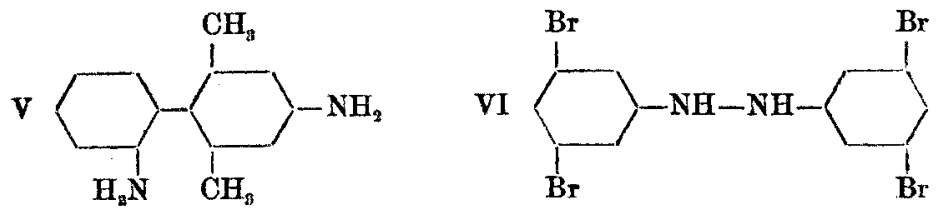

indem wir unser Diamin za 2,6-Dimethyldiphenyl entamidierten. Es bleibt also nur die Wahl zwischen $\Pi$ und V. Da gar kein Grund zu sehen ist, warum der methylfreie Kern des Hydrazokörpers $I$ in der Haaptreaktion sein ortho-Wasserstoffatom statt des sonst immer hierfür bevorzugten para-Wasserstoffatoms zar Hydrazogruppe wandern lassen sollte, wird man auch $\nabla$ ausscheiden und das Umlagerungsprodukt gemäB II als 2,6-Dimethyl-4,4'-diamino-dipheryl, also als Homologes des Benzidins, auffassen dürfen. Die Anhänfung der Methyle um die Kernverknüpfungsstelle hat demnach die Benzidinumlagerung nicht erschwert, geschweige denn verhindert.

Für die Charakterisierung des Abbankohlenwasserstoffs mußten zum Vergleich erst die beiden in Frage kommenden Diphenylhomologen - 2,6-Dimethyl- and 2,4-Dimethyl-diphenyl - durch Aufbaureaktionen hergestellt werden (Abschn. 52 u. 53).

Während ich mit der Niederschrift dieser Abhandlung beschäftigt bin, bringen die „Berichte "Mitteilungen über ähnliche Versuche, welche Richard Meyer, Wilhelm Meyer und Taeger') am 3,5,3',5'-Tetrabromhydrazobenzol (Formel VI) angestellt haben, also an

э) Ber. d. d. chem. Ges. 53, 2035, 2045 ff. (1920). 
einem nichtparasubstituierten Hydrazokörper, der an sämtlichen meta Stellen substituiert ist. Das ihm entsprechende Benzidin (VII) enthält demnach die sämtlichen 4 ortho-Plätze zur Kernverknüpfungsstelle besetzt.

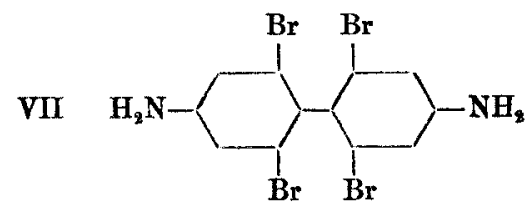

Eine gewisse Abneigung gegen das Zustandekommen dieser Gruppierung kann man aus den Beobachtungen der genannten Forscher ableiten, da sie fanden, dab jener Hydrazokörper der Umlagerung einen ganz ungewohnten Widerstand entgegensetzt. Wird die Umlagerung aber erzwungen, so ergibt sie zwei diprimäre Diamine der Diphenylreihe, von denen das eine in überwiegender Nenge entsteht und daher gemäB VII als tetrabromiertes Benzidin aufgefaßt wird.

48) Für die Darstellung des Ausgangsmateraals kon. densierten wir symm. $m$-Xylidin (1-Amino-3,-5-dimethylbenzol) mit Nitrosobenzol zu 3,5-Dimethylazobenzol, das dann zar Hydrazoverbindung reduziert wurde.

Für die Darstellung des symm. m-Xylidins hat W. A. Noyes') eine ausführliche Vorsehrift gegeben, die auf der Nitrierung des asymm. Acet-m-xylids zu 5-Nitro-4-acetamino-1,3-dimethyl-benzol, Verseifung dieses Nitroacetxylids, Entamidierung des entstandenen Nitroxylidins zu 5-Nitro-1,3-dimethyl-benzol und Reduktion dieses Nitroxylols beruht. Wir haben sie in der ersten und dritten Phase vereinfachen können²), ohne die Ausbente zu beeinträchtigen, und teilen daher unser Arbeitsverfahren mit. Man nitriert $100 \mathrm{~g}$ Acetsylid mit einem Gemisch von $200 \mathrm{~g}$ gewöhnlicher konz. Salpetersäure und $200 \mathrm{~g}$ rauchender Salpetersäure derart, daB man je $2-3 \mathrm{~g}$ in die Säure einträgt, bis die Temperatur von $35^{\circ}$ erreicht ist, von nun an durch Einstellen in Wasser kühlt und weiter kleine Portionen unter stetem Umrühren und Erhaltung der Temperatur

1) Journ. Amer. chem. Soc. 20, 800 (1898).

2) Nach dem Muster der in Meyer-Jacobsons Lehrb. d. organ. Chemie Bd. II, Tl. I (Leipzig 1902, S. 158-159) für m-Nitrotoluol gegebenen Vorschrift.

Annalen der Chomie 427. Band. 
auf $35-40^{\circ}$ einträgt; dann rührt man noch einige Minuten, läBt kurze Zeit stehen und gie $B t$ in viel Wasser. Das abgeschiedene Nitroacetxylid wird filtriert, mit Wasser bis zur Entfernung der letzten Salpetersäurespuren gewasch $n$ und drrch 1-2 stündiges Kochen mit $450 \mathrm{c} \cdot \mathrm{m}$ starker Salzsäure (D:1.14) verseift. Nach dem Filtrieren durch ein gehärtetes Filter wird das 5-Nitro-4-amino-1,3dimethyl-benzol durch Zuratz von 3-4 Vol. Wasser ausgefällt. Man löst es nun in 5 Tln. Alkohol (96 Proz.), versetzt allmählich mit 3 Tln. konz. Schwefelsäure und fügt nach dem Erkalten, während dessen eine Ausseheidung des Sulfats bei Vermeidung allzu starken Rülırens nicht erfolgt, tropfenweise eine gesättigte wäBrige Natriumnitritlösung (1,1 Molgew) unter Umrühren hinzu; darauf erhitzt man auf dem Wasserbade bis zum Aufhören der Stickst ffentwicklung, destilliert den gröBten Teil des Alkohols ab und treibt das symm. Nitro-m-xylol mit Wasserdampf über. Es wird auf dem Wasserbade einige Zeit mit verdünnter Natronlauge erwärmt, nach den Filtrieren und Waschen einmal aus Alkohol krystallisiert und dann nach den Angaben von Noyes mit Eisenpulver und verdünnter Essigsäure reduziert.

Zur Gewinnung des 3,5-Dimethy/-azobenzols versetzten wir eine Lösung von $20 \mathrm{~g}$ Nitrosobenzol in $80 \mathrm{ccm}$ Eisessig unter Wasserkühlung mit $23,4 \mathrm{~g}$ symm. $m$-Xylidin und überließen das braunrot gewordene Gemisch 24 bis 30 Stunden sich selbst. Dann brachten wir das Reaktionsprodukt, das reichlich Harz und violetten Farbstoff enthält, durch Wasser zor Abscheidung und schüttelten 4-5 mal mit Äther aus. Den aus den ätherischen Lösungen nach Abtreiben des Äthers erhaltenen, dunkelbraunen Rückstand behandelten wir im Ölbad von $130-150^{\circ}$ so lange mit überhitztem Wasserbade von etwa $150^{\circ}$, bis nichts mehr überging. Das Destillat wurde, nachdem die darin enthaltene Essigsäure durch Soda neutralisiert war, ausgeäthert, die ätherische Lösung getrocknet und abdestilliert. So erhielt man den Azokörper, frei von harzigen Beimengungen, als dunkelrotes Òl in einer Ausbente von 45-50 Proz. der Theorie. Es wurde im Vakuum von 18-20 mm Druck destilliert und ging dabei (nach unbedeutendem Vorlauf) zwischen $190^{\circ}$ und $200^{\circ}$ über; auch das destillierte ÖI $\left(D^{20}=1,060\right)$ erstarrte in einer Kältemischung nicht. 
$0,1632 \mathrm{~g}$ gaben $0,4771 \mathrm{CO}_{\mathrm{g}}$ und $0,0961 \mathrm{H}_{2} \mathrm{O}$.

$0,1869 \mathrm{~g}$ " $22,5 \mathrm{ccm}$ Stickgas bei $18^{\circ}$ und $761 \mathrm{~mm}$ Druck.

$\begin{array}{lcr} & \text { Ber. für } \mathrm{C}_{14} \mathrm{H}_{14} \mathrm{~N}_{2} & \text { Gef. } \\ \mathrm{C} & 79,93 & 79,73 \\ \mathrm{H} & 6,71 & 6,59 \\ \mathrm{~N} & 13,36 & 13,87\end{array}$

Wenn auch die Analyse ziemlich gut stimmte, so erwies sich doch, $d a b$ in dem so beleiteten Präparat noch keineswegs reines Dimethylazobenzol vorlag. Denn bei der Reduktion mit sal/saurer Zinnchlorürlösung wurde daralus neben anderen Produkten Benzidin in beträchtlicher Menge erhalten $(1 \mathrm{~g}$ schwefelsaures Benzidin aus $5 \mathrm{~g}$ Azokörper!). Nun erschien Bildung von Benzidin aus 3,5 Dimethylazobenzol zwar nicht ganz unmöglich; sie hätte sogar - wie in einer demnächst folgenden zusammenfassenden Abhandlung dargelegt werden soll - großes theoretisches Interesse besessen. Aber wir hielten es doch für wahrscheinlicher, daß das Benzidin seine Entstehung einer Verunreinigung mit Azobenzol verdanke, das aus Nitrosobenzol sich bilden konnte, indem dieses auf das Xylidin oxydierend wirkte ${ }^{1}$ ). Ditse Vermutung hat sich dann auch bestätigt. Denn durch weitere Reinigung jenes Azopräparats gelang es uns, die Benzidinbildung einzuschränken und schlieblich ganz zu vermeiden. Es geht daraus hervor, daß man bei Anwendung der so bequemen Methode zur Herstellung von. Azokörpern aus Nitrosokörpern und Arylaminen in bezıg auf die Einheitlichkeit der gewonnenen Präparate vorsichtig sein muß.

Die Reinigung führten wir aus, indem wir den einmal im Vakuum destillierten Azokörper im Vakuum fraktionierten, den höher siedenden Anteil dann in dio Hydrazoverbindung überführten und diese nmkrystallisierten. Aus $25 \mathrm{~g}$ des obigen Azokörpers wurde z. B.

1) Vgl. dazu: A uwers, Röhrig, Ber. d. d. chem. Ges. 30, 990 (1897). - Freundler, Juillard, Compt. rend. 148, 289 (1909). Bamberger, diese Annalen 420, 140 Anm. (1920). 
bei der Destillation unter $17-19 \mathrm{~mm}$ Druck nach einem unter $190^{\circ}$ übergehenden Vorlauf eine erste Fraktion von etwa $12 \mathrm{~g}$ zwischen $190^{\circ}$ and $195^{\circ}$, eine zweite von etwa $8 \mathrm{~g}$ zwischen $195^{\circ}$ und $198^{\circ}$ anfgefangen; da bei $197,5^{\circ}$ das Thermometer längere Zeit konstant blieb, darf man diese Temperatur als Siedepunkt des 3,5-Dimethylazobenzols betrachten.

Wir reduzierten nun $5 \mathrm{~g}$ der zweiten Fraktion in $25 \mathrm{ccm}$ Alkohol, die mit einer Lösung von $2 \mathrm{~g}$ Natriumhydroxyd in $4 \mathrm{ccm}$ Wasser vermischt waren, mit $8 \mathrm{~g}$ Zinkstaub. Nach vollendeter Reduktion filtrierten wir in eine Mischung von $100 \mathrm{ccm}$ Wasser mit $20 \mathrm{ccm}$ Schwefligs:̈urelösung; beim Abkühlen in Eiswasser setzte sich das 3,5-Dimethyl-hydrazobenzol krystallinisch ab. Es krystallisierte aus Alkohol in langen, feinen, farblosen Nadeln, schmolz scharf bei $78-79^{\circ}$ und änderte diesen Schmelzpunkt bei nochmaliger Krystallisation aus Alkohol nicht mehr, während die Hydrazoverbindung aus nicht fraktioniertem Azokörper stets mit unscharfem Schmelzpunkt erhalten worden war und nur durch vielfaches Umkrystallisieren zu scharfem Schmelzen gebracht werden konnte. Die bei $78-79^{\circ}$ scharf schmelzenden Präparate aber lieferten bei der Umlagerung (vgl. den nächsten Abschnitt) kein Benzidin mehr.

$0,1525 \mathrm{~g}$ gaben (nach Dennstedt verbrannt) $0,4392 \mathrm{CO}_{2}$ and $0,1104 \mathrm{H}_{2} \mathrm{O}$.

0,1477 g gaben nach Kjeldahl. Krüger $\mathrm{NH}_{3}$, das zur Neutralisation $13,75 \mathrm{ccm} / 10^{\mathrm{n}} \cdot \mathrm{H}_{2} \mathrm{SO}_{4}$ verbrauchte.

$0,1445 \mathrm{~g}$ gaben $17,2 \mathrm{ccm}$ Stickgas bei $2^{\circ}$ und $759 \mathrm{~mm}$ Druck.

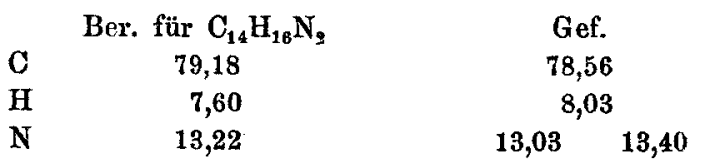

49) Unter Übergehung der Versuche, die an den angereinigten - d. h. Azobenzol enthaltenden - Präparaten des 3,5-Limethylazobenzols ansgeführt warden, beschreibe ich hier nur den Verlauf der Umlagerung, wie wir ihn schlieblich an der reinen, scharf bei $78-79^{\circ}$ 
schmelzenden Hydrazoverbindung beobachten. Wir versetzten eine Lösung von je $5 \mathrm{~g}$ Dimethylhydrazobenzol in $30 \mathrm{ccm}$ warmem Alkohol allmählich unter Umschütteln mit einer Lösung von $6 \mathrm{~g}$ Zinnchlorür in $15 \mathrm{ccm} 25 \mathrm{pro}$ zentiger Salzsäure. Nach einiger Zeit beginnt die Ausscheidung eines Zinndoppelsalzes in prächtigen vierseitigen Platten, das nach 24 Stunden von der zinnhaltigen Mutterlauge abfiltriert wurde. Seine Lösung in $500 \mathrm{ccm}$ Wasser wurde durch Schwefelwasserstoff entzinnt, dann auf etwa das halbe Volum eingeengt. Auf Zusatz von Soda fiel nun das im nächsten Abschnitt zu beschreibende Dimethyldiaminodiphenyl in einer Menge von 2,5 g ans; anfangs harzig, verwandelt es sich bald in ein Haufwerk feiner Nadeln and zeigte dann schon den Schmelzp. 120-122, war also fast rein. Aus der alkalischen Lösung worden durch Ausäthern noch $0,3 \mathrm{~g}$ von den gleichen Eigenschaften erhalten.

Aus der zinnhaltigen Mutterlauge trieben wir, nachdem sie alkalisch gemacht war, die durch Spaltung entstandenen Amine mit Wasserdampf ab; sie waren in nur sehr geringer Menge vorhanden $(0,2 \mathrm{~g}$ als Hydrochloride gewogen). Auch die mit Wasserdampf nicht flüchtige Aminfraktion, welche nun durch Ausäthern erhalten wurde und $1,8 \mathrm{~g}$ wog, erwies sich als das gleiche Dimethyldiaminodiphenyl. Zur Prüfung auf etwa beigemengte andere Amine wurde ans ihrer verdünnten salzsauren Lösung durch konz. Salzsäure ein Hydrochlorid-Anschuß gefällt. Sowohl aus dem in farblosen Nadeln ausfallenden Salz wie aus seiner Mutterlange wurde das gleiche Amin erhalten, das durch einmaliges Umkrystallisieren ans Petroläther auf den richtigen Schmelzpunkt kam, bzw. sich mit Benzaldehyd zum Dibenzalderivat vom Schmelzp. $199-200^{\circ}$ kondensierte. Die Nitritreaktion gab bei keiner Fraktion Anzeichen für die Gegenwart eines Semidins.

Die Umlagerung hatte also ein einheitliches Diamin der Diphenylreihe in einer Ausbeute von etwa 95 Proz. ergeben. 
50) 2,6-Dimethyl-4,4'diamino-diphenyl $(2,6-D i-$ methyl-benzidin) - Formel II in tbschn. 47 - krystallisiert aus einem Gemisch von Benzol und Petroläther in langen farblosen Nadeln, schmilzt bei $124^{\circ}$ und löst sich leicht in Alkohol, Äther und Benzol, weniger in Petroläther, nicht unbeträchtlich in heißem Wasser. Im Gegensatz zum Benzidin gibt seine verdünnte salzsaure Lösung auf Zusatz von Schwefelsäure nicht alsbald einen Niederschlag eines schwer löslichen Sulfats; erst nach längerem Stehen scheidet sich das Sulfat in langen Spießen ab. Während ferner salzsaures Benzidin (ebenso anch $o$-Tolidin $=3,3^{\prime}$-Dimethyl-benzidin) in verdïnnter wäbriger Lösung nit Kaliumpermanganat eine tiefblaue Färbung liefert ${ }^{1}$ ), die durch Salzsäure in Gelbrot umschlägt, durch Fssigsäure oder viel Wasser aber wiederhergestellt wird, entfärbt die Lösung unseres salzsauren Diamins Kaliumpermanganat und färbt sich dabei selbst nur schwach gelb; nach Zusatz größerer Mengen von Kaliumpermanganat tritt dann Trübung ohne bemerkenswerte Färbung ein ${ }^{2}$ ).

$0,1684 \mathrm{~g}$ gaben $0,4904 \mathrm{CO}_{2}$ und $0,1116 \mathrm{H}_{2} \mathrm{O}$.

$0,1632 \mathrm{~g}, 19,0 \mathrm{cem}$ Stickgas bei $18^{\circ}$ und $768 \mathrm{~mm}$ Druek.

$\begin{array}{ccr} & \text { Ber. für } \mathrm{C}_{14} \mathrm{H}_{16} \mathrm{~N}_{2} & \text { Gef. } \\ \mathrm{C} & \mathbf{7 9 , 1 8} & \mathbf{7 9 , 4 1} \\ \mathrm{H} & \mathbf{7 , 6 0} & \mathbf{7 , 4 1} \\ \mathrm{N} & 13,22 & \mathbf{1 3 , 5 3}\end{array}$

Als primäres Diamin haben wir unser Umlagerungsprodukt noch durch sein Verhalten gegen Benzaldehyd gekennzeichnet.

Das Benzaldehydderivat - 2,6-Dimethyl-4,4'-bis[benzylidenamino] diphenyl - scheidet sich nach kurzem Erwärmen von 1 Molgew. des Diamins mit 2,2 g Molgew.

1) Vgl. Saget, Chem. Zentralbl. 1902, I, 897.

2) Ähnlich verhält sich 2-Mrthoxy-benzidin [Ber. d. d. chem. Gea. 36, 4077 (1903)], während 3.Äthoxy-benzidin [Weinberg, Ber. d. d. chem. Ges. 20, 3176 (1887)] eine erst grüne, dunn blaue Färbang unter Abscheidung eines Niedergchlags gibt. 
Benzaldehyd in Alkohol beim Erkalten ab. Aus Petrolatther krystallisiert es in schwach gelben, haarfeinen Nadeln; Schmelzp. 199-200.

$0,1683 \mathrm{~g}$ gaben $11,3 \mathrm{ccm}$ Stickgas bei $19^{\circ}$ und $749 \mathrm{~mm}$ Druck.

$\begin{array}{ccc} & \text { Ber. für } \mathrm{C}_{28} \mathrm{H}_{24} \mathrm{~N}_{3} & \text { Gef. } \\ \mathrm{N} & 7,23 & \mathbf{7 , a ̆ 7}\end{array}$

51) Zur Entamidierung des im vorigen Abschnitt beschriebenen Benzidin-Homologen wandten wir, nachdem wir mit anderen Methoden nicht zam Ziele gelangt waren, das Verfahren von $\mathrm{Mai}^{\mathrm{l}}$ ) an, mit dessen Hilfe Mai selbst schon aus Benzidin mit guter Ausbeute Diphenyl bereitet hatte. Wir erzielten nach seinen Angaben beim Benzidin dasselbe Ergebnis; bei nnserem Homologen verlief die Reaktion indessen leider nicht so glatt, ergab aber immerhin bei Opferung von $28 \mathrm{~g}$ des Diamins eine für unsere $Z$ wecke genïgende Menge des Kohlenwasserstoffs.

Wir diazotierten je $5 \mathrm{~g}$. Diamin in $10 \mathrm{ccm}$ konz. Salzsäure und $56 \mathrm{~cm}$ Wasser mit $3,3 \mathrm{~g}$ Natriumnitrit. Diese Lösung vermischten wir bei $0^{\circ}$ mit einer Lösung von unterphosphoriger Säure, die durch allmähliches Eintragen von $25 \mathrm{~g}$ Calciumhypophosphit in eine Mischung von $6,6 \mathrm{ccm}$ konz. Schwefelsäure und $66 \mathrm{ccm}$ Wasser (bei $80 \%$, Filtrieren und Abkühlen bereitet war. Nachdem das Gemisch über Nacht in Eiswasser gestanden hatte, wurde ausgeäthert, die ätherische Lösung mit Alkali geschüttelt, ihr Rückstand dann mit Wasser äbergetrieben. Der hierbei gesammelte Kohlenwasserstoff - 2,6-Dimethyl-diphenyl (vgl. Abschn. 52) - wurde dann für sich destilliert und ging der Hauptmenge nach zwischen $260^{\circ}$ und $265^{\circ}$ (unkorr.) als schwach gelbliches Öl über; von dieser Fraktion wurden $5 \mathrm{~g}$ (aus $28 \mathrm{~g}$ Diamin) erhalten. Sie wurde zur Reinigung mit Natrium erhitzt, dann nochmals destilliert und ging jetzt ganz farblos innerhalb derselben Temperaturgrenzen über.

3) Ber. d. d. chem. Ges. 35, 162 (1902). 
214 Jacobson, Weitere Experimentalbeiträge zur Kenntris

$0,1896 \mathrm{~g}$ gaben $0,6395 \mathrm{CO}_{2}$ und $0,1241 \mathrm{H}_{2} \mathrm{O}$.

$0,2012 \mathrm{~g} " 0,6822 \mathrm{CO}_{2}, 0,1395 \mathrm{H}_{2} \mathrm{O}$.

\begin{tabular}{lcrr} 
& Ber. für $\mathrm{C}_{14} \mathrm{H}_{14}$ & \multicolumn{2}{c}{ Gef. } \\
$\mathbf{C}$ & $\mathbf{9 2 , 2 6}$ & 91,95 & $\mathbf{9 2 , 4 7}$ \\
$\mathbf{H}$ & $\mathbf{7 , 7 4}$ & $\mathbf{7 , 3 2}$ & $\mathbf{7 , 7 6}$
\end{tabular}

Um Handhaben für den Vergleich mit den durch Aufbau gewonnenen Präparaten von 2,6- und 2,4-Dimethyl-diphenyl (s. Abschn. 52 und 53) zu gewinnen: untersuchten wir die Nitrierung dieses Kohlenwasserstoffs.

Durch einen Capillarheber ließen wir $1 \mathrm{~g}$ in eine Mischung von $5 \mathrm{~g}$ konz. Schwefelsäure und $3 \mathrm{~g}$ rauchender Salpetersäure tropfen. Nachdem die Mischung, die schon Kryställchen enthielt, über Nacht gestanden hatte, wurde sie in Wasser gegossen, wobei sich das entstandene Nitroderivat sofort in fester, vollkommen krystallinischer Form abschied. Aus Benzol krystallisiert es in durchsichtigen, glasglänzenden, vierseitigen, scharfwinkligen Täfelchen vom Schmelzp. 254-256 ; der Schmelzpunkt erhöhte sich durch Krystallisation aus Eisessig auf $257-258^{\circ}$ und blieb dann konstant. Die Stickstoff bestimmung zeigte, da $B$ Trinitro-2,6-dimethyldiphenyl vorlag.

$0,2510 \mathrm{~g}$ gaben 28,4 ccm Stickgas bei $21^{*}$ und $765 \mathrm{~mm}$ Druck. Ber. für $\mathrm{C}_{14} \mathrm{H}_{11} \mathrm{O}_{6} \mathrm{~N}_{3}$
$\mathbf{N}$
13,27
13,15

Gef.

Wenn man dieses Trinitroderivat durch 3 stündiges Erwärmen mit einem Gemisch von konz. Schwefelsäure und rauchender Salpetersäure weiter nitriert, erhält man Tetranitro-2,6-dimethyldiphenyl, das aus Eisessig in mikroskopischen rechtwinkligen länglichen Täfelchen krystallisiert und bei $227-229^{\circ}$ schmilzt.

$0,1464 \mathrm{~g}$ gaben $0,2514 \mathrm{CO}_{2}$ und $0,0+30 \mathrm{II}_{2} \mathrm{O}$.

$0,2180 \mathrm{~g} \quad, \quad 29,7 \mathrm{ccm}$ Stickgas bei $23^{\circ}$ und $769 \mathrm{~mm}$ Druck.

$\begin{array}{ccr} & \text { Ber. für } \mathrm{C}_{14} \mathrm{H}_{10} \mathrm{O}_{8} \mathrm{~N}_{4} & \text { Gef. } \\ \mathbf{C} & 46,36 & 46,82 \\ \mathrm{H} & 2,78 & 3,29 \\ \mathrm{~N} & 15,50 & 14,94\end{array}$


52) Den Aufbau des 2,6-Dimethyl-diphenyls wollten wir - vom $v$-m-Xylidin (1-Amino-2,6-dimethyl-benzol) ausgehend - zunächst nach dem Bambergerschen Verfahren ${ }^{1}$ ) aus $N$-Nitrosoacetylid durch Einwirkung von Benzol bewirken; hierbei fanden wir den leichten Übergang der orthomethylierten Nitrosoanilide in Indazole ${ }^{2}$ ) anf, der Bambergers Methode in solchen Füllen für den Ersatz von $\mathrm{NH}_{2}$ durch $\mathrm{C}_{6} \mathrm{H}_{5}$ untanglich macht.

Wir wandten uns daher der Methode von Möhlau and Berger ${ }^{3}$ zu und ließen anf festes Xyloldiazoniumchlorid Benzol in Gegenwart von Aluminiumchlorid einwirken. Entsprechend den Erfahrungen von Möhlau and Berger an Homologen des Benzoldiazoniumchlorids war das Hauptprodukt der Reaktion Chlorxylol. Immerhin erhielten wir daneben eine kleine Menge des gewünschten Kohlenwasserstoffs, die zur Identifizierung mittels des Trinitroderivats ausreichte.

Trockenes salzsaures $\mathrm{v} \cdot \mathrm{m} \cdot \mathrm{Xylidin}^{4}$ ) - hergestellt durch Einleiten von trockenem Chlorwasserstoff in die konz. ätherische Lösung des Xylidins, Absaugen und Erwärmen auf $40-50^{\circ}$ (unter Cmschaufeln) bis zur völligen Entfernung des anhaftenden Chlorwasserstoffs wurde in 5 TIn. absoluten Alkohols suspendiert und unter Eiskühlung tropfenweise mit frisch destilliertem Amylnitrit (ein Drittel mehr als die theoretische Menge) versetzt. Durch Äther fiel nun das Xyloldiazoniumchlorid in glänzend weißen Kryställchen aus. Es wurde an der Laft getrocknet und sofort weiter verarbeitet, indem $6 \mathrm{~g}$ - mit etwas Benzol überschichtet - in kleinen Portionen zu $25 \mathrm{ccm}$ thiophenfreiem Benzol gegeben

1) Ber. d. d. chem. Ges. 30, 366 (1897).

2) Ber. d. d. chem. Ges. 41, 660 (1908).

3) Ber. d. d. ehem. Ges. 26, 1994 (1893).

4) Wir folgten für die Darstellung des Xyloldiazoniumchlorids den Angaben von B. Hirseh, Ber. d. d. chem. Ges. 30, 1149 (1879); die Vorschrift von Hantzsch n. Jochem (Ber. d. d. chem. Ges. 34, 3337 [1901] ergab in unserem Falle schlechtere Resultate. 
wnrden, das mit $2 \mathrm{~g}$ Aluminiumchlorid versetzt war and anf dem Wasserbade erwärmt warde; mit der Zngabe einer neuen Menge Diazoniumchlorids warde stets bis zur Beendigung der jeweils einsetzenden, durch Gasentwicklung sich kenntlich machenden Reaktion gewartet. Das Gemisch wurde nun nacheinander mit Wasser, verdünnter Salzsäure, verdünnter Natronlauge and wieder mit Wasser durchgeschüttelt, die so gereinigte Benzollösung dann mit Chlorcalcium getrocknet und das Benzol unter Anwendung einer Kolonne abdestilliert. Der Rückstand (aus $27 \mathrm{~g}$ Diazoniumchlorid) lieferte bei weiterer Fraktionierung mit einer Kolonne $12,7 \mathrm{~g}$ halogenhaltiges Öl bis $190^{\circ}, 1 \mathrm{~g}$ Destillat von $190-215^{\circ}$ und $0,6 \mathrm{~g}$ völlig halogenfreies Destillat von 215-260'. Als diese letzte Fraktion nun, wie im Abschn. 51 für den AbbanKohlenwasserstoff beschrieben ist, nitriert warde, erhielten wir ein Präparat, das nach dem Umkrystallisieren aus Eisessig unter jem Mikroskop völlig gleiches Aussehen wie das Irinitroderivat des Abbau-Kohlenwasserstoffs besaß, bei $251-253^{\circ}$ schmolz und nach dem Mischen mit diesem Trinitroderivat keine Erniedrigung des Schmelzpunkts zeigte.

53) Wir haben endlich auch das zweite DiphenylHomologe, das für den Abbau-Koblenwasserstoff in Frage kommen konnte (vgl. Abschn. 47), - das 2,4-Dimethyldiphe"yl - hergestellt, indem wir das Diazoniumchlorid des as-m-Xylidins (1-Amino-2,4-dimethyl-benzol) der Reaktion von Möhlau und Berger unterwarfen und hierfür genau ebenso verfuhren, wie im vorigen Abschnitt geschildert ist. Auch hier bestand das Rohöl (45 g aus $100 \mathrm{~g}$ Diazoniumchlorid) zum großen Teil aus Chlorxylol (Siedep. $186^{\circ}$ ). Der Teil, der unter gewöhnlichem 1)rack bis $200^{\circ}$ nicht überging, betrug nur etwa ein Drittel. Er wurde im Vakuum fraktioniert und siedete der Hauptmenge nach unter $17 \mathrm{~mm}$ Druck konstant bei $150-152^{\circ}$. Doch war auch diese Fraktion noch schwach halogenhaltig und gelblich gefärbt. Sie warde daher noch durch Destil- 
lation über Natrium gereinigt und ging jet»t unter $767 \mathrm{~mm}$ Druck bei $270-276^{\circ}$ (unkorr.) als wasserklares öl über. $0,1964 \mathrm{~g}$ gaben $0,6640 \mathrm{CO}_{9}$ und $0,1390 \mathrm{H}_{2} \mathrm{O}$.

$\begin{array}{ccc} & \text { Ber. für } \mathrm{C}_{14} \mathrm{H}_{14} & \text { Gef. } \\ \mathbf{C} & 92,26 & \mathbf{9 2 , 1 9} \\ \mathrm{H} & \mathbf{7 , 7 4} & \mathbf{7 , 9 2}\end{array}$

Dieser Kohlenwasserstoff verhielt sich nun beim Nitrieren durchaus anders als unser Abbau-Kohlenwasserstoff. Hielt man die Bedingangen ein, die im Abschn. 51 für die Gewinnung des Trinitroderivats angegeben sind, so zeigte sich der Unterschied schon darin, daß das Nitroprodukt in der Nitıiersäure als Öl obenauf schwamm and auch nach dem Eingießen in Wasser halbfest (gummiartig) blieb; beim Umkrystallisieren wurden nur unscharf (am $160^{\circ}$ ) schmelzende Präparate erhalten. Als dieses Rohprodukt nun weiter durch etwa zweistündiges Erwärmen auf siedendem Wasserbade mit dem Gemisch von konz. Schwefelsäure und rauchender Salpetersäure nitriert wurde, erhielt man ein Tetranitro-2,4-dimeihyldiphenyl, das sich durch Krystallisation aus Methylalkohol, dann aus Benzol (mit Petroläther) reinigen ließ und dann den Schmelzp. 154,5-155 $5^{0}$ zeigte.

$0,1569 \mathrm{~g}$ gaben $0,2690 \mathrm{CO}_{2}$ und $0,0426 \mathrm{H}_{2} \mathrm{O}$.

$0,1693 \mathrm{~g} \# \quad 23,0 \mathrm{ccm}$ Stickgas bei $18,5^{\circ}$ und $757 \mathrm{~mm}$ Druck.

$\begin{array}{ccr} & \text { Ber. für } \mathrm{C}_{14} \mathrm{H}_{10} \mathrm{O}_{8} \mathrm{~N}_{4} & \text { Gef. } \\ \mathrm{C} & 46,36 & 46,77 \\ \mathrm{H} & 2,78 & 3,04 \\ \mathrm{~N} & 15, \mathbf{0} 0 & 15,51\end{array}$

\section{Versuche, die Hydrazo-Umlagerung zu verallgemeinern.}

54) Die Hydrazo-Umlagerung besteht darin, daB zu der beiderseits direkt in aromatische Kerne eingreifenden IIydrazogruppe - HN.NII-Wasserstoff aus diesen Kernen wandert, dessen ursprünglicher Platz nun entweder zur Diphenylverknüpfung benut\%t oder von einem Rest Ar. NH - aufgesucht wird. Ich habe mir die Frage vorgelegt, ob ein solcher Vorgang auch eintreten kann, wenn die Hydrazogruppe 
a) einerseits aromatisch, andererseits rein aliphatisck gebunden ist, wie in den Reduktionsprodukten der zahlreich bekannten Verbindungen, die als "fettaromatische Azokörper" bzw. ihnen desmotrope Hydrazone aufgefaßt werden können;

b) einerseits direkt an Aryl gebunden, andererseits durch ein $C$-Glied von Aryl getrennt ist, wie im symm. Phenylbenzylhydrazin $\mathrm{C}_{6} \mathrm{H}_{5} \cdot \mathrm{NH} . \mathrm{NH} . \mathrm{CH}_{2} \cdot \mathrm{C}_{6} \mathrm{H}_{5}$;

c) beiderseits von Aryl durch je ein C-Glied getrennt ist, wie im symm. Dibenzylhydrazin $\mathrm{C}_{6} \mathrm{H}_{5} \cdot \mathrm{CH}_{2}$. NH.NH. $\mathrm{CH}_{2}, \mathrm{C}_{6} \mathrm{H}_{5}$.

Die Versuche in dieser Richtung sind aber ergebnislos verlaufen.

55) Bei dem eben erwähnten Fall a) konnte es sich selbstverständlich nicht um den Eintritt einer Diphenylumlagerung handeln, da ja nur ein Aryl im Molekül vorhanden ist. Möglich erscheint aber Semidinumlagerung; uud da nach meinen Erfahrungen paraständiges Äthoxyl die Bildung von o-Semidinen besonders begünstigt, wurden zur Prüfung der Frage einige fettaromatische Azoverbindungen hergestellt, welche in ihrem Benzolkern Äthoxyl in $p$-Stellang enthalten. Man konnte z. B. daran denken, daß das unten beschriebene $[p-\ddot{A}$ thoxyphenyl]-hydrazon des Brenztraubenaldehyds bei der Reduktion einen Hydrazokörper liefern, und dab dieser sich zu einem semidinartigen Produkt umlagern würde, das wahrscheinlich sich gleich weiter intramolekular zu einem Chinoxalinderivat kondensieren würde:
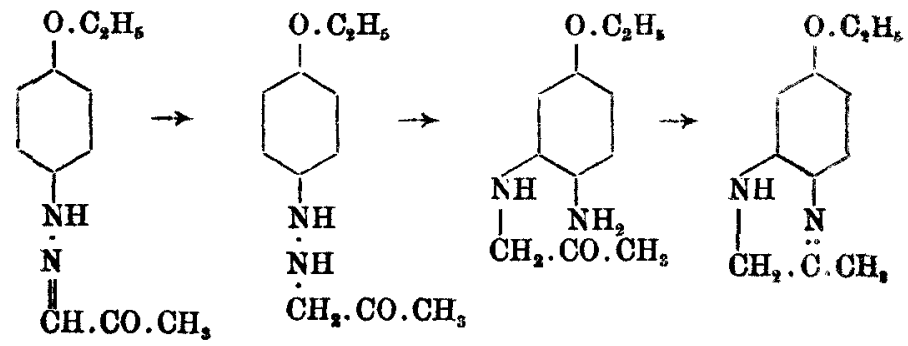
Die Versuche sind ausführlicher mit den analytischen Belegen in der Dissertation von Herrn St. Pink $\mathbf{u s}^{1}$ ) beschrieben. Sie zeigten, daß jenes Hydrazon gegenüber sauren Reduktionsmitteln recht beständig ist, bei eintretender Reduktion aber Phenetidin abspaitet; in alkalischer Lösung wird es leicht reduziert und liefert gleichfalls Phenetidin. Im folgenden werden daher nur die bei dieser Gelegenheit dargestellten Repräsentanten der Hydrazone and Hydrazine kurz aufgezählt.

Durch Kombination von diazotiertem $p$-Phenetidin mit Acetessigsäure wurde das Brenztraubenaldehyd-[päthoxyphenyl]-hydrazon $\mathrm{C}_{11} \mathrm{H}_{14} \mathrm{O}_{2} \mathrm{~N}_{2}=\mathrm{CH}_{3}$.CO.CH:N.NH. $\mathrm{C}_{6} \mathrm{H}_{4} \cdot 0 . \mathrm{C}_{2} \mathrm{H}_{5}$ bereitet, das aus Benzol in orangegelben Blättchen krystallisiert, bei $144,5^{\circ}$ schmilzt und sich leicht in Alkohol, ziemlich leicht in heißem Benzol und Ligroin mit dunkelgelber Farbe löst. Auch von konz Schwefelsäure wird es mit rein dunkelgelber Farbe anfgenommen. In kaustischem Alkali löst es sich in Gegenwart von etwas Alkohol mit rotgelber Farbe.

Daneben entsteht ${ }^{2}$ ) bei der Kombination stets in erheblicher Menge der entsprechende Formazylkörper das Di-p-äthoxy-formazylmethylketon $\mathrm{C}_{19} \mathrm{H}_{22} \mathrm{O}_{3} \mathrm{~N}_{4}=\mathrm{CH}_{3}$. CO. C(N:N. $\left.\mathrm{C}_{6} \mathrm{H}_{4}, 0 . \mathrm{C}_{2} \mathrm{H}_{5}\right): \mathrm{N} . \mathrm{NH} \cdot \mathrm{C}_{6} \mathrm{H}_{4} \cdot 0 . \mathrm{C}_{2} \mathrm{H}_{5}$-, der sich durch seine geringere Löslichkeit in Alkohol abtrennen läßt, schimmernde dunkelrote Nädelchen darstellt, bei $143^{\circ}$ schmilzt und sich in konz. Schwefelsäure mit indigblauer Farbe, in Alkali (nach dem Anfeuchten mit Alkohol) mit tief dunkelroter Farbe löst.

Die Kombination von diazotiertem $p$-Phenetidin mit Methylacetessigester ergibt nach dem Verseifen des zuerst gebildeten Äthylesters (rote Nadeln vom Schmelzp.

1) „Über Thioderivate und gemisehte Azoderivate des $p$ Phenetidins" (Bern 1896), S. 26-33.

*) Vgl. dazu: Bamberger, Ber. d. d. chem. Ges. 24, 3260 (1891); Bamberger u. Lorenzen, Ber. d. d. chem. Ges. 25, 3539 (1892). 
$\left.110^{\circ}\right)$ das Brenztrauliensäure-[p-äthoxyphenyl]-hydrazon $\mathrm{C}_{11} \mathrm{H}_{14} \mathrm{O}_{3} \mathrm{~N}_{2}=\mathrm{CH}_{3} \cdot \mathrm{C}\left(\mathrm{CO}_{2} \mathrm{H}\right): \mathrm{N} \cdot \mathrm{NH} . \mathrm{C}_{6} \mathrm{H}_{4} \cdot \mathrm{O} \cdot \mathrm{C}_{2} \mathrm{H}_{5} . \quad \mathrm{Es}$ krystallisiert aus Benzol in kanariengelben Nadeln, schmilzt - rasch erhitzt - bei $120-122^{\circ}$ unter Kohlendioxyd-Abspaltung und löst sich in Alkalien, sowie in konz. Schwefelsäure mit gelber Farbe. Die Farbe der Lösung in konz. Schwefelsäure wird durch Zusatz oxydierender Mittel nicht verändert ${ }^{1}$ ).

Die wäßrige Iösung seines Natriumsalzes gibt bei der Reduktion mit Natriumamalgam die $\alpha-\left[p-\ddot{d}_{1} / h^{\prime} x y-\right.$ phe"y/lyydra:ino] propionsäure $\mathrm{C}_{11} \mathrm{H}_{18} \mathrm{O}_{3} \mathrm{~N}_{2}=\mathrm{CH}_{3} . \mathrm{CH}\left(\mathrm{CO}_{2} \mathrm{H}\right)$. NH.NH. $\mathrm{C}_{6} \mathrm{H}_{4}, 0 . \mathrm{C}_{2} \mathrm{H}_{5}$. Sie krystallisiert aus $/$ asser in feinen gelblich-weißen Nädelchen, schmilzt - rasch erhitzt - unter Zersetzung bei $128-138^{\circ}$ und reduziert Fehlingsche Lösung schon in der Kälte.

56) Symm. Phenylbenzy/hydrazin stellte Hr. Dr. H. Jost nach den Angaben von O. Schlenk ${ }^{2}$ ) aus Benzaldehydphenylhydrazon her.

Das Verfahren wurde in folgender Weise etwas abgekürzt und vereinfacht: Zu einer sirdenden Lösung von $20 \mathrm{~g}$ Benzaldehydphenylhydrazon in $300 \mathrm{~cm}$ Alkohol gibt man innerhalb 3-4 Stunder unter Durchleiten von $\mathrm{CO}_{2}$ etwa $400 \mathrm{~g}$ dreiprozentiges Natriumamalgan, kühlt dann $a b$, säuert unter Wasserkühlung mit verdünnter salzsäure schwaeh an, gieBt vom Quecksilber ab und fügt nun konz. Salzsäure hinzu; das in Krystallblüttern abgeschiedene Hydrochl rid wird abgesaugt. die Mutterlauge liefert nach den Einleiten von Chlorwasserstoff über Nacht noch eine weitere Krystailisation. Ausbeute etwa $14 \mathrm{~g}$ reines Hydrochlorid.

Die Umlagerung wurde durch mehrtägiges Stehenlassen mit Alkohol und konz. Salzsäure, mit ätherischer Lösung von Chlorwasserstoff, mit stärkster wäßriger Salzsäure oder mit verdünntem Alkohol, der Salzsäure und Zinnchlorür enthielt, versucht. In keinem Falle ließ sich eine Veränderung nachweisen.

1) Vgl. dazu v. Pechmann u. Runge, Ber. d. d. chem. Ges. 27, 1697 Anm. (1894).

2) J. pr. [2] 78, 50 (1908). 
Zincke und Greune, Uber Sulfaminphthalsäure usvo. 221

Im Gegensatz dazu wird nach neueren Beobachtungen von Franzen und Fürst') das o-Aminoderivat $\mathrm{H}_{2} \mathrm{~N}$. $\mathrm{C}_{6} \mathrm{H}_{4} \cdot \mathrm{NH} \cdot \mathrm{NH} \cdot \mathrm{CH}_{2} \cdot \mathrm{C}_{6} \mathrm{H}_{5}$ durch verdünnte Mineralsäuren sehr leicht verändert, wobei 2-Phenyl-benzimidazol, Benzylamin, $o$-Phenylendiamin und Ammoniak entstehen.

57) Beim symm. Dibenzy/h,'drazin ${ }^{2}$ ) versuchte Herr Dr. P. Schmidt Umlagerung durch eintägiges Stehenlassen von $5 \mathrm{~g}$ des Hydrochlorids mit $30 \mathrm{~g}$ konz. Schwefelsầure zu erzielen; die Aufarbeitung ergab aber nur unverändertes Dibenzylhydrazin. Bei energischerer Säurewirkung erfolgte weitgehende Zersetzung ${ }^{3}$ ).

\section{Tiber Sulfaminphthalsäure und Sulfimid- phthalsäure;}

von Th. Zincke und II. Greune.

[Aus dem Chemischen Institut der Universität zu Marburg.]

(Eingelaufen am 11. August 1921.)

Vor einiger Zeit hat der Fine von uns ${ }^{4}$ ), ausgehend vom Nophthul'am, die Sulfimidphthalsä̈re (I) in reinem Zustande dargestellt und ihre Beziehungen zur Sulfaminphthul.äure (II) klargelegt. Durch Erhit\%en mit verdünnter Salzsäure geht das Sulfimid rasch und leicht in die Sulfamiısäıre über: umgekehrt kann diese durch Frhitzen für sich oder durch Erwärmen mit konz. Schwefelsäure in das Sulfimid übergeführt werden.

1) Diese Annalen 412. 17, 32 (1917).

2) Curtius. J. pr. [2] 62, 92 (1900).

3) Vgl auch Franzen u. Kraft-J.pr. [2] 84, 128, 137, 138 (1211) - über Spaltung von $\alpha, \beta$-Dibenzylphenylhydrazin und von Tribenzylhydrazin durch Salzsäure.

4) Zincke, diese Annalen 416, 65 (1918). 